\title{
FORMAÇÃO DE PREÇOS E CARACTERIZAÇÃO DO MERCADO DE FRANGO EM SÃO PAULO
}

\author{
MAURÍCIO VAZ LOBO BITTENCOURT \\ Engenheiro Agrônomo
}

Orientador: Prof. Dr. GERALDO SANT'ANA DE CAMARGO BARROS

Dissertação apresentada à Escola Superior de Agricultura "Luiz de Queiroz", da Unversidade de São Paulo, para obtenção do título de Mestre em Agronomia, Área de Concentração: Economia Agrária.

P I R A C I C A B A

Estado de São Paulo - Brasil

Setembro - 1995 
Dados Internacionais de Catalogação na Publicação (CIP)

DIVISÃO DE BIBLIOTECA E DOCUMENTAÇAO - Campus "Luiz de QueirOz"/USP

Bittencourt, Maurício Vaz Lobo

Formação de preços e caracterização do mercado de frango en são Paulo. Piracicaba, 1995.

161p. ilus.

Diss. (Mestre) - ESALQ

Bibl iografia.

1. Avicultura de corte - Aspecto econômico - Ş̄o Paulo 2. Preço agrícola - Săo Paulo I. Escola Superior de Agricultura Luiz de Queiroz, Piracicaba

CDD 338.176513

338.13 


\title{
FORMAÇÃO DE PREÇOS E CARACTERIZAÇÃO DO MERCADO DE FRANGO EM SÃO PAULO
}

\author{
MAURÍCIO VAZ.LOBO BITTENCOURT
}

Aprovada em: 20.10.1995

Comissão julgadora:

Prof. Dr. Geraldo Sant'ana de Camargo Barros

ESALQ/USP

Prof. Dr. Heloísa Lee Burnquist

ESALQ/USP

Prof. Dr. Danilo Rolim Dias de Aguiar

UFV

Prof. Dr. GERALDO SANT'A J DE CAMARGO BARROS Orientador 
Ofereço este trabalho d̀ minha esposa MARCLA ADRIANE e à minha filha BRUNA 


\section{AGRADECIMENTOS}

O presente trabalho é resultado de aproximadamente 3 anos de estudo e pesquisa, mas sem o apoio e incentivo de algumas pessoas, o mesmo não existiria. Por isso, gostaria de agradecer formalmente às principais pessoas que me ajudaram neste período.

Dentre as pessoas que me ajudaram de uma forma ou de outra, para a realização desta dissertação, bem como para a conclusão do mestrado, gostaria de citar e agradecer à minha esposa MÁRCIA ADRIANE GONÇALVES BITTENCOURT, que primeiramente me incentivou e apoiou, aos meus amigos, e também incentivadores, JUDAS TADEU GRASSI MENDES, VÂNIA DI'ADDARIO GUIMARÃES E FRANCISCO CÂNDIDO GUIMARÃES, que sempre nos momentos de dúvidas ou dificuldades procuravam me ouvir e solucionar tais problemas, através da experiência de cada um deles. Na figura de meu grande amigo e professor JUDAS TADEU, vi o quão importante é a Economia Rural para a minha profissão, e hoje, só tenho a agradecê-lo.

Sem dúvida, não poderia deixar de prestar as minhas homenagens e meus agradecimentos ao meu orientador, professor e amigo, GERALDO SANT'ANA DE CAMARGO BARROS, o qual é um grande profissional, e que nunca deixou de me ouvir e de me incentivar na sequência da nossa pesquisa. Mesmo quando não tinha tempo, dava um jeito de me atender, seja para tratar da dissertação, do curso, ou de qualquer outro assunto, até mesmo pessoal. Muito obrigado, Prof. GERALDO, por termos tido um relacionamento sadio e sincero ao longo destes 4 anos, e que sem dúvida alguma perdurarão por muito tempo.

Agradeço também aos meus Pais SCHEILA E JOÃO ALFREDO e ao meu Avô NILSON, que além de sempre me incentivarem, foram os verdadeiros responsáveis pela 
minha formação escolar e acadêmica, bem como pessoa, pela formação e confirmação de meu caráter.

Muito obrigado aos meus amigos ARMANDO VAZ SAMPAIO e MARCOS MINORU HASEGAWA pelo incentivo, apoio e pelos "debates" sobre os mais variados assuntos vistos em nosso curso, além do auxílio e das valiosas sugestões para a realização deste trabalho.

Gostaria de agradecer também à MÍRIAM BACCHI e aos professores HELOÍSA LEE BURNQUIST e RODOLFO HOFFMAN pela ajuda dispensada no esclarecimento da metodologia do trabalho, além das importantes sugestões dadas para este trabalho.

Muito obrigado às bibliotecárias ANGÉLICA e LUCIANE, que sempre foram muito atenciosas e grandes amigas, solidárias e compreensivas, nos momentos mais dificeis.

Obrigado também a ADRIANO DE CAMARGO CARDOZO, a LUIZ ALFREDO STURION, e a todos os professores e funcionários do Departamento de Economia e Sociologia Rural, pela atenção dispensada durante o nosso período de convivência.

Não poderia deixar de agradecer ao $\mathrm{CNPq}$ pelo apoio financeiro dispensado, pois este um foi fator preponderante na conclusão do Mestrado e na realização desta dissertação. 


\section{SUMÁRIO}

Página

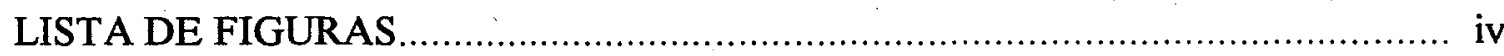

LISTA DE TABELAS ................................................................... v

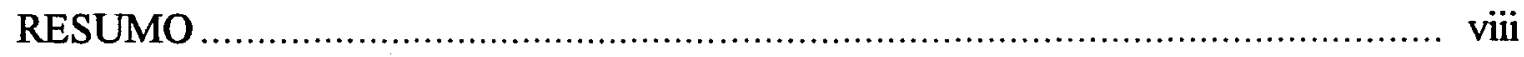

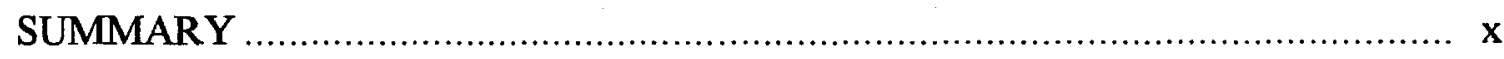

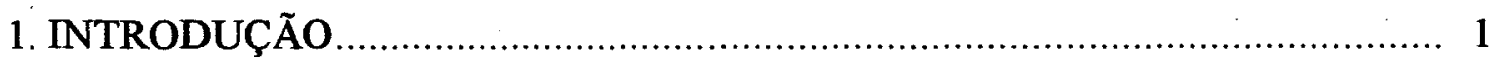

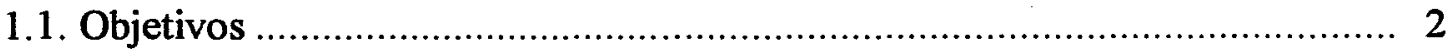

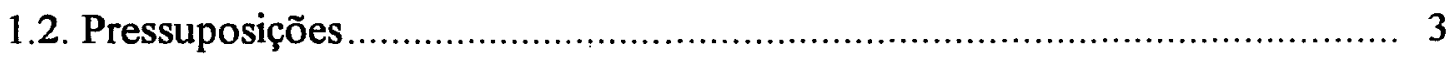

1.3. Hipóteses .......................................................................... 3

2. MERCADO DE FRANGO: DESEMPENHO NAS DÉCADAS DE 70 A $90 \ldots \ldots .5$

2.1. Sistema de produção de frango..................................................... 6

2.1.1. Transformação do sistema de produção................................. 6

2.1.2. Caracterização da indústria de frango de corte........................ 7

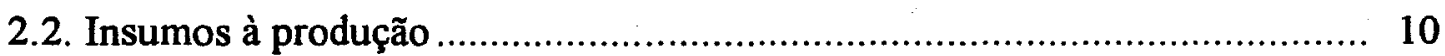

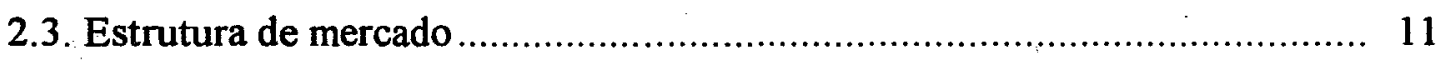

2.3.1. Integração vertical ................................................... 12

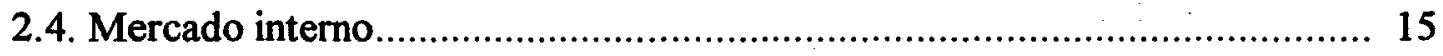

2.4.1. Evolução.................................................................. 15

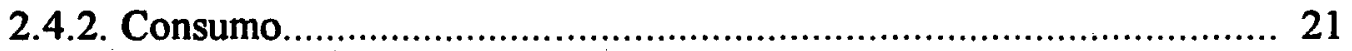

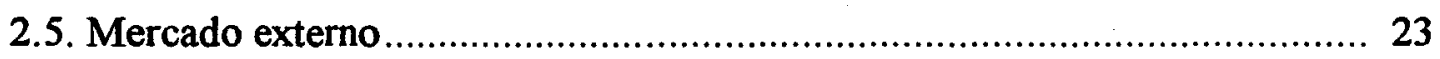

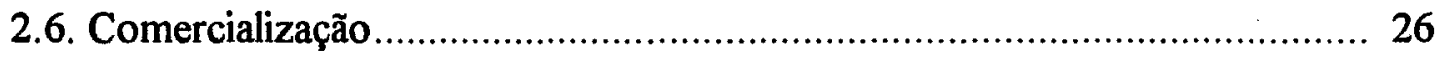




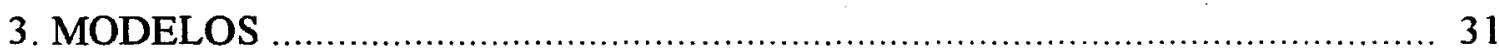

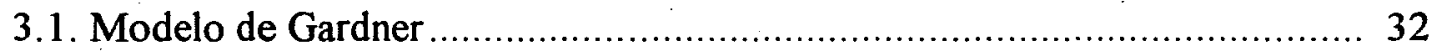

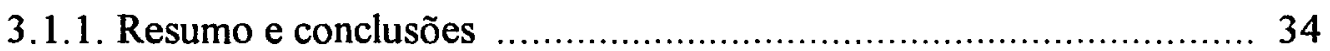

3.1.2. Principais limitações do modelo.................................................... 35

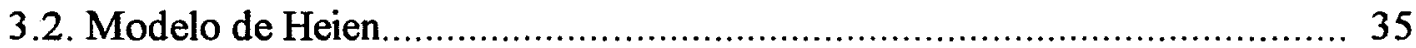

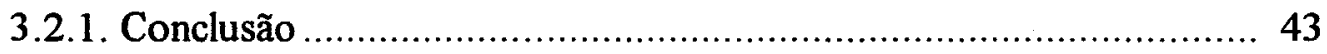

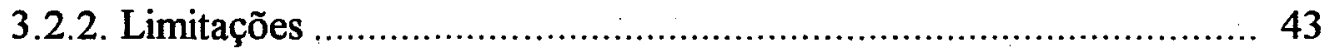

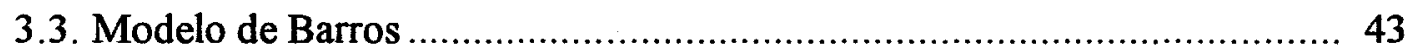

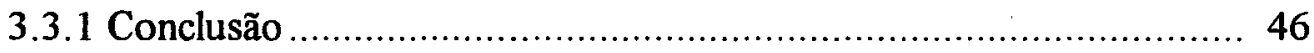

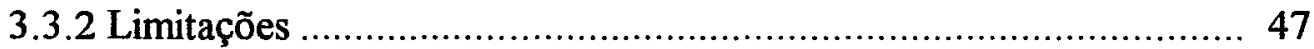

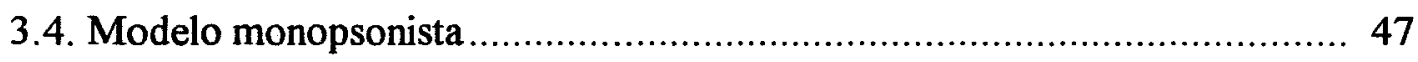

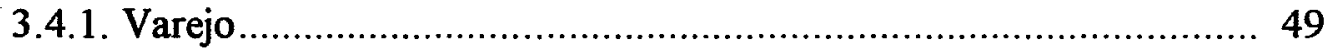

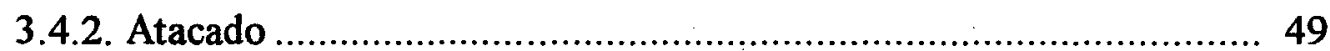

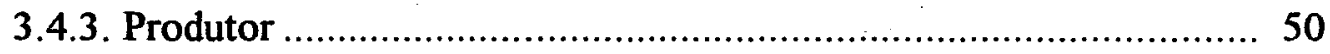

3.4.4. Maximização de lucro ............................................................ 50

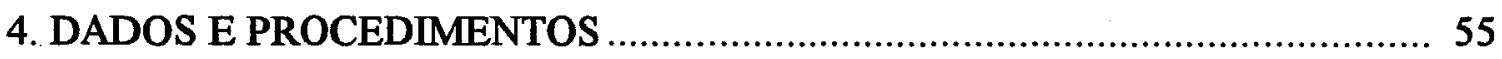

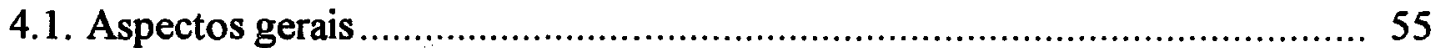

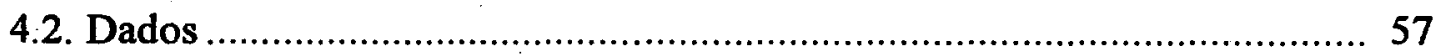

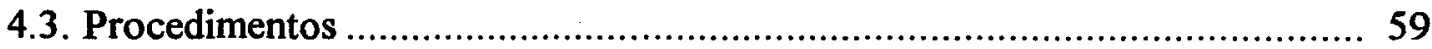

4.3.1. Testes de estacionariedade e de cointegração ................................ 60

4.3.1.1 Séries de tempo estacionárias e não estacionárias .................... 60

4.3.1.2 Testes de estacionariedade ou raizes unitárias ........................ 65 
4.3.1.3 Testes de cointegração e mecanismo de correção de erro. 64

4.3.1.3.1 Método de Engle \& Granger 65

4.3.1.3.2 Método de Johansen. 68

4.3.2. Modelos VAR com correção de erro 73

4.3.2.1 Modelos VAR convencionais 74

4.3.2.2 Modelos VAR estruturados. 81

4.3.2.2.1.Estrutura do modelo VAR 83

5. RESULTADOS E DISCUSSÃO 87

5.1. Modelo da integração 88

5.1.1 Testes de raiz unitária. 88

5.1.2 Testes de cointegração 93

5.1.3 Modelo VAR com correção de erro 94

5.2. Modelo de monopsônio 103

5.2.1. Testes de raiz unitária. 103

5.2.2. Testes de cointegração... 110

5.2.3. Modelo VAR estruturado (Bernanke) com correção de erro 112

6.CONCLUSÕES 126

7.REFERÊNCIAS BIBLIOGRÁFICAS 130

APÊNDICE 1 : Estatísticas dos testes de raiz unitária e de cointegração 141

APÊNDICE 2 : Figuras da análise de auto-regressão vetorial com correção de erro para o modelo da integração.

APÊNDICE 3 : Figuras da análise de auto-regressão vetorial estruturado com correção de erro para o modelo de monopsônio em SP 154 


\section{LISTA DE FIGURAS}

Figura $\mathbf{n}^{\circ}$

Página

1 Preços reais de frango recebidos pelos produtores em São Paulo 17

2 Preços reais de frango recebidos pelos produtores no Paraná.................... 18

3 Preços reais de frango recebidos pelos produtores em Santa Catarina ........ 18

4 Relação de preços entre frango / boi gordo em São Paulo........................ 20

5 Relação de preços entre frango / milho em São Paulo .......................... 20

6 Relação de preços entre frango / preço pago pelo kg de ração em São Paulo

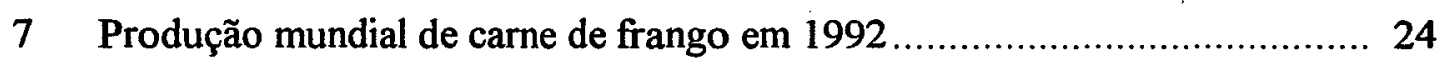

8 Margem absoluta de comercialização de carne de frango em São Paulo ..... 27

9 Representação gráfica do modelo monopsonista ................................. 54 


\section{LISTA DE TABELAS}

Tabela $n^{\circ}$

Página

1 As maiores empresas em abate de aves no Brasil em 1992 e a participação percentual na produção...

2 Produção de carnes no Brasil de 1989 a 1994 (1000 Toneladas) 12

3 Principais estados do Brasil no número de abate em $1977,1984,1988$ e 1992 (mil aves).

4 Consumo interno de carnes no Brasil de 1989 a 1995 (Kg/hab/ano).

5 Exportações brasileiras de carne de frango de 1975 a 1995 (Toneladas) ... 23

6 Produção mundial de carne de frango de 1993 a 1995 24

7 Principais paises exportadores de carne de frango em 1994 (1000 Toneladas)

8 Exportações brasileiras de frango inteiro e em cortes de 1991 a 1994 (Toneladas) 26

9 Participação dos segmentos de distribuição no mercado de frango. 29

10 Participaçã́o de frangos nas vendas do supermercado 29

11 Tipos de frango mais vendidos nos supermercados. 30

12 Variáveis utilizadas na pesquisa ............................................... 88

13 Testes de raiz unitária, modelo sem constante e sem tendência $(\tau)$.......... 89

14 Testes de raiz unitária, modelo sem constante e sem tendência $(\tau)$.......... 89

15 Testes de raiz unitária, modelo com constante e sem tendência $\left(\tau_{\mu}\right) \ldots \ldots \ldots 90$

16 Testes de raiz unitária, modelo com constante e sem tendência $\left(\tau_{\mu}\right) \ldots \ldots . .91$

17 Testes de raiz unitária, modelo com constante e com tendência $\left(\tau_{\tau}\right) \ldots \ldots \ldots 92$ 
18 Testes de raiz unitária, modelo com constante e com tendência $\left(\tau_{\tau}\right)$

19 Resultados dos testes para determinação do número de relações de cointegração

20 Estimativas dos autovalores $(\lambda)$, autovetores da matriz de cointegração $(\boldsymbol{\beta})$

21 Respostas a choque no preço do frango ao produtor em SC (PpSC) no modelo da integração .

22 Decomposição da variância dos erros de previsão do preço do frango ao produtor em SC (PpSC) no modelo da integração, em porcentagem

23 Respostas a choque no preço do frango ao produtor em SP (PpSP) no modelo da integração.

24 Decomposição da variância dos erros de previsão do preço do frango ao produtor em SP (PpSP) no modelo da integração, em porcentagem

25 Respostas a choque no preço do frango ao produtor no PR (PpPR) no modelo da integração

26 Decomposição da variância dos erros de previsão do preço do frango ao produtor no PR (PpPR) no modelo da integração, em porcentagem.

27 Testes de raiz unitária, modelo sem constante e sem tendência $(\tau)$ 104

28 Testes de raiz unitária, modelo sem constante e sem tendência $(\tau)$ 105

29 Testes de raiz unitária, modelo com constante e sem tendência $\left(\tau_{\mu}\right) \ldots \ldots . .106$

30 Testes de raiz unitária, modelo com constante e sem tendência $\left(\tau_{\mu}\right) \ldots \ldots . .107$

31 Testes de raiz unitária, modelo com constante e com tendência $\left(\tau_{\tau}\right) \ldots \ldots \ldots 108$

32 Testes de raiz unitária, modelo com constante e com tendência $\left(\tau_{\tau}\right) \ldots \ldots . .109$

33 Resultados dos testes para determinação do número de relações de cointegração

34 Estimativas dos autovalores $(\lambda)$, autovetores da matriz de cointegração ( $\boldsymbol{\beta})$ 
35 Matriz de interações contemporâneas $(\Gamma)$ para o modelo VAR estruturado

36 Decomposição da variância dos erros de previsão do índice de custo de produção do frango em SP (IProd) no modelo de monopsônio, em porcentagem.

37 Decomposição da variância dos erros de previsão do índice de produção industrial (x) no modelo de monopsônio, em porcentagem

38 Decomposição da variância dos erros de previsão da taxa de juros real (Tj) no modelo de monopsônio, em porcentagem

39 Decomposição da variância dos erros de previsão do preço da carne bovina (PcBov) no modelo de monopsônio, em porcentagem.

40 Decomposição da variância dos erros de previsão do preço do frango ao produtor (PpSP) no modelo de monopsônio, em porcentagem.

41 Decomposição da variância dos erros de previsão do preço do frango no atacado (PaSP) no modelo de monopsônio, em porcentagem.

42 Respostas a choque no preço do frango no atacado (PaSP) no modelo de monopsônio a choques no PpSP, no próprio PaSP, no PvSP e no PcBov

43 Decomposição da variância dos erros de previsão do preço do frango no varejo (PvSP) no modelo de monopsônio, em porcentagem

44 Respostas a choque no preço do frango no varejo (PvSP) no modelo de monopsônio a choques no PcBov, no PpSP e no próprio PvSP 


\title{
FORMAÇÃO dE PREÇOS E CARACTERIZAÇÃo DO MERCADO DE FRANGO EM SÃO PAULO
}

\author{
Autor: MAURÍCIO VAZ LOBO BITTENCOURT
}

Orientador: Prof . Dr. GERALDO SANT'ANA DE CAMARGO BARROS

\section{RESUMO}

Este trabalho tem como principais objetivos a determinação das relações e formação de preços existentes entre os principais Estados produtores: São Paulo, Paraná e Santa Catarina, bem como analisar e caracterizar o mercado de frango no Estado de São Paulo, que é o principal consumidor, por meio das interações entre o mercado de frango e os mercados de insumos de produção, comercialização e de produtos substitutos, como a carne bovina.

Para se atingir tais objetivos, foram estimados dois modelos: o da Integração e o de Monopsônio. O Modelo da Integração está relacionado com o primeiro objetivo, sendo que, para tal, foi utilizado o modelo de autoregressão vetorial (VAR) convencional com correção de erro. Já o Modelo de Monopsônio foi o resultado da estimação de um modelo de autoregressão vetorial (VAR) com procedimento de Bernanke e correção de erro, estruturado no Modelo Monopsonista proposto para o mercado de frango.

O Modelo da Integração mostrou que há uma forte influência do Estado de Santa Catarina sobre os demais, principalmente devido ao alto grau de integração vertical do mercado. Verificou-se, também, que na determinação dos preços no Estado do Paraná, estes são muito influenciados pelas informações decorrentes dos Estados de São Paulo e 
Santa Catarina. Ou seja, os resultados obtidos da análise dinâmica dos preços desses Estados demonstraram que, realmente, há uma forte interação entre os mesmos, devido, provavelmente, à integração vertical, característica do setor avícola.

Quanto ao Modelo de Monopsônio, este demonstrou que o Modelo Monopsonista proposto é adequado à representação do mercado de frango, ou qualquer outro mercado com as mesmas características, pois os coeficientes estimados foram, quase todos, os esperados de acordo com este modelo teórico. Desta análise, verificou-se que os vários níveis do mercado se interagem, de forma que os frigoríficos, ou integradoras, determinam, antecipadamente, a quantidade e o preço a ser pago aos produtores. O varejo, por sua vez, adota uma política de "markup" para determinar o preço a ser cobrado dos consumidores. Sendo que o preço da carne bovina exerce um importante papel na determinação dos preços de frango, tanto a nível de atacado, quanto de varejo.

Foi também preocupação deste trabalho o uso de procedimentos econométricos adequados para a correta utilização de séries de tempo, de modo a se obterem estimativas estáveis e coerentes com a teoria econômica. Entre esses procedimentos, destacam-se a utilização de testes para determinação de defasagens, como os de Akaike e Schwarz, testes de raiz unitária e cointegração, como os testes de Dickey \& Fuller e Johansen, para a estimação de modelos VAR com correção de erro. 


\title{
PRICES FORMATION AND THE CHICKEN MARKET CHARACTERIZATION IN SĀO PAULO
}

\author{
Author: MAURÍCIO VAZ LOBO BITTENCOURT
}

Adviser: Prof'. Dr. GERALDO SANT'ANA DE CAMARGO BARROS

\section{SUMMARY}

The main goals of this research is to evaluate the relationship and price formation among the most important state chicken producers: São Paulo, Paraná and Santa Catarina, and also analyze and characterize the chicken market in the State of São Paulo, which is the main chicken consumer, through interactions between the chicken market and the markets of production inputs, marketing and substitute products, as is beef.

In order to achieve such goals, two models were estimated: one of Integration and the other of Monopsony. The Integration Model is related with the first objective, and for this it was used the conventional Vector Autoregression Model (VAR) with error correction. On the other hand, the Monopsony Model was the outcome of the estimation of a Vector Autoregression Model (VAR) with Bernanke's procedure and error correction, structured on the Monopsonist Model proposed for the chicken market.

The Integration Model showed a strong influence of the State of Santa Catarina over the others, mainly due to the high degree of market vertical integration. It was also observed that in the price determination in the State of Paraná, those are very influenced by the informations coming from the States of the São Paulo and Santa Catarina. In the other words, the results achieved of the prices dynamic analysis from these states showed 
that, indeed, there is a strong interaction among themselves, due, likely, to the vertical integration, which is a feature of the poultry sector.

Regarding to the Monopsony Model, this proved that the Monopsonist Model proposed is an appropriate representation of the chicken market, or any other market with the same characteristics, so the estimated coefficients were, almost all, as expected, according to this theoretical model. From this analysis, it was observed that the various levels of market interact to each other, in such a way that slaughters cattle, or integrated firms determine, in advance, the quantity and the price to be paid to the producers. The retailer adopts a "markup" policy to determine the price to be charged to the consumers. It has to be considered that the beef price has an important role in the determination of the chicken prices, both at the wholesaler and retailer level.

In this research, there was also a concern in the use of a suitable econometric procedure to the correct utilization of time series, in order to obtain stable and coherent estimates, according to the economic theory. Among those procedures, it was used the test for determining the time lags, as are the Akaike and Schwarz tests, tests of unit root and cointegration, as are the Dickey \& Fuller and Johansen tests, for the estimation of VAR models with error corrèction. 


\section{1 - INTRODUÇÃO}

A avicultura, no Brasil, tem sofrido modificações muito pronunciadas em todo o processo produtivo, no processamento e embalagem, chegando ao consumo, com características bem diferentes àquelas encontradas há duas décadas passadas. Estas modificações deram ao setor um perfil tipicamente industrial, conforme GIULIETTI et alii (1980), o que, aliado à complexidade do setor produtivo, o diferencia, em muito, dos outros setores agropecuários.

Esta complexidade se observa na cadeia de produção, com um desenvolvimento acelerado na seleção genética das aves, nas rações, no controle de doenças, no processamento, na distribuição e na comercialização, entre outras várias atividades que estão definitivamente inseridas no processo global de produção de carne de frango.

Todo este processo foi introduzido e adaptado, com sucesso, do sistema vigente em outros países, principalmente nos Estados Unidos. O Brasil apresenta, atualmente, uma produção média anual superior aos 3 milhões de toneladas de carne e um consumo - "per capita" que saltou de 12 para 19 quilos em cerca de 5 anos.

O setor se caracterizou, ao longo dos anos, pela constante evolução tecnológica. Estes progressos técnicos resultaram em acréscimos contínuos à produtividade, propiciando aumentos na produção que, aliados a acréscimos relativamente menores na demanda, ocasionaram queda nos preços reais recebidos pelos produtores ao longo do tempo. 
Com a queda dos preços ao longo dos anos, a carne de frango se tornou uma fonte de proteína acessível à dieta de boa parte da população brasileira, principalmente às classes de mais baixa renda, além de se tornar uma importante concorrente das demais carnes.

O mercado de frango, além de apresentar grandes mudanças de ordem tecnológica, que, consequentemente, foi a responsável pelo rápido crescimento da produção, apresenta a característica peculiar da distribuição geográfica da produção, com esta se concentrando nos Estados de São Paulo, Paraná, Santa Catarina e Rio Grande do Sul.

Por isso, é importante se verificar as relações entre os principais produtores das regiões Sul e Sudeste, bem como analisar a formação de preços e a interação com outras variáveis econômicas do Estado de São Paulo, principal consumidor e detentor do maior plantel de matrizes e poedeiras do país, verificando-se, assim, as relações entre as carnes de frango e bovina, por um lado, com os mercados de soja e milho, por outro.

\section{1 -Objetivos}

Este trabalho tem como objetivos:

a) determinar as relações de preços existentes entre as principais regiões produtoras de frango do Brasil, ou seja, os estados da região Sul e o Estado de São Paulo;

b) determinar as relações de preços existentes entre os vários níveis (produtor, atacado e varejo) do mercado de frango no Estado de São Paulo, bem como entre os preços dos demais mercados que com este interagem (milho, soja e boi), testando um 
modelo teórico para a determinação de tais relações. Faz-se, também, uma caracterização da evolução do mercado de frango nos últimos 20 anos.

\section{2 -Pressuposições}

a) O comportamento dos preços no mercado de frango é influenciado, predominantemente, por mudanças oriundas do lado da oferta - por utilizar matéria-prima agrícola como insumo produtivo, estando sujeito a todas as condições que propiciam alterações na produção (como, por exemplo, o clima e a sazonalidade); e pelas frequentes alterações de natureza tecnológica.

b) Devido às particularidades do mercado - grau de concentração e padrão industrial - espera-se que prevaleça um sistema de "markup" na formação de preços de frango, tanto a nível de atacado, quanto de varejo.

\section{3 - Hipóteses}

As seguintes hipóteses serão testadas neste trabalho :

a) Há interação entre o mercádo de frango e os mercados de carne bovina, de milho e de soja; o primeiro, por ser um bem de consumo substituto, e os demais, por serem importantes insumos de produção.

b) Os mercados de frango, no Sul e Sudeste do País, devem estar bem integrados; particularmente, espera-se forte influência de Santa Catarina, que ocupa papel preponderante nas exportações, na tecnologia de produção e no comércio. Deve, também, ser importante o papel de São Paulo na formação de preços, por se tratar de um 
4.

importante centro consumidor e de contar com o maior número de matrizes e de poedeiras do país. 


\section{2 - MERCADO DE FRANGO : DESEMPENHO NAS DÉCADAS DE 70 A 90}

O mercado de frango é complexo, havendo uma grande interação entre as várias atividades de suporte ao setor, formando, como afirma LIMA (1984), um "sistema de produção de frango".

O setor avícola apresenta uma estrutura em que as grandes empresas ou agroindústrias fornecem insumos de produção ao produtor e este fornece mão-de-obra e instalações apropriadas. A maior parte da produção nacional se dá desta maneira, com forte interação da agroindústria com os produtores. Existe, porém, em menor proporção, um sistema de produção em que o produtor cria e abate frango, que é posteriormente vendido ao mercado varejista ou ao consumidor, conforme GIULIETTI et alii (1980). Trata-se, por isso, de um sistema em que os produtores só criam e vendem o produto aos intermediários ou aos abatedouros.

Espera-se interação importante entre o mercado de frango e: a) os mercados de carne bovina e suína, pois estas são carnes substitutas; b) os mercados de soja e milho, devido ao fato de que estes produtos compõem praticamente a totalidade das rações utilizadas no processo produtivo; e, finalmente, c) o mercado externo que, a partir da metade da década de 70 , passou a absorver parcela importante da produção nacional, exportando cerca de 13,6\% do total produzido no ano de 1995. 


\section{1 - Sistema de produção de frango}

\subsection{1 - Transformação do sistema de produção}

Segundo LIMA (1984), foi em meados dos anos 60 que a estruturação da atividade avícola ocorreu, principalmente a partir da iniciativa de empresas estrangeiras produtoras de linhagens, que, associadas a grupos nacionais, traziam consigo toda uma tecnologia já desenvolvida desde o início do século. Esta tecnologia não encontrou obstáculos para ser utilizada no Brasil.

Foi no princípio da década de 60 , no Sul do País, que teve início uma atividade estruturada e específica na criação de frango, aproveitando toda a estrutura do sistema de produção de suínos e de milho. Os aviários, nessa época, eram de madeira e pequenos,

com cerca de $9 \mathrm{~m}^{2}$, abrigando 100 aves. $O$ aquecimento era feito com fogão a lenha. A partir do final da década de 60, a avicultura, já mais bem estruturada, apresentava instalações aquecidas com campânulas a querosene e abrigavam de 1000 a 1200 aves $^{1}$.

Esta estruturação da atividade ocorreu, inicialmente, em algumas regiões do Sul do País, feita notadamente por imigrantes europeus, enquanto no restante do País prevalecia uma atividade doméstica de baixa produtividade e qualidade e de nenhum caráter empresarial.

Foi desta maneira que surgiu, principalmente no estado de Santa Catarina, a avicultura integrada, envolvendo empresas que eram especializadas basicamente na produção de carne de suínos e que passaram a adotar um sistema de cooperação com os criadores.

\footnotetext{
${ }^{1}$ Revista Aves e Ovos - Agosto/1993.
} 
Segundo LIMA (1984), foi a partir da iniciativa de empresas estrangeiras produtoras de linhagens, associadas a grupos nacionais, que ocorreu a estruturação da atividade avicola.

Com este impulso da atividade, houve intensa expansão da demanda por medicamentos, vacinas e ração adequadas às linhagens importadas, fazendo com que se instalassem fábricas especializadas com o propósito de atender a esta demanda. Expandiu-se também o número de frigorificos controlados pelo Serviço de Inspeção Federal, de modo a garantir um controle de qualidade mais rígido sobre o processo de produção.

Um bom exemplo desta alteração no processo produtivo é a substituição da farinha de peixe utilizada como complemento alimentar das aves, e que conferia um sabor estranho à carne, por farelo de soja, a partir da metade da década de $70^{2}$.

Segundo LIMA (1984), no início da década de 80, com a retração do mercado interno $\mathrm{e}$ as dificuldades do mercado internacional, começa a haver um aperto generalizado das margens de lucro, quebrando os granjeiros mais ineficientes e forçando a uma reestruturação em termos de integração da produção em São Paulo e Rio Grande do Sul, onde boa parte da produção não era, ainda, integrada.

\subsection{2 - Caracterização da indústria de frango de corte}

Segundo LUCE \& KARSTEN (1992), a produção de frango é dividida em segmentos, cada qual com funções especializadas, sendo que os segmentos de criação de matrizes e incubação dos ovos são coordenados pelas próprias empresas integradoras.

A seguir, caracterizam-se as várias etapas constituintes do sistema de produção de frango:

\footnotetext{
${ }^{2}$ Revista Aves e Ovos - Agosto/1993.
} 


\section{a) Seleção genética}

O objetivo principal desta etapa é o de se obter linhagens que tenham indivíduos com características desejáveis de peso, estrutura fisica, rusticidade, precocidade, fertilidade, conversão alimentar, idade de abate, entre outras.

Esta é uma etapa que exige investimento de muito capital, podendo não trazer retorno imediato devido ao próprio processo de seleção ser lento e dependente de componentes genéticos muito complexos, o que exige muita pesquisa científica.

Segundo LUCE \& KARSTEN (1992), esta atividade não está incorporada ao processo de integração, sendo ainda realizada predominantemente no exterior. As poucas empresas que a realizam no Brasil estão vinculadas a grupos internacionais.

A realidade econômica brasileira faz com que o Governo não tenha, como seria desejável, recursos para investir em pesquisa para este segmento, através dos órgãos federais e estaduais. Assim, este papel tem sido desempenhado pela iniciativa privada e, principalmente, por empresas multinacionais.

\section{b) Produção das matrizes e pintos}

Neste segmento tem-se dois tipos de matrizes resultantes : as matrizes avós e as matrizes pais. As matrizes avós são obtidas da reprodução das linhagens procedentes do processo de seleção genética. Elas dão origem aos reprodutores utilizados como matrizes pais. As matrizes pais são as responsáveis pela produção dos pintos comerciais que serão os frangos de corte. Esta atividade faz parte de qualquer sistema de integração vertical.

No Brasil, as empresas que executam este processo são grandes e em pequeno número, segundo LIMA (1984). 


\section{c) Criação ou engorda}

Aqui tem-se a produção do frango comercial pronto para o abate a partir da cria e engorda dos pintos oriundos da etapa anterior. Neste segmento há um maior controle de custo, devido ao grande consumo de ração, medicamentos e uso de mão-de-obra especializada.

Houve neste segmento uma tendência de não concentração da atividade de criação, pois as integradoras preferiam aumentar o número de produtores integrados a incrementar o potencial produtivo dos mesmos, conseguindo, assim, maior poder de barganha, conforme LIMA (1984). No entanto, atualmente, as integradoras comportamse de maneira diferente, preferindo criadores bem estruturados e com grande potencial, diminuindo o número de integrados e aumentando a capacidade de produção e eficiência destes. Isto é constatado verificando-se, em Santa Catarina, as dificuldades impostas pelas integradoras para que novos criadores possam ser integrados.

A eficiência técnica da criação é muito importante como parâmetro para as integradoras monitorarem o desempenho dos integrados. GUTMARÃES (1990) menciona que a eficiência técnica de criação se dá pela análise de quatro parâmetros: 1) a taxa de conversão ( $\mathrm{kg}$ de frango / $\mathrm{kg}$ de ração consumida ) ; 2 ) peso médio das aves abatidas ; 3) taxa de mortalidade; e 4) precocidade.

A integração vertical caracteriza-se não por executar a atividade de criação ou engorda, mas sim por estabelecer seu controle através de contratos de fornecimento préestabelecidos, conforme LUCE \& KARSTEN (1992). 


\section{2 - Insumos à produção}

Dentre os vários insumos necessários ao sistema produtivo, alguns se destacam por serem essenciais e muito importantes na estrutura de custo do avicultor.

O primeiro deles é a ração, que é utilizada desde o início do processo até a fase de terminação, sendo específica de acordo com a idade e propósito das aves. Representa cerca de 60 a $70 \%$ do custo total da avicultura ${ }^{3}$.

O segundo envolve os medicamentos e vacinas utilizadas no processo, que estão diretamente ligados à eficiência técnica no que concerne, principalmente, à taxa de mortalidade.

As rações utilizadas na avicultura são compostas basicamente por milho e farelo de soja e são balanceadas nutricionalmente para atender às exigências das aves.

A escassez do milho tem se constituído em ponto de estrangulamento para a avicultura, dada a importância do produto na composição das rações. A principal preocupação é com relação ao futuro, pois a taxa de crescimento da avicultura é muito maior do que a da produção de milho, havendo possibilidade de existirem problemas sérios de abastecimento de milho no País, não só no setor avícola mas em todos os outros que dele dependem como matéria-prima básica.

O Governo Federal procura controlar o mercado interno por meio dos estoques reguladores e o externo principalmente com a política cambial, tentando manter uma certa regularidade no abastecimento de milho durante $o$ ano.

\footnotetext{
3 Informativo da ANAB - Jan/Fev /1993; e Revista Aves e Ovos - Maio/1993.
} 


\section{3 - Estrutura de mercado}

KOCH (1980) define estrutura de mercado como sendo o conjunto de elementos do ambiente que influencia e é influenciado pela conduta e desempenho da firma no mercado no qual ela opera. Ou seja, existe uma correlação entre a estrutura de um mercado, a conduta das empresas e a eficiência destas.

O mercado avícola apresenta imperfeições, que podem ser dimensionadas por: (a ) quatro maiores empresas em termos de volume de abate ( Sadia, Perdigão, Ceval e Frangosul ) representam cerca de $30 \%$ do total abatido no país, o que sugere o poder de mercado das mesmas (Tabela 1); ( b ) as empresas avícolas também agem como verdadeiros oligopólios, dificultando a entráda de novas empresas no mercado, principalmente por possuirem o domínio da tecnologia necessária; ( c ) existem outras duas barreiras à entrada de novas empresas no mercado: a economia de escala e os grandes requerimentos de capital. Para os produtores, o fato de existir um contrato não significa que venderão o produto pelo preço que estipularem, mas sim pelo que a integradora estabelecer. Este poder de barganha das integradoras lhes dão características de oligopsonistas no mercado de frango vivo produzido pelos avicultores.

A Tabela 1 relaciona as maiores empresas de abate de frango para o ano de 1992, indicando a importância de cada uma na produção nacional. Nota-se a predominância das empresas de Santa Catarina ( Sadia , Perdigão, entre outras ).

Para GUIMARÃES (1990), estes grandes abatedouros são diferenciados quanto ao grau de modernização, tamanho e grau de integração. Há uma tendência de concentrar os abates em estabelecimentos de maior tamanho e automatizados, buscando uma melhoria na qualidade do produto. 
Tabela 1 - As maiores empresas de abate de aves no Brasil em 1992 e a participação percentual na produção.

\begin{tabular}{|lcc|}
\hline Empresas & $\mathrm{n}^{\circ}$. de aves abatidas & $(\%)$ \\
\hline Grupo Sadia & 278.971 .404 & 14.45 \\
Grupo Perdigão & 141.343 .012 & 7.32 \\
Grupo Ceval & 96.077 .736 & 4.98 \\
Grupo Frangosul & 84.501 .242 & 4.38 \\
Grupo Avipal & 66.314 .712 & 3.44 \\
Grupo Chapecó & 58.023 .617 & 3.01 \\
Grupo Pena Branca & 45.520 .689 & 2.36 \\
Coop.C.Oeste Catarinense & 31.811 .988 & 1.65 \\
Cia. Avícola Minuano & 28.117 .583 & 1.46 \\
DaGranja Alimentos S/A & 23.507 .385 & 1.22 \\
Coop.C.de Latic. do Paraná & 22.804 .979 & 1.18 \\
Rio Branco Alimentos S/A & 17.960 .368 & 0.93 \\
Coop.Agric.Consolata LTDA & 16.482 .957 & 0.85 \\
SO Frango Alimentos S/A & 15.830 .416 & 0.82 \\
\hline & & 49.45 \\
\hline Sub-total & 954.499 .286 & 50.55 \\
\hline & & 100.00 \\
\hline Outros & 975.886 .415 & \\
\hline Produção Nacional & 1.930 .385 .701 & \\
\hline
\end{tabular}

Fonte : ANAB , Extraido de Revista Aves e Ovos - Junho/1993.

\subsection{1 - Integração vertical}

Integração é um termo normalmente utilizado para descrever o aspecto organizacional da produção, segundo MIGHELL \& JONES (1963) e KOCH (1980), citados por MARQUES \& AGUIAR (1993).

KOCH (1980) define dois tipos de integração : 
1 - Integração Horizontal - ocorre quando duas ou mais firmas se combinam atuando no mesmo estágio do processo produtivo.

2 - Integração Vertical - ocorre quando duas ou mais firmas colocadas sob a mesma organização atuam em estágios separados do mesmo processo produtivo.

Segundo KOHLS \& WILEY (1955), SEAVER (1957), MUELLER \& COLLINS (1957), SEAGRAVES \& BISHOP (1958) e SCHERER (1970), citados por MARQUES (1991), as empresas se integram para aumentar sua eficiência econômica, obtendo os seguintes beneficios :

a ) redução nos custos, devido a operarem em escala ;

b ) detém ganhos que normalmente seriam dos intermediários ;

c ) redução do grau de incerteza associado à entrega dos produtos agrícolas utilizados como matéria-prima.

A integração vertical desenvolveu-se no Sul do País e é tida como responsável direta pelo sucesso da avicultura naquela região durante estes últimos vinte anos. Com o passar do tempo, esta integração chegou a outros estados, sendo que, em São Paulo, em 1985 , a avicultura integrada foi responsável por mais de $75 \%$ da produção total, conforme GUIMARÃES (1990). Isto é confirmado por MARQUES (1991), através do aumento do número de frigoríficos integrados que em 1969 era de apenas um, e que passou a ser vinte e dois, em 1991.

O vínculo entre as empresas integradoras e os avicultores é obtido através de várias formas e modalidades de contrato existentes. $\mathrm{O}$ contrato tem a finalidade de assegurar às integradoras o fornecimento de frango com as especificações requeridas para abate de forma estável e regular. Para o integrado é uma maneira de manter uma renda estável, executando uma atividade com fornecimento garantido de insumos e assistência técnica por parte das empresas. 
GUIMARÃES (1990) diz que quanto maior o número de etapas integradas, maior a facilidade de coordenar todas elas, com aumento de eficiência, redução de capacidade ociosa e instabilidade de produção, e ainda difusão mais fácil de tecnologia entre os segmentos envolvidos.

Conforme GUIMARÃES (1990) e MARQUES \& AGUIAR (1993), a forma de contrato mais utilizada na avicultura é a de pagamento de acordo com a taxa de conversão e mortalidade. Ou seja, a indústria paga ao avicultor de acordo com a sua eficiência. Para isto, há uma fórmula chamada Fator de Produção :

$\mathrm{FP}=\frac{\text { viabilidade } \times \text { ganho de peso } / \text { dia }(\mathrm{Kg} / \text { dia }) \times 100}{\text { taxa de conversão }}$

onde a viabilidade é igual a (100 - \% de mortalidade).

O fator de produção é comparado a um fator de produção padrão, igual a 150, para saber se o produtor deve receber bônus ou penalidade. Há também um preço líquido base estipulado pela empresa para cobrir as despesas de insumos e ainda obter uma margem para pagamento de outros fatores.

A penalidade ou bônus é determinada através de uma regra de três simples :

FP Preço base

FP avicultor $\mathrm{X}$

sendo $\mathbf{X}$ o preço a ser pago ao produtor.

Poder-se-ia acreditar que o produtor integrado tivesse condições de colocar o seu produto a preços pré-fixados e compatíveis com os seus custos de produção, mas os contratos não protegem o avicultor contra instabilidades no preço do produto. $O$ avicultor tem sua receita variando em função das variações do preço base ditado pela integradora, o qual se baseia no comportamento do mercado. 


\section{4 - Mercado interno}

\subsection{1 - Evolução}

A produção de frango tem crescido muito nas últimas duas décadas, passando de 2.080.000 toneladas em 1989 para cerca de 3.434 .000 toneladas, em 1994 , o que corresponde a um aumento de aproximadamente $65,09 \%$. Verifica-se, na Tabela 2 , que entre os principais tipos de carne consumidos no País, a carne de frango é a que apresenta maior crescimento da produção.

Tabela 2 - Produção de carnes no Brasil (1000 toneladas) de 1989 a 1994.

\begin{tabular}{|cccc|}
\hline ANO & FRANGO & BOI & SUÍNO \\
\hline 1989 & 2080 & 4365 & 953 \\
1990 & 2356 & 4400 & 1000 \\
1991 & 2628 & 4520 & 1150 \\
1992 & 2892 & 4500 & 1250 \\
1993 & 3144 & 4520 & 1215 \\
1994 & 3434 & 4580 & 1251 \\
\hline
\end{tabular}

Fonte : APINCO/IBGE/MAARA/DFARA.

Extraído de Síntese Anual da Agricultura de Santa Catarina (1994).

A cadeia produtiva de carne de frango, incluindo a produção de insumos (ração, medicamentos, equipamentos, etc.), somada ao segmento de produção de ovos, gera um PIB anual estimado em cerca de 9 bilhões de dólares, empregando cerca de 1,5 milhão de pessoas $^{4}$.

\footnotetext{
${ }^{4}$ Revista Aves e Ovos - Agosto/1993.
} 
A produção de frango, no Brasil, ocorre, principalmente, nos estados do Sul e Sudeste. O Estado de São Paulo já foi o maior produtor, mas ainda detém o maior número de matrizes, tanto para corte como para postura.

A Tabela 3 mostra a evolução dos abates, no Brasil, nos anos de 1977, 1984, 1988 e 1992. Nota-se que o número de aves abatidas aumentou consideravelmente ao longo dos anos. Constata-se, também, o surgimento do poderio avícola do Sul do País, que desbanca São Paulo da liderança no número de abates.

Tabela 3 - Principais estados do Brasil no número de abates - 1977,1984,1988 e 1992 (mil aves)

\begin{tabular}{|lcrlccccc|}
\hline Estados & 1977 & $\%$ & 1984 & $\%$ & 1988 & $\%$ & 1992 & $\%$ \\
\hline SP & 112.497 & 41.2 & 167.408 & 23.3 & 154.003 & 17.9 & 256.040 & 20.4 \\
PR & 18.549 & 6.8 & 141.411 & 19.6 & 188.618 & 21.9 & 268.560 & 21.4 \\
SC & 81.557 & 29.9 & 244.723 & 34.0 & 295.717 & 34.4 & 362.484 & 29.0 \\
RS & 39.844 & 14.6 & 106.165 & 14.8 & 155.889 & 18.1 & 252.667 & 20.2 \\
\hline & & & & & & & & \\
Sub-total & 252.487 & 92.5 & 659.707 & 91.7 & 794.227 & 92.3 & 1.139 .751 & 91.0 \\
\hline & & & & & & & & \\
Outros & 20.518 & 7.5 & 60.036 & 8.3 & 65.143 & 7.7 & 112.235 & 9.0 \\
\hline & & & & & & & & \\
& & & & & & & & \\
Total c/SIF & 273.005 & 100.0 & 719.743 & 100.0 & 859.370 & 100.0 & 1.251 .986 & 100.0 \\
\hline
\end{tabular}

Fonte: ANAB, Ministério da Agricultura, Serviço de Inspeção Federal (SERPA), Anuário Estatístico.

Extraído de GUIMARÃES (1990) e Revista Aves e Ovos - Junho/93.

O Estado de São Paulo, segundo MARQUES (1991), apresentou evolução na sua estrutura de integração. O número de frigoríficos integrados, em 1969, era de apenas um, três em 1971, quatro em 1980 e, em 1991, vinte e dois. O crescimento da integração foi lento na década de 70, tendo evoluído bastante nas décadas seguintes. 
No entanto, boa parte da produção paulista vem de criações independentes, ou seja, não integradas, seja por desconhecimento do avicultor das vantagens advindas da integração, ou por localização, que impossibilita esta integração. Enfim, pode-se referir a São Paulo como um estado em que a integração tem ainda um bom caminho a percorrer. Talvez por este motivo, os preços recebidos por seus produtores apresentam uma variabilidade maior que a encontrada nos Estados do Sul.

A Figuras 1, 2 e 3 revelam o comportamento dos preços reais recebidos pelos produtores nos estados de São Paulo, Paraná e Santa Catarina.

Figura 1 - Preços reais de frango recebidos pelos produtores em São Paulo, em R\$ de Outubro de 1995.

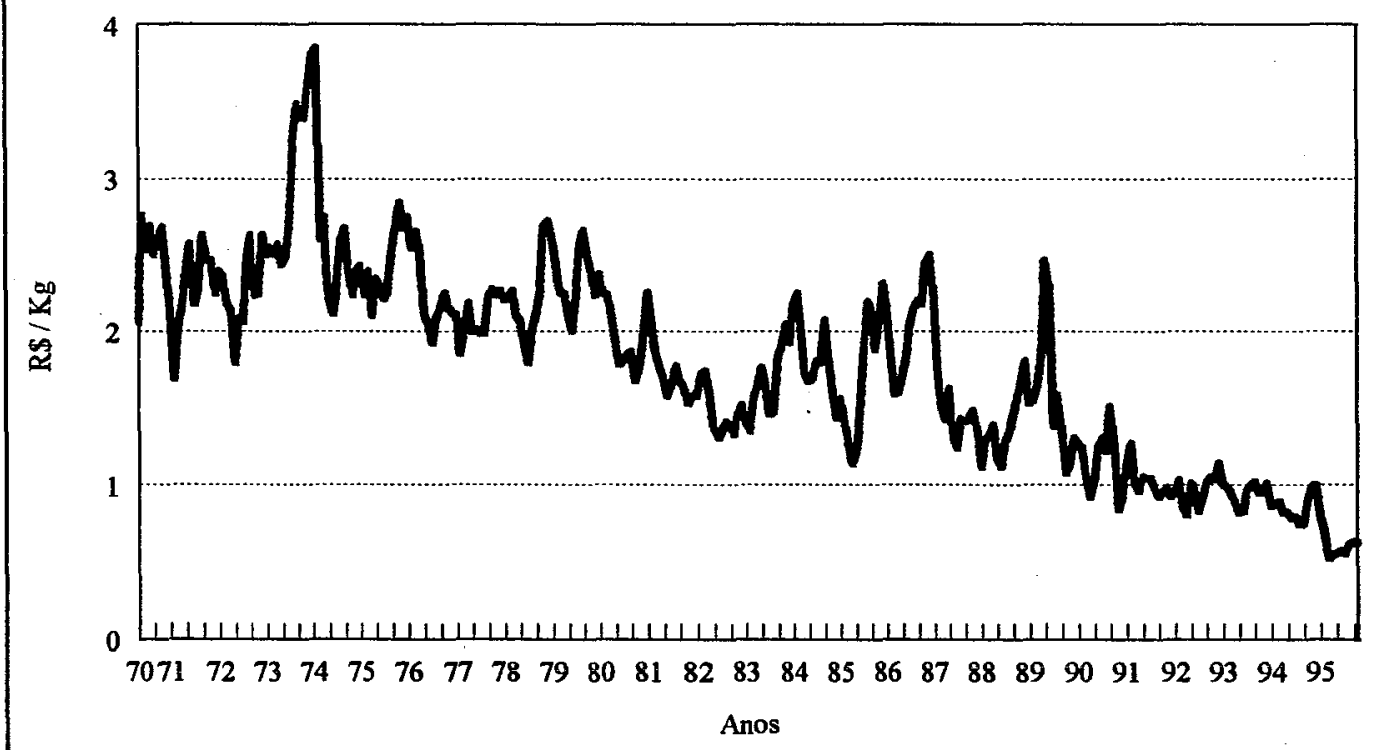

Fonte : Instituto de Economia Agrícola (IEA/SP). 
Figura 2 - Preços reais de frango recebidos pelos produtores no Paraná, em R\$ de Outubro de 1995.

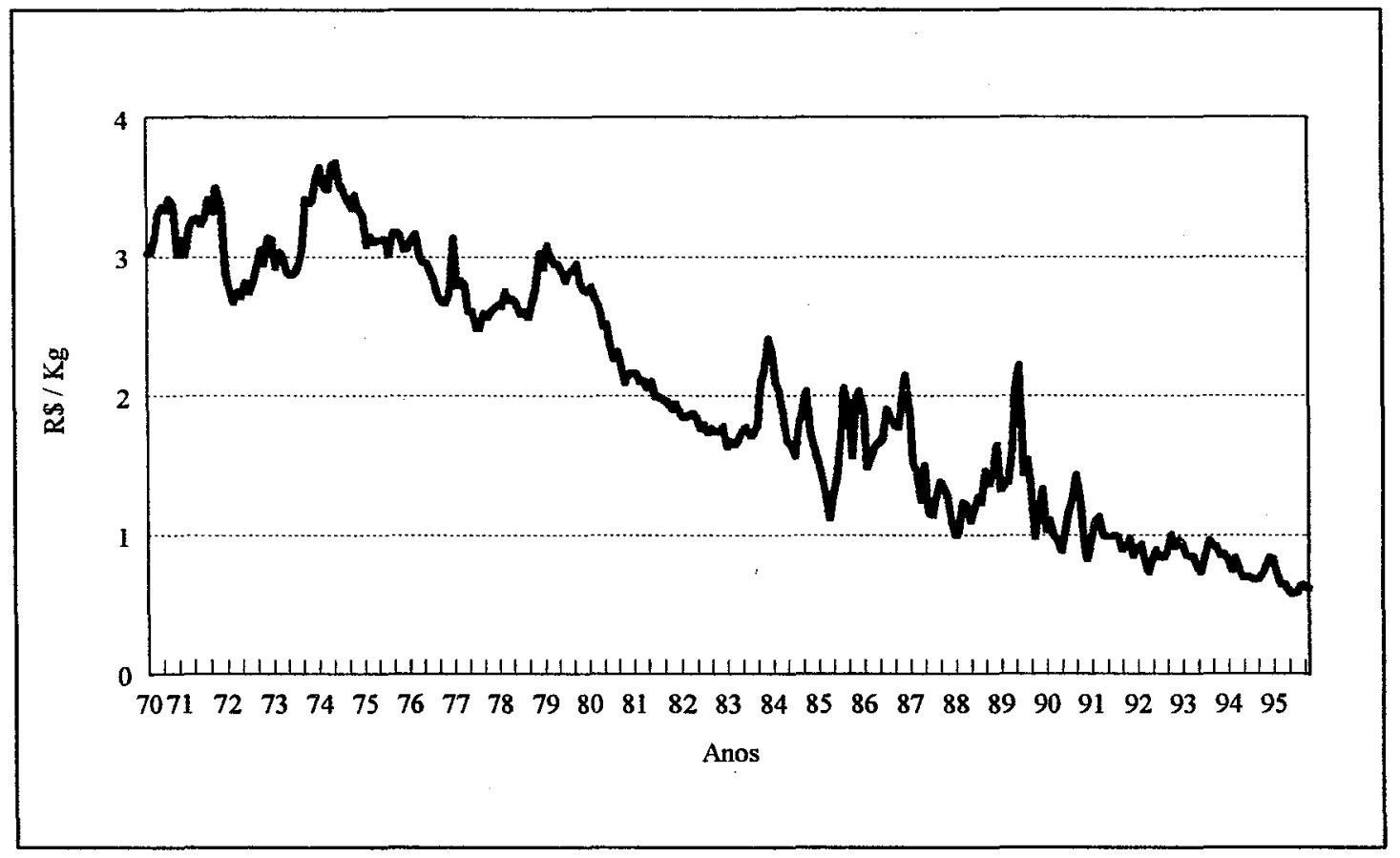

Fonte : Secretaria da Agricultura e do Abastecimento (DERAL/PR).

Figura 3 - Preços reais de frango recebidos pelos produtores em Santa Catarina, em R\$ de Outubro de 1995.

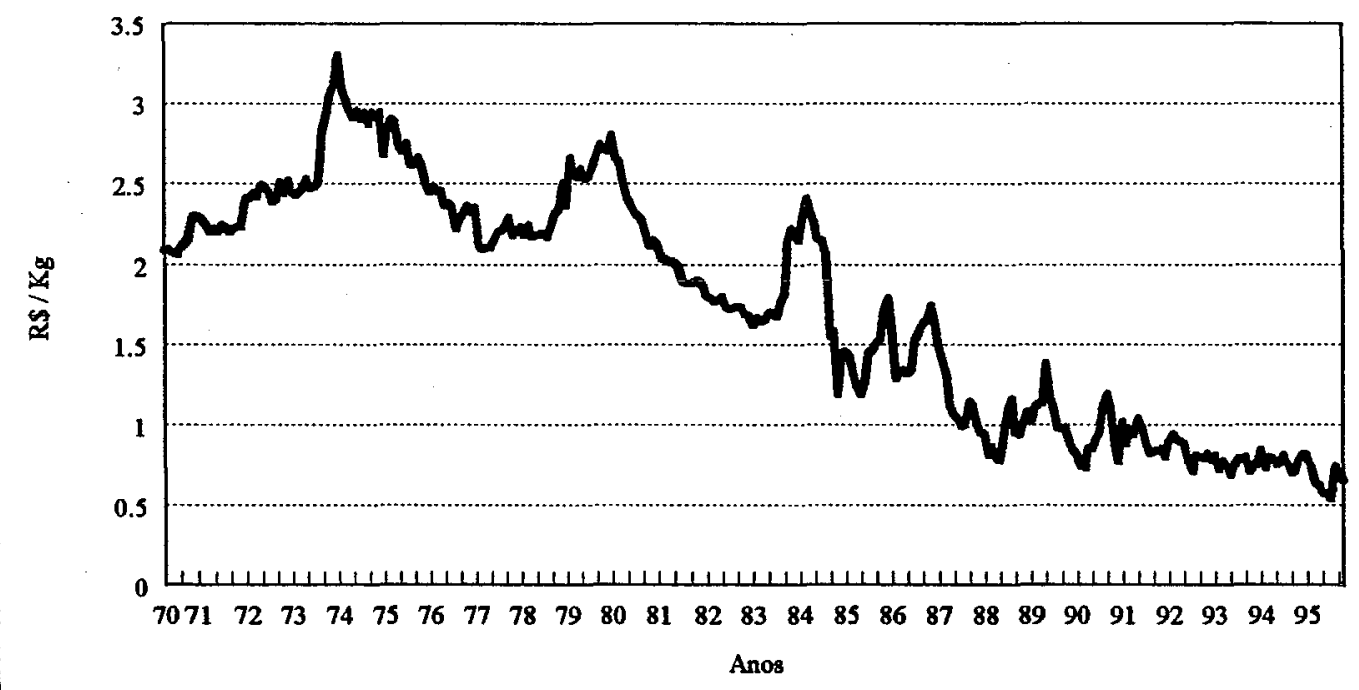

Fonte : Instituto CEPA/SC. 
Os preços reais recebidos pelos produtores, de modo geral, têm tido um comportamento de queda ao longo dos anos, pois os incrementos de produção e produtividade experimentados pelo setor são realmente expressivos. Conforme ZIRLIS et alii (1990), no período de 1970 a 1988 o setor cresceu a uma taxa média anual de $13,7 \%$.

As Figuras 4, 5 e 6 mostram a evolução da relação de preços por quilograma entre o frango e o boi gordo, frango e o milho, e frango e a ração, podendo-se verificar que a relação entre os mesmos foi decrescente na década de 70. Nos anos seguintes houve uma certa estabilização.

O preço da carne de boi apresenta um comportamento cíclico de médio prazo, que influencia diretamente a relação de preços frango-boi. Quando ocorre uma alta nos preços do boi, essa relação de preços cai, implicando substituição da carne bovina pela carne de frango por parte do consumidor. Em um segundo momento, este aumento de demanda por frango provocaria elevação nos seus preços, podendo aparecer um crescimento na relação de preços frango-milho, aumentando a rentabilidade da produção de frango. Isto faz com que o setor avícola se adapte a uma nova realidade de preços. Haveria uma realocação dos fatores de produção de todo o setor para proporcionar um aumento no suprimento de carne de frango, de modo a atender ao aumento da demanda, amenizando este aumento nos preços. 
Figura 4 - Relação de preços entre frango / boi gordo em São Paulo

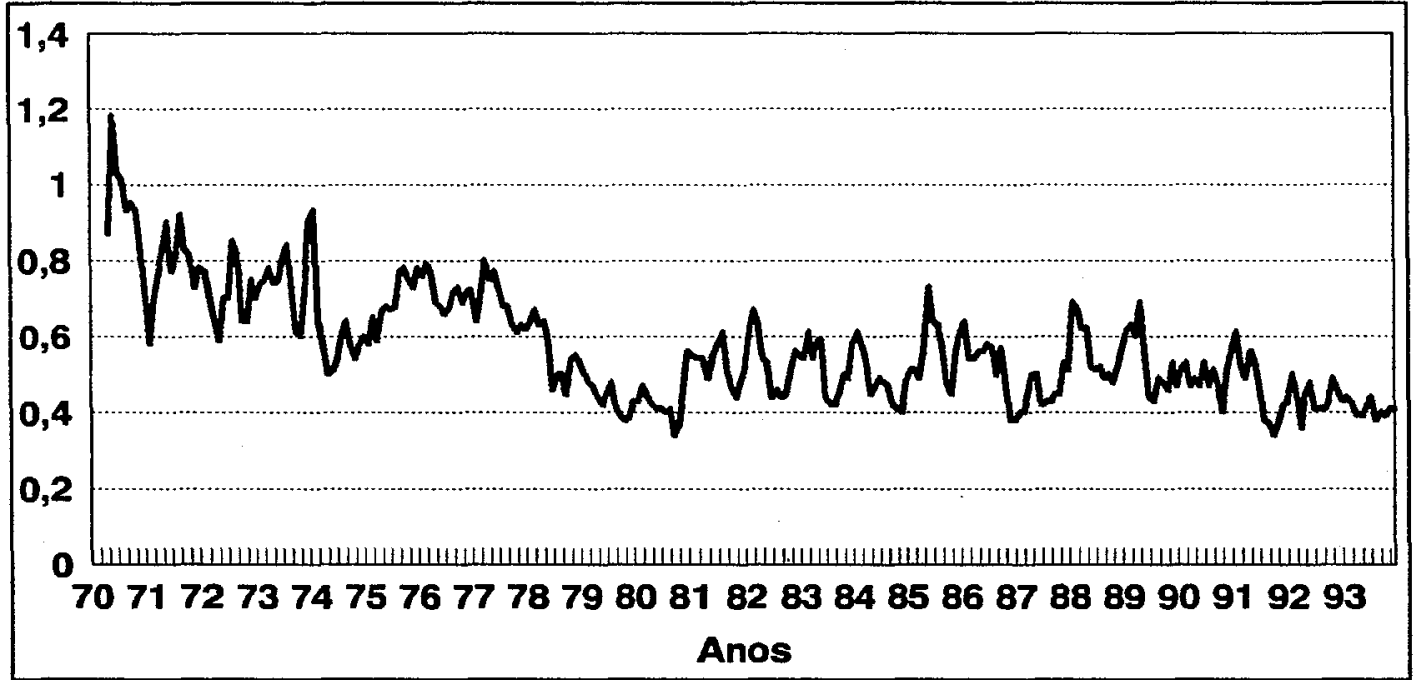

Fonte : Instituto de Economia Agrícola (IEA/SP).

Figura 5 - Relação de preços entre frango / milho em São Paulo

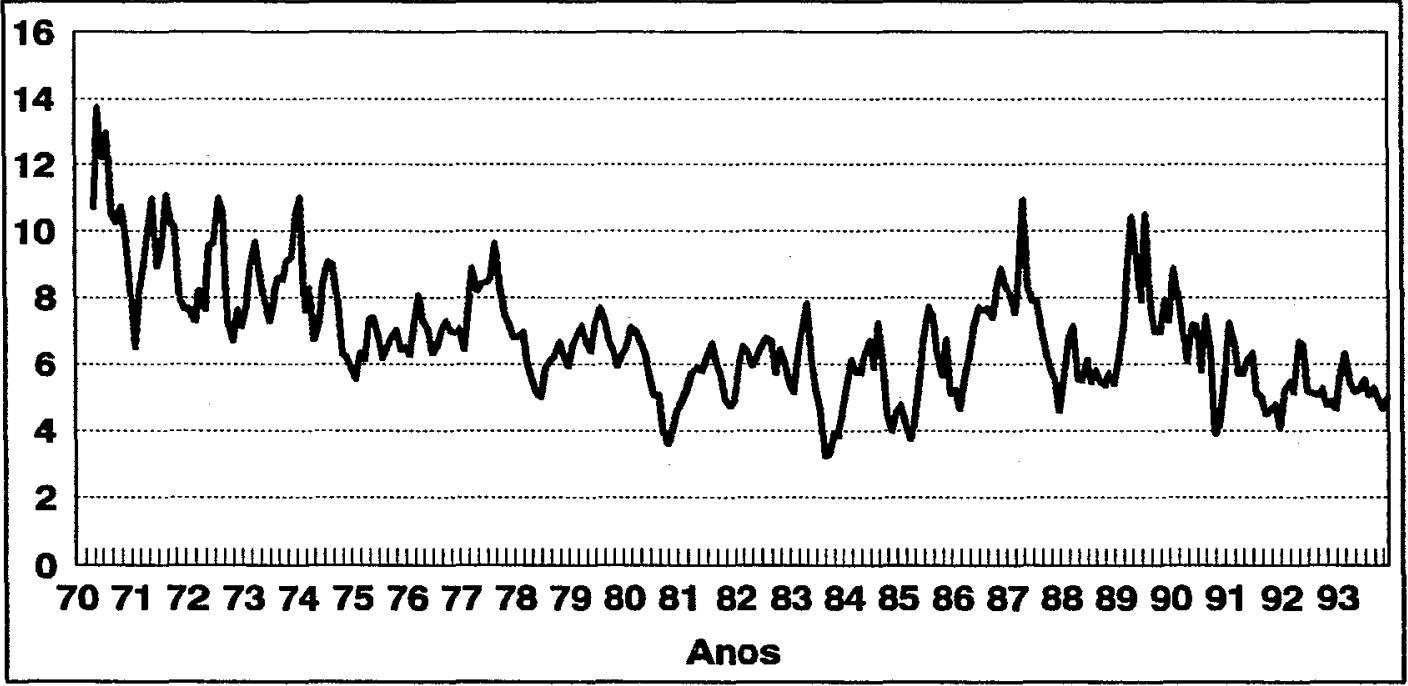

Fonte : Instituto de Economia Agrícola (IEA/SP). 
Figura 6 - Relação de preços entre frango / preço pago pelo kg de ração em São Paulo

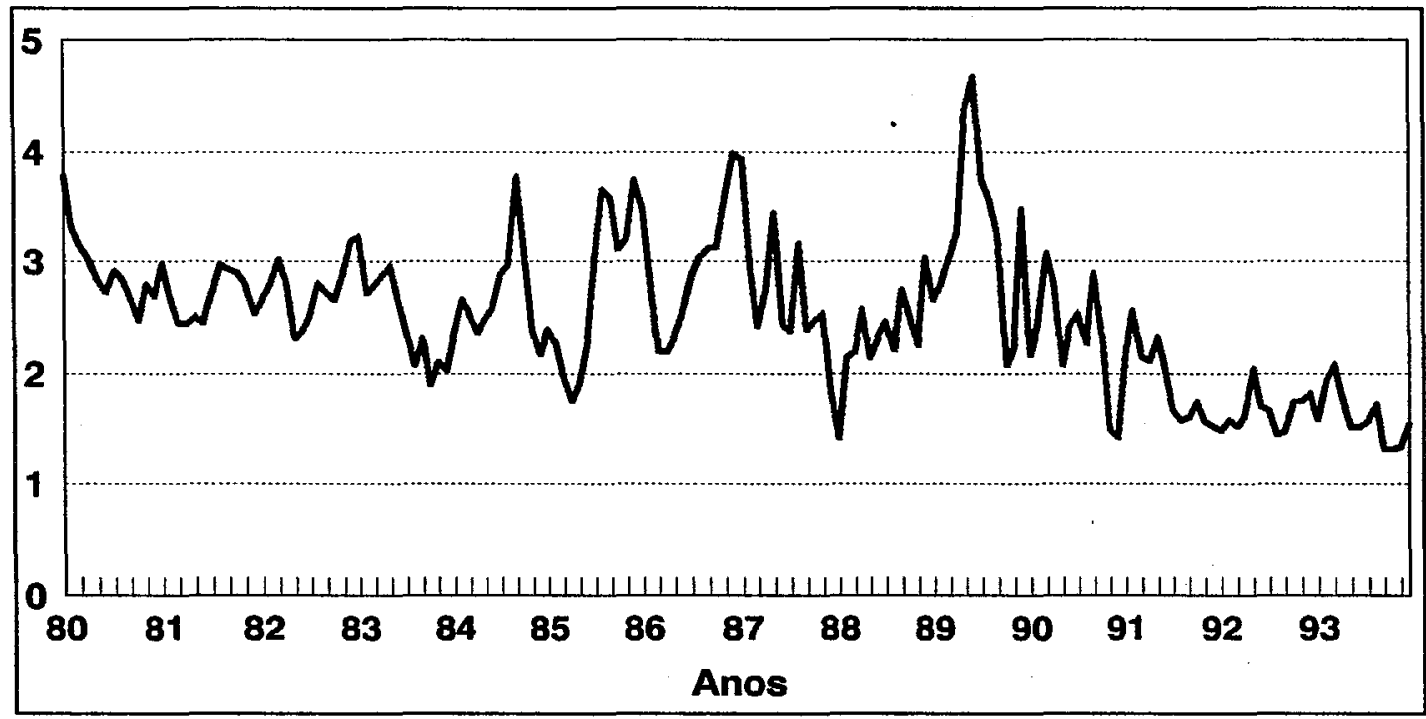

Fonte : Instituto de Economia Agrícola (IEA/SP).

É interessante salientar que esta realocação de fatores de produção e consequente aumento de oferta só é possível se houver um aumento no número de pintos alojados, matrizes e avós, demorando de 13 a 18 meses, conforme GUTMARÃES (1990). O período de alta dos preços do boi é em média de 2 a 3 anos, se repetindo a cada 6 a 7 anos, o que é suficiente para que o ajuste na avicultura ocorra.

\subsection{2 - Consumo}

A principal característica do consumo de carnes no Brasil é que este sempre teve como destaque a carne bovina. Outros tipos de carnes sempre apareceram como fonte de proteína alternativa, conforme o comportamento do preço da carne bovina.

Deve-se destacar o costume e gosto dos consumidores, que sempre preferiram carne bovina às outras carnes. Geralmente os consumidores se alimentavam da carne de 
frango aos fins de semana, pois no cotidiano das famílias a praticidade de se preparar a carne de boi era muito maior, dado que o frango era vendido apenas inteiro.

Com o passar do tempo, as modificações no processamento do frango, queda no seu preço relativo e aumento da produção, entre outras causas, fizeram com que os hábitos da população se modificassem substancialmente, aumentando o consumo de carne de frango ao longo dos últimos 20 anos.

A Tabela 4 mostra a evolução do consumo dos principais tipos de carnes no Brasil, podendo-se verificar um crescimento muito grande no de carne de frango, sendo que as demais permaneceram com um nível de consumo relativamente estável.

O consumo de frango parece tender a aumentar, pois além de estar cada vez mais acessível à população, os agentes responsáveis pela venda e promoção do produto estão utilizando cada vez mais "marketing" e tecnologia de processamento visando incrementar o consumo. Em 1994 o consumo foi de 18,3 kg por habitante e, em 1995, há uma previsão de consumo da ordem de $20 \mathrm{~kg}$ por habitante.

Tabela 4 - Consumo interno de carnes no Brasil de 1989 a 1995 (Kg/hab./ano)

\begin{tabular}{|cccc|}
\hline Ano & Frango & Boi & Suíno \\
\hline 1989 & 12.4 & 24.7 & 6.6 \\
1990 & 13.4 & 23.6 & 7.0 \\
1991 & 15.0 & 22.8 & 7.0 \\
1992 & 16.0 & 22.8 & 7.3 \\
1993 & 17.3 & 23.7 & 7.6 \\
1994 & 18.3 & 24.5 & 7.7 \\
$1995^{*}$ & 20.0 & 25.4 & 7.9 \\
\hline
\end{tabular}

Fonte : APA, IBGE/MAARADFARA e IEA.

* Previsão 


\section{5 - Mercado externo}

As exportações brasileiras de carne de frango começaram na metade da década de 70, com apenas 3.469 toneladas por ano, mas foram alcançando níveis bem maiores, iniciando a década de 80 com cerca de 165.000 toneladas, ou seja, um volume exportado 47,5 vezes maior do que o verificado em 1975. De 1980 até 1995, as exportações subiram a taxas não tão altas. Em 1994, por exemplo, as estimativas de exportações são da ordem de 450.000 toneladas, cerca de 2,73 vezes maior que às verificadas em 1980 (Tabela 5).

O Brasil tem se destacado na produção e nas exportações de frango nos últimos anos graças à rápida assimilação de tecnologia advinda de países desenvolvidos, além da tecnologia nacional, e à rápida e progressiva resposta aos investimentos realizados nos parques industriais, principalmente nos estados do Sul (Tabelas 6 e 7 e Figura 7 ).

Conforme mostra a Tabela 7, o Brasil é o terceiro maior exportador de carne de frango do mundo, só sendo superado pelos Estados Unidos e França.

Tabela 5 - Exportações brasileiras de carne de frango de 1975 - 1994 (toneladas)

\begin{tabular}{|lc|cc|}
\hline Ano & Exportação & Ano & Exportação \\
\hline 1975 & 3.469 & 1985 & 269.009 \\
1976 & 19.636 & 1986 & 224.651 \\
1977 & 32.829 & 1987 & 214.483 \\
1978 & 50.805 & 1988 & 241.782 \\
1979 & 81.096 & 1989 & 243.981 \\
1980 & 165.000 & 1990 & 299.218 \\
1981 & 293.935 & 1991 & 321.754 \\
1982 & 301.793 & 1992 & 370.000 \\
1983 & 289.301 & 1993 & 415.952 \\
1984 & 280.284 & 1994 & 450.000 \\
\hline
\end{tabular}

Fonte : IBGE/UBA/APINCO/ABEF. 
Tabela 6 - Produção mundial de carne de frango

\begin{tabular}{|c|c|c|c|c|c|c|}
\hline \multirow[b]{2}{*}{ Países } & \multicolumn{2}{|c|}{1993} & \multicolumn{2}{|c|}{$1994^{(1)}$} & \multicolumn{2}{|c|}{$1995^{(2)}$} \\
\hline & mil ton. & $\%$ & mil ton. & $\%$ & mil ton. & $\%$ \\
\hline EUA & 9.986 & 34.7 & 10.668 & 35.1 & 11.133 & 35.1 \\
\hline BRASIL & 3.143 & 10.9 & 3.400 & 11.2 & 3.740 & 11.8 \\
\hline CHINA & 2.300 & 8.0 & 2.600 & 8.6 & 3.000 & 9.5 \\
\hline JAPÃO & 1.252 & 4.4 & 1.210 & 4.0 & 1.215 & 3.8 \\
\hline MÉXICO & 1.030 & 3.6 & 1.040 & 3.4 & 1.040 & 3.3 \\
\hline FRANÇA & 1.046 & 3.6 & 1.060 & 3.5 & 1.030 & 3.2 \\
\hline OUTROS & 9.951 & 34.8 & 10.370 & 34.2 & 10.571 & 83.3 \\
\hline TOTAL & 28.708 & 100.0 & 30.353 & 100.0 & 31.729 & 100.0 \\
\hline
\end{tabular}

Fonte : USDA
(1) Estimativa

(2) Previsão

Figura 7 - Produção mundial de carne de frango em 1995

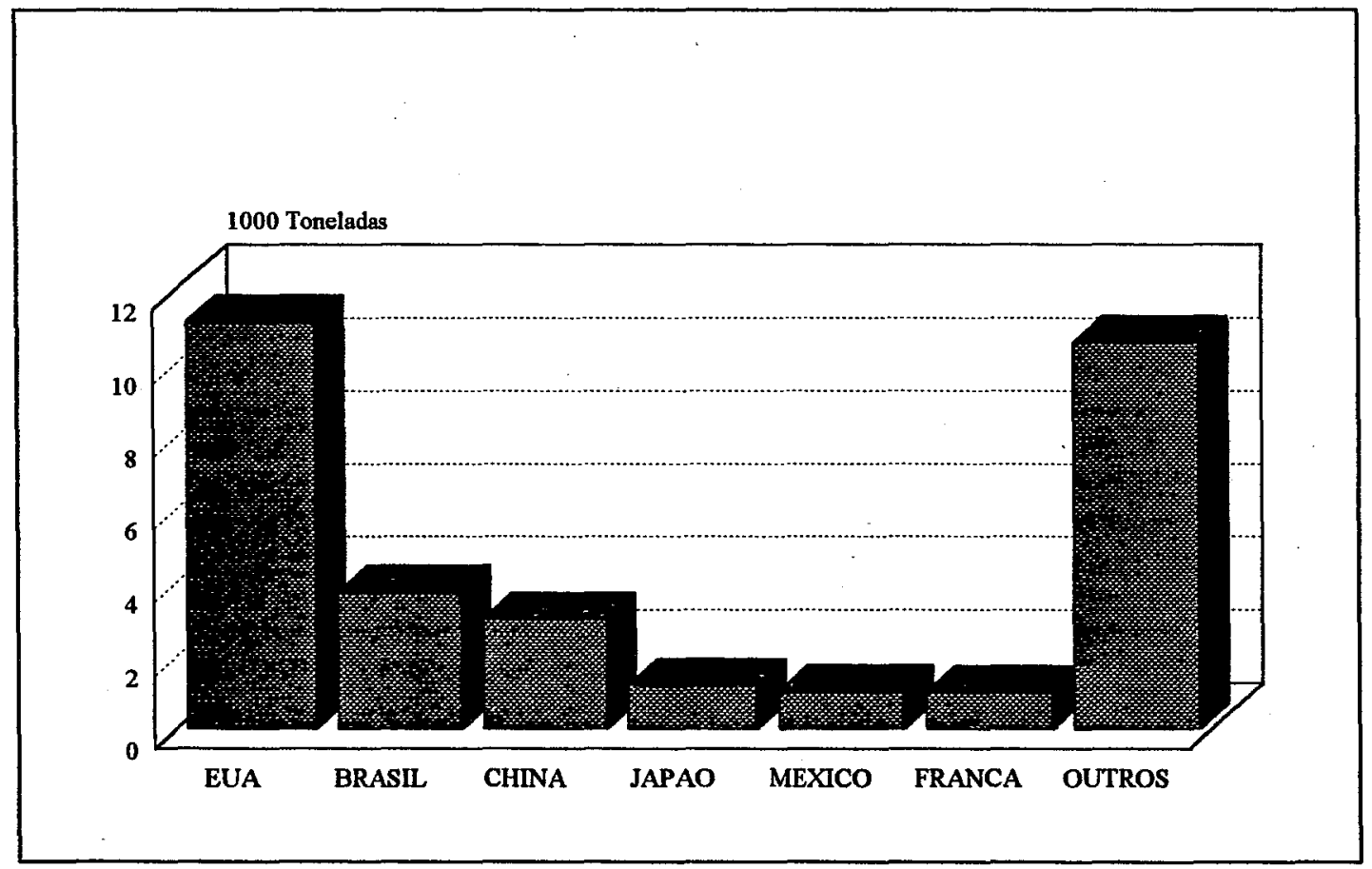

Fonte : USDA 
Tabela 7 - Principais países exportadores de carne de frango (1000 toneladas) em 1994

\begin{tabular}{|ccc|}
\hline Pais & Quantidade Exportada & $\%$ \\
\hline EUA & 1220 & 34.0 \\
FRANÇA & 480 & 13.4 \\
BRASIL & 460 & 12.8 \\
OUTROS & 1424 & 39.8 \\
TOTAL & 3584 & 100.0 \\
\hline
\end{tabular}

Fonte : USDA.

As empresas avícolas brasileiras têm encontrado dificuldades em manter esta participação no mercado internacional, por causa dos subsídios que os produtores europeus e americanos aplicam. Por exemplo, a Comunidade Econômica Européia (CEE), desde a metade de 1992, vem sobretaxando suas importações de peito e coxa de frango brasileiros. Ou seja, a CEE reforçou a política protecionista, sobretaxando os cortes de aves provenientes do Brasil, em valores equivalentes a US\$402/t para coxas e sobrecoxas e US\$ 738/t para o peito. Esta é uma forma da CEE se defender dos preços dos produtos adquiridos do Brasil, que têm ficado abaixo dos valores mínimos por ela estabelecidos ${ }^{5}$.

As exportações brasileiras de frango inteiro ou em pedaços podem ser observadas na Tabela 8 , onde constata-se exportação de cerca de 280 mil toneladas de frango inteiro e 201 mil toneladas de frango em cortes em 1994. Entre os maiores importadores de frango brasileiro incluem-se a Arábia Saudita, Comunidade Econômica Européia, Japão, Argentina e Hong Kong. O principal é a Arábia Saudita. Os principais importadores de frango inteiro brasileiros são a Arábia Saudita e a Argentina respectivamente. No que se refere a cortes de frango, o Japão continua sendo nosso maior importador.

5 Acompanhamento Conjuntural da Agropecuária - número 21- Dezembro/1992. 
Tabela 8 - Exportações brasileiras de frango inteiro e em cortes de 1991 a 1994 (em toneladas)

\begin{tabular}{|l|c|c|c|c|}
\hline Produto & 1991 & 1992 & 1993 & 1994 \\
\hline Inteiros & 203.000 & 232.000 & 287.000 & 280.000 \\
Cortes & 119.000 & 140.000 & 146.000 & 201.000 \\
Total & 322.000 & 372.000 & 433.000 & 481.000 \\
\hline
\end{tabular}

Fonte : ABEF.

A manutenção das exportações brasileiras nestes níveis só serão obtidas se se dispuser de uma estratégia de expansão de exportação para os países asiáticos, pois elas enfrentam uma acirrada competição dos Estados Unidos e França, além de não contarem com os subsídios existentes nestes países. Para piorar o cenário, a Arábia Saudita tem adotado uma política de incentivo à produção interna, com redução nas taxas de importação de insumos destinados à alimentação de todos os tipos de criação, buscando a auto-suficiência no setor carnes. O Japão também tem modificado sua política de importações, aumentando consideravelmente as importações da Tailândia, dificultando a manutenção das exportações brasileiras e americanas. Já os países asiáticos, de modo geral, demandam basicamente frango em cortes, que é um produto com maior valor agregado em comparação com o frango inteiro. Daí a busca pelo mercado de países do Sudeste e Sul da Ásia, cujas economias vêm apresentando rápido crescimento ${ }^{6}$.

\section{6 - Comercialização}

Após a produção, os frangos são transportados para o frigorífico, para serem abatidos e vendidos ao consumidor final. Mas a comercialização é bem mais ampla,

\footnotetext{
${ }^{6}$ Acompanhamento Conjuntural da Agropecuária - números 21 e 30 - Dezembro/1992 e Setembro/1993.
} 
incluindo desde o transporte de ração para alimentação de matrizes, transporte dos pintos, até a venda ao consumidor de frango inteiro ou em cortes, congelado ou resfriado.

Segundo BARROS (1987), a eficiência deste sistema pode ser avaliada através de sua capacidade de abastecer os centros consumidores com uma oferta estável de carne de frango, a preços também estáveis e acessíveis.

Pode-se verificar, na Figura 8 , que a evolução da margem absoluta total de comercialização de frango mostra uma tendência bastante acentuada de queda a partir da década de 80 , o que pode ser atribuída ao progresso tecnológico do setor e a uma sensível melhoria na estrutura de comercialização.

Figura 8 - Margem absoluta de comercialização de carne de frango em São Paulo, em R\$ de Outubro de 1995.

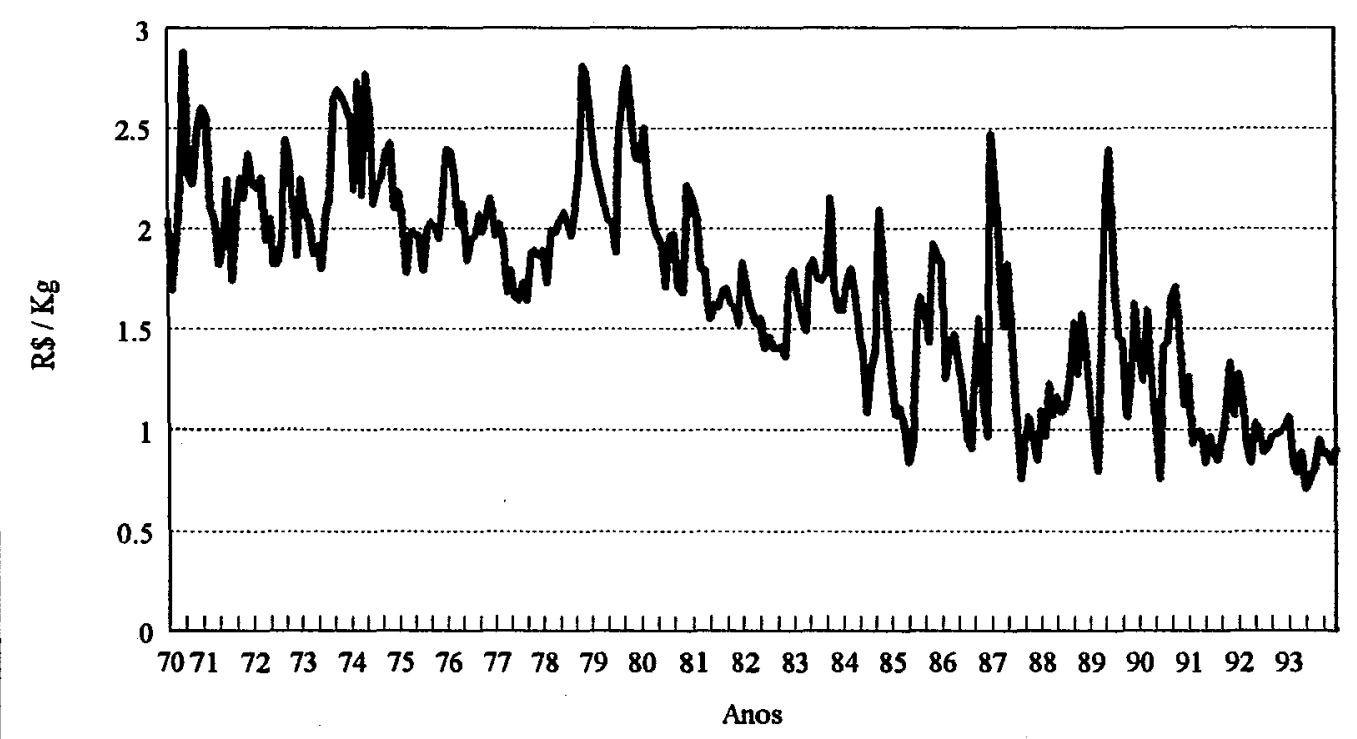

Fonte : Instituto de Economia Agricola (IEA/SP) 
Os grandes grupos empresariais do Sul do País são, na verdade, grandes abatedouros que controlam o fluxo de produção por meio da distribuição dos insumos básicos, retirando frango pronto para o abate conforme as suas necessidades e capacidade de abate. Executam também uma outra função, que é a de comercializar seus produtos junto a supermercados ou estabelecimentos afins, com marca registrada e utilização de estratégias pesadas de "marketing," inclusive com diferenciações de produtos finais, como hambúrgueres, salsichas, almôndegas e vários outros produtos originários do frango.

Segundo ZIRLIS et alii (1990), no estado de São Paulo os abatedouros determinavam com meses de antecedência a quantidade de frango vivo a fluir para os mesmos em dado período. Ocorria assim uma compra programada, mediante compromissos informais com os criadores para entrega em épocas pré-fixadas, de quantidades determinadas, ao preço vigente na data de entrega. Do total adquirido pelos abatedouros, $92 \%$ eram destinados ao mercado interno e $8 \%$ ao externo. Destes $92 \%$, $40 \%$ destinavam-se diretamente ao mercado varejista, outros $40 \%$ a intermediários atacadistas e $12 \%$ diretamente ao consumidor.

Segundo BARROS (1987), a distribuição da renda é importante determinante da estrutura de comercialização, afetando diretamente a eficiência do sistema. $\mathrm{O}$ sistema de comercialização organiza-se de modo a atender às exigências da demanda, havendo uma relação direta entre a estrutura de comercialização e a distribuição de renda, com aquela se especializando em estratos de renda específicos. Por exemplo, LIMA (1984) explica o maior consumo de frango no Sul e Sudeste em relação ao restante do país, argumentando que nestas regiões há maior poder aquisitivo por parte da população e renda melhor distribuida. Assim, os estratos de renda mais baixos tenderiam a ser abastecidos por feiras 
livres, pequenos armazéns, entre outros. Enquanto os estratos de maior poder aquisitivo seriam abastecidos basicamente por supermercados.

As Tabelas 9 e 10 mostram que o supermercado é o principal ponto de venda de frango ao consumidor, com cerca de 35 a $40 \%$ do total vendido. A participação de frangos nas vendas do supermercado está na casa de 3,7\%, com tendência de crescimento.

Tabela 9 - Participação dos segmentos de distribuição no mercado de frango

\begin{tabular}{|l|c|}
\hline \multicolumn{1}{|c|}{ Local de Compra de Frango } & Participação estimada em \% \\
\hline Supermercados & 35 a 40 \\
Avícolas & 20 a 25 \\
Açougues & 20 a 25 \\
Feira e Sacolões & 15 \\
Outros (merc. municip./ granjas) & 5 \\
\hline
\end{tabular}

Fonte : Parente \& Rojo Consultoria de Marketing

Extraído de Revista Aves e Ovos - Setembro / 93 e Fevereiro / 95.

Tabela 10 - Participação de frangos nas vendas do supermercado

\begin{tabular}{|l|c|}
\hline \multicolumn{1}{|c|}{ Produtos } & Participação nas vendas em \% \\
\hline Frangos & 3,7 \\
Massas alimentícias & 1,2 \\
Salgadinhos & 0,7 \\
Sucos & 0,4 \\
\hline
\end{tabular}

Fonte : Revista Aves e Ovos - Setembro/93.

Esta tendência de aumento na venda de frango por parte dos supermercados é explicada pelo fato do frango proporcionar uma boa relação entre giro de estoque e prazo de pagamento. Promoções de frangos inteiros resfriados (que apresentam uma margem menor) aliadas às vendas de frangos em partes (que permitem maiores margens 
devido ao seu maior valor agregado) são estratégias comumente utilizadas. O tipo de frango mais vendido é o inteiro e resfriado, conforme a Tabela 11 abaixo.

Tabela 11 - Tipos de frango mais vendidos nos supermercados

\begin{tabular}{|lc|cc|}
\hline \multicolumn{2}{|c|}{ Frangos resfriados e congelados } & \multicolumn{2}{c|}{ Frangos inteiros e em partes } \\
\hline & Participação nas & & Participação nas \\
Frangos & vendas das lojas & Frangos & $\%$ \\
& $\%$ & & 75 \\
Resfriados & 90 & Inteiros & 25 \\
Congelados & 10 & Partes & lojas \\
\hline
\end{tabular}

Fonte : Revista Aves e Ovos - Setembro/93.

Conforme a ANAB, Associação Nacional dos Abatedouros do Brasil, 70\% dos frangos comercializados em São Paulo são resfriados. Segundo ZIRLIS et alii (1990), para se obter frango resfriado após o abate são necessários preparo e embalagem, sendo o produto transportado em carros resfriados. Já no caso do frango congelado, após o abate o produto é acondicionado e remetido para tonéis de congelamento e, em seguida, para câmaras frigoríficas. Isto demonstra a complexidade do processo de comercialização de frangos no estado de São Paulo. 


\section{3 - MODELOS}

No capítulo anterior foi apresentada a evolução do mercado de frango. Neste capítulo, apresentam-se alguns modelos teóricos que tratam da formação de preços em mercados agropecuários, a curto prazo. Com isso, busca-se fundamentos para uma interpretação mais segura das análises empíricas a serem efetuadas adiante.

Segundo SIMS (1989), existem muitos economistas fazendo pesquisa com modelos econométricos envolvendo equações de regressão com pequena ou nenhuma teoria formal. No entanto, existem também aqueles que o fazem dando este tratamento teórico, como SIMS (1986), ORDEN \& FACKLER (1989), BLANCHARD \& WATSON (1986) citado por SIMS (1989), com modelos estruturais e comportamentais.

BABULA \& BESSLER (1990) também verificam que alguns autores determinam o número de variáveis incluídas e defasagens a serem consideradas de uma maneira mecânica, sem dar atenção à teoria. No entanto, segundo SIMS (1989), FRIEDMAN (1953), citado por BABULA \& BESSLER (1990), o modelo "ideal" deve ter as seguintes características: a) incorporar um comportamento teórico explícito; b) ter conexão com os dados; c) permitir aceitabilidade com um nível de alto grau de confiança para os testes de hipóteses e inferências; d) ter uma especificação parcial, ao menos guiada pela proposta analítica em mãos; e) prever acuradamente através da amostra.

Com o intuito de obter um modelo que cumpra as exigências descritas acima, aqui são apresentados dois dos modelos teóricos mais utilizados nos estudos de formação 
de preços dos produtos agrícolas, bem como um modelo monopsonista, proposto com base na estrutura econômica do mercado em estudo.

O principal objetivo desta seção é dar uma abordagem teórica geral a respeito do processo de formação de preços nos vários níveis de mercado, tendo em vista os pressupostos referentes ao mercado de frango.

A seguir estão resumidamente expostos os dois principais modelos de formação de preços, os quais poderão ser encontrados na íntegra nas referências originais. Segundo a maior parte dos trabalhos referentes a formação de preços de produtos agrícolas, como BRORSEN et alii (1985), THOMPSON \& LYON (1989), BARROS (1990), GUTMARÃES (1990) , FAMINOW \& LAUBSCHER (1991) , LYON \& THOMPSON (1993), entre outros, os modelos mais utilizados para este fim são o de GARDNER (1975) e o de HEIEN (1980). Com base no modelo de HEIEN, também será apresentado o modelo de BARROS (1990), o qual foi importante na elaboração do modelo monopsonista proposto para caracterização do comportamento dos preços neste mercado.

\section{1 - Modelo de GARDNER (1975)}

Este modelo examina as consequências do equilíbrio competitivo nos mercados de produto e de fatores sobre a relação entre os preços de alimentos no varejo e ao produtor.

O trabalho baseia-se em um único produto final e dois insumos usados na sua produção, sendo estes a matéria-prima agrícola e o insumo de comercialização. 
Considera-se um ambiente competitivo, com vários agentes econômicos comercializando o produto agrícola e adicionando a este o insumo de comercialização, um agregado de serviços de processamento e transporte, entre outros. Da combinação do insumo à matéria-prima agrícola, tem-se o produto final. $\mathrm{O}$ modelo prevê um equilíbrio instantâneo nos mercados.

A função de produção da indústria, com retorno constante a escala é:

$$
x=f(a, b)
$$

A demanda pelo produto final (x) é:

$$
\mathrm{x}=\mathrm{D}(\mathrm{Px}, \mathrm{N})
$$

Px é o preço de varejo e $\mathbf{N}$ é uma variável exógena deslocadora de demanda. $\mathbf{O}$ modelo se completa pelas equações que representam os insumos: a (matéria-prima agrícola) e b (insumos de comercialização). As firmas maximizam o lucro, adquirindo as quantidades de a e b que igualam os seus preços aos valores de seus produtos marginais:

$$
\begin{gathered}
P b=P \times f_{b} \\
e \\
P a=P \times f_{a}
\end{gathered}
$$

As equações de oferta de insumos são:

$$
\begin{gathered}
\mathrm{Pb}=\mathrm{g}(\mathrm{b}, \mathrm{T}) \\
\mathrm{e} \\
\mathrm{Pa}=\mathrm{h}(\mathrm{a}, \mathrm{W})
\end{gathered}
$$

onde $\mathbf{T}$ e $\mathbf{W}$ são variáveis exógenas deslocadoras das ofertas de insumos e $\mathbf{P}_{\mathbf{a}}$ e $\mathbf{P}_{\mathbf{b}}$ são preços da matéria prima e do insumo de comercialização. 
Estas duas equações, em condições normais (como curva de demanda decrescente e de oferta não decrescente), terão uma solução única para cada conjunto de variáveis exógenas $\mathbf{T}, \mathbf{W}$ e $\mathbf{N}$. Estas 6 equações podem ser reduzidas a apenas 3; são elas:

$$
\begin{aligned}
& D(P x, N)=f(a, b) \\
& g(b, T)=P \times f_{b} \\
& h(a, W)=P x f_{a} \\
& O \text { modelo mostra o comportamento dos mercados diante de alterações nas }
\end{aligned}
$$
variáveis exógenas $\mathbf{N}, \mathbf{W}$ e $\mathbf{T}^{7}$. Mediante estas variações na demanda primária, na oferta agrícola e na oferta de insumos de comercialização, tem-se os efeitos na relação de preços Px/Pa. Notar que esta relação associa-se diretamente à margem relativa de comercialização [(Px - Pa)/Px].

\subsection{1 - Resumo e conclusões}

O modelo competitivo de Gardner permite as seguintes conclusões:

a) aumentos na demanda primária reduzirão a relação de preços $\mathbf{P x} / \mathbf{P a}$, desde que a elasticidade-preço da oferta do insumo de comercialização seja maior que a das matériasprimas agrícolas, como se espera, já que insumos de mercado têm mais usos alternativos;

b) aumentos na oferta de produtos agrícolas aumentarão a relação $\mathbf{P x} / \mathbf{P a}$;

c) aumentos na oferta de insumo de comercialização fazem com que se reduza a relação $\mathbf{P x} / \mathbf{P a}$;

d) a elasticidade de transmissão de preços, que mede a relação entre variações de preço ao consumidor e ao produtor, tende a ser negativa para choques oriundos da oferta de

\footnotetext{
${ }^{7}$ Em BARROS (1987) tem-se uma abordagem gráfica destas variaçðes.
} 
insumo de comercialização, e positiva mas menor ou igual a um para variações na oferta e demanda primárias.

\subsection{2 - Principais limitações do modelo}

1) Trata-se de um modelo estático comparativo, levando-se em consideração apenas o equilibrio de longo-prazo.

2 ) O equilíbrio é alcançado, instantaneamente, nos mercados considerados.

O próprio GARDNER trata de algumas destas limitações, mas também chama a atenção de que algumas alterações nas proposições iniciais poderão realmente eliminar algumas destas limitações, mas com prejuízo na interpretação dos resultados obtidos, em comparação com o modelo original.

\section{2 - Modelo de HEIEN (1980)}

Segundo AGUIAR (1994), a principal diferença entre os modelos de GARDNER e de HEIEN é a suposição, deste, de desequilíbrio de curto-prazo no mercado varejista.

Segundo HEIEN (1980), o equilíbrio simultâneo nos três níveis de mercado do modelo de GARDNER só é realista quando se tem situações envolvendo períodos de tempo em que as alterações no estoque são pequenas ou inexistentes em relação à demanda total. Entretanto, para períodos de tempo considerados curtos, ocorrem desequilíbrios nestes mercados.

O modelo de HEIEN tenta ocupar uma lacuna deixada pelo modelo de GARDNER, no que diz respeito à dinâmica do processo de transmissão e formação de 
preços. Inclui uma análise que demonstra a trajetória dinâmica percorrida entre um equilíbrio e outro dos mercados de produtor, atacado e varejo.

A análise a seguir é baseada em HEIEN (1980), onde tem-se que as letras maiúsculas representam quantidades e as minúsculas, os respectivos preços.

\section{Varejo :}

A função de demanda é dada por :

$$
\mathbf{R}^{\mathrm{d}}=\mathrm{h}_{1}(\mathrm{r}, \mathrm{y})
$$

onde $\mathbf{R}^{\mathbf{d}}$ é a quantidade demandada no varejo; $\mathbf{r}$ é o preço de varejo e y representa os fatores exógenos, como a renda.

A função de oferta é :

$$
\mathrm{R}^{\mathrm{S}}=\mathrm{h}_{2}(\mathrm{r}, \mathrm{w}, \mathrm{z})
$$

onde $\mathbf{R}^{S}$ é a quantidade ofertada; $\mathbf{w}$ é o preço de atacado e $\mathbf{z}$ representa fatores exógenos, como os serviços de comercialização.

\section{Atacado :}

A função de demanda é representada por :

$$
W^{d}=h_{3}(r, w, z)
$$

onde $\mathbf{W}^{\mathbf{d}}$ representa a quantidade demandada no atacado.

A função de oferta é :

$$
W^{s}=h_{4}(w, f, x)
$$


onde $\mathbf{W}^{\mathbf{S}}$ representa a quantidade ofertada pelos atacadistas ; $\mathbf{f}$ é o preço ao produtor e $\mathbf{x}$ representa outros custos dos atacadistas.

Produtor :

A função de demanda ao produtor é :

$$
F^{d}=h_{5}(w, f, x)
$$

onde $\mathbf{F} \mathbf{d}$ representa a quantidade demandada pelo produto agrícola.

A oferta é dada por :

$$
F^{S}=h_{6}(f)
$$

HEIEN não especifica uma relação que represente o mercado de insumos de comercialização, e não pressupõe equilibrio instantâneo nos três níveis de mercado. Especifica, sim, equações de ajustamento de preços, seguindo o comportamento dos excessos de demanda :

$$
\begin{aligned}
& r=h_{7}\left(R^{d}-R^{s}\right) \\
& w=h_{8}\left(W^{d}-W^{s}\right) \\
& f=h_{9}\left(F^{d}-F^{s}\right)
\end{aligned}
$$

Com a especificação das relações acima, o modelo está completo, com apenas uma exceção - a de que ao nível de varejo é inviável o ajustamento por excesso de demanda, pois devido ao grande número de produtos neste nivel de mercado, os varejistas se acham impossibilitados de acompanhar os mercados de todos eles. Em uma 
situação mais realista, os varejistas aplicariam um "markup" sobre os preços pagos pelos insumos ou matérias-primas.

Segundo HEIEN, considerando a hipótese de retornos constantes à escala ao varejo, a função de custo das firmas no varejo é dada por:

$$
\begin{gathered}
\mathrm{C}=\mathrm{h}_{10}\left(\mathrm{R}^{\mathrm{s}}, \mathrm{w}, \mathrm{z}\right) \\
\mathrm{ou} \\
\mathrm{C}=\mathrm{h}_{10}(\mathrm{w}, \mathrm{z}) \mathrm{R}^{\mathrm{s}}
\end{gathered}
$$

Onde o custo marginal é :

$$
\frac{\partial C}{\partial R}=\mathrm{h}_{10}(\mathrm{w}, \mathrm{z})
$$

que em competição perfeita origina :

$$
r=h_{10}(w, z)
$$

No curto-prazo, é razoável a pressuposição de que, para cada unidade de produto, necessita-se de "proporçọes fixas" de insumos. Isto corresponde a uma função de produção do tipo Leontief, que para os varejistas seria :

$$
\mathrm{R}=\min \left(\mathrm{W} / \alpha_{1}, \mathrm{Z} / \alpha_{2}\right)
$$

e, por consequência, tem-se a função de custo :

$$
C=\left(\alpha_{1} w+\alpha_{2} z\right) R
$$

Então, de (22), tem-se sob competição : 


$$
r=\alpha_{1} w+\alpha_{2} z
$$

A função de produção de Leontief implica que a elasticidade de substituição $(\sigma)$ entre $\mathbf{W}$ e $\mathbf{Z}$ é zero. No longo-prazo, esta hipótese de proporções fixas é irreal, mas considerando-se uma situação de curto-prazo, a relação expressa pela equação (25) representa uma política de preços ótima para as firmas, sendo o preço de venda fixado com base nos preços dos insumos e matéria-prima. Permanece, porém, a questão do ajuste entre oferta e demanda. Considera-se, como ilustração, um modelo simplificado com apenas dois níveis de mercado, produtor e varejo :

$$
\begin{aligned}
& R=\min \left(F / \alpha_{1}, Z / \alpha_{2}\right) \\
& \text { onde : } \\
& r_{t}=\alpha_{1} f_{t}+\alpha_{2} z_{t}
\end{aligned}
$$

A demanda pelo produto agrícola fica :

$$
F_{t} d=\alpha_{1} R_{t}^{d}
$$

onde $\alpha_{1}>0$.

Quanto à demanda de varejo, tem-se :

$$
R_{t} d=a_{0}+a_{1} r_{t}
$$

onde $a_{1}<0$. 
E a oferta do produtor fica :

$F_{t} s=b_{o}+b_{1} f_{t}$

onde $\mathbf{b}_{\mathbf{1}}>\mathbf{0}$.

O equilíbrio ao nível de produtor é obtido pelo excesso de demanda :

$$
\Delta f_{t}=\beta_{o}\left(F_{t} d-F_{t} s\right)
$$

onde $\beta_{\mathbf{0}}>\mathbf{0}$.

Como o preço de varejo é dado por (27), ao varejista só resta determinar a quantidade a ser ofertada, $\mathbf{R}_{\mathbf{t}} \mathbf{s}$. Desde que a firma não pode predizer com certeza a quantidade demandada, uma solução sugerida é a igualdade entre a oferta corrente e a demanda do período anterior :

$$
R_{t} S^{S}=R_{t-1}{ }^{d}
$$

De acordo com esta expressão, dado um incremento na demanda, ao nível de varejo, num certo período, estoques serão removidos acima do esperado, permanecendo inalterados os preços de varejo e de produtor. No início do próximo período, os estoques serão incrementados por meio da regra dada por (32). Este incremento em $\mathbf{R}^{\mathbf{S}}$ será transmitido ao nível de produtor por meio de (28) e os preços de varejo e produtor aumentarão de acordo com (31) e (27). O aumento no preço de varejo tenderá a restringir a demanda ao varejo, fazendo com que haja uma queda na quantidade ofertada pelo varejo $\mathbf{R}^{\mathbf{S}}$ no próximo período. Este processo irá ter sequência por vários períodos até que os preços e quantidades estejam em um novo equilíbrio, dado que a nova solução seja estável. 
HEIEN, a fim de testar a estabilidade do sistema de equações formado por (26) a (32), reduziu as mesmas a um sistema de equações a diferença de $2^{\mathrm{a}}$ ordem :

De (29) e (32) :

$R_{t} s=a_{0}+a_{1} r_{t-1}$

E da equação (28), tem-se :

$F_{t} d=\alpha_{1}\left(a_{o}+a_{1} r_{t-1}\right)$

De (30) e (31) obtém-se :

$$
f_{t}=\frac{\beta_{0} \alpha_{1} a_{0}-\beta_{0} b_{0}}{1+\beta_{0} b_{1}}+\frac{\beta_{0} \alpha_{1} a_{1}}{1+\beta_{0} b_{1}} r_{t-1}+\frac{1}{1+\beta_{0} b_{1}} f_{t-1}
$$

Simplificando a equação (35), obtém-se :

$$
f_{t}=k_{o}+k_{1} r_{t-1}+k_{2} f_{t-1}
$$

Substituindo (35) em (27), tem-se :

$$
r_{t}=\alpha_{1} k_{0}+\alpha_{1} k_{1} r_{t-1}+\alpha_{1} k_{2} f_{t-1}+\alpha_{2} z_{t}
$$

A solução do sistema de equações reduzidas formado por (36) e (37) será estável se o módulo da equação característica de (36) e (37) ficar no círculo unitário. As duas raizes dadas por $\lambda^{2}+\lambda\left(-\mathrm{k}_{1} \alpha_{1}-\mathrm{k}_{2}\right)=0$ são : 


$$
\lambda_{1}=0 \quad \mathrm{e}
$$

$\lambda_{2}=\mathrm{k}_{1} \alpha_{1}+\mathrm{k}_{2}$, que HEIEN mostra possivelmente ser menor que 1.

Para finalizar, HEIEN mostra que a função de custo é normalmente :

$$
\mathrm{C}=\mathrm{F} \mathbf{f}+\mathrm{Zz}
$$

Sendo:

$$
\frac{\partial C}{\partial f}=\mathrm{F} \quad \text { e } \quad \frac{\partial C}{\partial z}=\mathrm{Z}
$$

E como as firmas possuem função de produção de Leontief e retornos constantes à escala, a seguinte função de custo é obtida:

$$
C=h_{10}(f, z, R)=h_{10}(f, z) R=\left(\alpha_{1} f+\alpha_{2} z\right) R
$$

onde tem-se que :

$$
\mathrm{R} \alpha_{1}=\frac{\partial C}{\partial f} \quad \text { e } \quad \mathrm{R} \alpha_{2}=\frac{\partial C}{\partial z}
$$

pois as funções de demanda por insumos são :

$$
F=\alpha_{1} R \quad \text { e } \quad Z=\alpha_{2} R
$$


Então tem-se que o preço de varejo é igual ao custo marginal :

$$
\frac{\partial C}{\partial R}=\mathrm{r}=\alpha_{1} \mathrm{f}+\alpha_{2} \mathrm{z}
$$

\subsection{1 - Conclusão}

A regra de "markup" é consistente em situações onde se tem retornos constantes à escala e tecnologia fixa, que seria o caso de curto-prazo.

Deve-se atentar ao fato de que o período considerado na estimação seja suficientemente curto para que tenha validade a hipótese de função de produção de Leontief, pois, do contrário, deve-se usar o modelo de GARDNER.

\subsection{2 - Limitações :}

A principal limitação deste modelo é sua pressuposição de mercados concorrenciais a nível de produtor, que no caso do frango pode ser considerada relativamente forte.

\section{3 - Modelo de BARROS (1990)}

Este modelo é estruturado com base no de HEIEN, mas com algumas características próprias, como considerar os três níveis de mercado e considerar que o atacadista, por trabalhar com maiores quantidades de produtos, possa assumir o papel de líder nas variações de preços, já que o modelo leva em conta a questão de que o acesso à informação não é uniforme entre as partes envolvidas na comercialização de produtos agrícolas. 
Neste modelo tem-se que, no atacado, o ajustamento de preços ocorre instantaneamente, enquanto que, nos níveis de produtor e varejo, este ajustamento seria defasado em relação ao atacado, devido ao produtor comercializar pequena quantidade de produto e os varejistas não serem especializados. O preço ao produtor se dirigiria até o equilíbrio por meio de ajustes parciais. Enquanto os varejistas adotariam uma política de "markup" para definição do preço de equilíbrio para o qual o mercado se dirigiria também por meio de ajustes parciais.

No curto-prazo as firmas de comercialização, ao atacado e varejo, operariam de acordo com uma função de produção do tipo Leontief :

$$
\mathrm{V}=\min \left\{\mathrm{A} / \mathrm{b}_{1}, \mathrm{Z} / \mathrm{b}_{2}\right\}
$$

$$
A=\min \left\{P / c_{1}, X / c_{2}\right\}
$$

onde $\mathbf{V}, \mathbf{A}$ e $\mathbf{P}$ são quantidades do produto ao varejo, atacado e produtor, respectivamente; $\mathbf{Z}$ e $\mathbf{X}$ são quantidades de insumos de comercialização usados ao varejo e ao atacado, respectivamente; $\mathbf{b}_{1}, \mathbf{b}_{2}, \mathbf{c}_{1}$ e $\mathbf{c}_{2}$ são coeficientes técnicos de produção.

No varejo, a demanda é uma função linear do próprio preço :

$$
\mathrm{v}_{\mathrm{t}}^{\mathrm{d}}=\theta_{\mathrm{o}}+\theta_{1} \mathrm{v}_{\mathrm{t}}
$$

onde $\theta_{1}<0$.

O preço de equilibrio do varejo é dado por :

$$
v_{t}^{*}=b_{1} a_{t}+b_{2} z_{t}
$$


onde $\mathbf{a}$ e $\mathbf{z}$ são preços do produto ao atacado e do insumo de comercialização ao varejo.

O ajustamento de preços no varejo se dá por ajustes parciais :

$$
\mathrm{v}_{\mathrm{t}}-\mathrm{v}_{\mathrm{t}-1}=\alpha\left(\mathrm{v}_{\mathrm{t}}^{*}-\mathrm{v}_{\mathrm{t}-1}\right)
$$

onde $\mathbf{0}<\alpha<1$.

O preço de atacado se forma instantaneamente, por excesso de demanda:

$$
a_{t}-a_{t-1}=\delta\left(A_{t}^{d}-A_{t} s\right)
$$

onde $\delta>\mathbf{0}$.

A demanda ao atacado é obtida pela conversão da demanda ao varejo observada no período anterior :

$$
A_{t} d=b_{1} V_{t-1} d
$$

A oferta ao nível de atacado é obtida pela conversão da oferta ao produtor :

$$
A_{t} s=P_{t} s / c_{1}
$$

A oferta ao produtor é uma função linear do preço recebido no período anterior:

$$
\mathbf{P}_{\mathbf{t}} \mathbf{s}=\gamma_{\mathrm{o}}+\gamma_{1} \mathbf{p}_{\mathrm{t}-1}
$$

onde $\gamma_{1}>0$. 
O preço de equilíbrio ao produtor é dado por :

$$
\mathrm{p}_{\mathrm{t}}^{*}=\frac{a_{1}-c_{2} x_{\mathrm{t}}}{c_{1}}
$$

No curto-prazo, o preço ao produtor se ajusta de acordo com a expressão :

$$
p_{t}-p_{t-1}=\beta\left(p_{t}^{*}-p_{t-1}\right)
$$

onde $0<\beta<1$.

Após sucessivas substituições algébricas, chega-se às seguintes equações de transmissão de preços a serem estimadas :

$$
\begin{aligned}
& \mathrm{a}_{\mathrm{t}}=(1-\alpha) v_{t-1}+\alpha b_{1} a_{t}+\alpha b_{2} z_{t} \\
& \mathrm{p}_{\mathrm{t}}=(1-\beta) \mathrm{p}_{\mathrm{t}-1}+\frac{\beta}{c_{1}} a_{t}-\frac{\beta c_{2}}{c_{1}} x_{t} \\
& \mathrm{v}_{\mathrm{t}}=\delta\left(\theta_{0} b_{1}-\frac{\gamma_{0}}{c_{1}}\right)+\delta b_{1} \theta_{1} v_{t-1}-\frac{\delta \gamma_{1}}{c_{1}} p_{t-1}+a_{t-1}
\end{aligned}
$$

\subsection{1 - Conclusão}

O ajustamento de preços ao nível de atacado ocorre instantaneamente, de acordo com o excesso de demanda, porque duas condições favorecem tal situação. A primeira delas é o fato do custo de mudança de preços ser baixo, por serem as vendas centralizadas em local e tempo definidos, onde as transações são bastante frequentes para que compradores e vendedores mantenham-se em contato sobre possíveis alterações de preços. A segunda é a de que nos níveis de produtor e varejo as transações ocorram de maneira descentralizada e com alguma defasagem em relação às transações no atacado, 
ocasionando ajustamentos parciais de preços e que o preço de equilíbrio de mercado seja alcançado somente após razoável permanência das alterações ocorridas nas condições de oferta e demanda que motivaram os ajustes de preço. Este preço de equilíbrio é compatível com uma política de "markup" sobre os custos.

\subsection{2 - Limitações}

A principal limitação deste modelo é a de que o mesmo não é adequado ao presente estudo do mercado de frango por ter sido construído para se determinar o comportamento dos preços no mercado hortifrutícola. Além do que, há a necessidade de se buscar um modelo com características que dizem respeito somente ao mercado em estudo, como, por exemplo, componentes de mercado não concorrencial, além das características advindas da integração vertical.

\section{4 -Modelo monopsonista}

O modelo apresentado a seguir é uma tentativa de se representar o mercado de frango. O modelo é baseado principalmente em HEIEN (1980) e BARROS (1990). Mas para elaboração deste modelo foram importantes alguns componentes teóricos concernentes aos modelos de PERRY (1978) e BLAIR \& KASERMAN (1983). Em PERRY (1978), um modelo econômico faz uma análise importante da integração vertical no caso de monopsônio, concluindo que a integração vertical elimina a perda de eficiência verificada normalmente pelo comportamento monopsonístico. Seu modelo conclui ainda que o aumento na utilização de insumos pelo monopsonista integrado proporciona maior produção a preços menores para os consumidores. BLAIR \& 
KASERMAN (1983) mostram um modelo onde o objeto de estudo também é a integração vertical sob a ótica monopsonística. Analisam diferentes situações de mercado levando em conta a rentabilidade em cada uma delas, mediante comparações matemáticas e gráficas de rentabilidade de situações de monopsônio com diferentes custos de aquisição de insumos e também em situações sem a presença de monopsônio.

As principais hipóteses do modelo monopsonista proposto são:

( a ) considera-se a decisão de um agente atacadista (frigorífico) que compra monopsonisticamente do produtor e vende concorrencialmente ao varejista ;

( b ) esse atacadista maximiza o lucro igualando preço de venda ao custo marginal ;

( c ) para vender, em ( $t$ ), ao varejista, tem que encomendar, em ( t-1 ), ao produtor;

( d ) o agente decide, pois, com base em informações disponíveis em ( t-1 ), que espera se mantenham em $(t)$;

( e ) o varejista vende concorrencialmente em ajuste instantâneo.

Sejam as variáveis :

$\mathbf{V}=$ carne de frango no varejo

$\mathbf{A}=$ carne de frango no atacado

$\mathbf{F}=$ frango ao produtor

$\mathbf{Z}=$ carne de boi no varejo

$\mathbf{B}=$ insumos de comercialização no varejo

$\mathbf{C}=$ insumos de comercializacão no atacado

$\mathbf{G}=$ insumos de produção

$\mathbf{X}=$ renda dos consumidores

As letras maiúsculas representam quantidades e as letras minúsculas, preços. 


\subsection{1 - Varejo}

A oferta de carne de frango no varejo é obtida de uma função de produção do tipo Leontief :

$$
\mathrm{V}_{\mathrm{t}} \mathrm{s}=\min \left\{\frac{A_{t}}{\alpha}, \frac{B_{t}}{\beta}\right\}
$$

onde :

$\alpha, \beta>0$.

A demanda por carne de frango no varejo é considerada uma função linear do próprio preço no varejo, da renda dos consumidores e do preço da carne de boi no varejo:

$$
\mathrm{V}_{\mathrm{t}}^{\mathrm{d}}=\gamma_{\mathrm{o}}+\gamma_{1} \mathrm{v}_{\mathrm{t}}+\gamma_{2} \mathrm{Xt}+\gamma_{3} \mathrm{z}_{\mathrm{t}}
$$

onde :

$$
\gamma_{1}<0 \text { e } \gamma_{2}, \gamma_{3}>0^{8} \text {. }
$$

O preço no varejo é dado por :

$$
v_{t}=\alpha a_{t}+\beta b_{t}
$$

onde $a_{t}$ é o preço de venda do frango do atacadista ao varejista; e $b_{t}$ é o preço do insumo de comercialização no varejo.

\subsection{2 - Atacado}

A produção de carne de frango, ao atacado, é também representada por uma função de produção do tipo Leontief :

\footnotetext{
${ }^{8}$ Note que assume-se a hipótese (lógica) de que a carne de frango é não-inferior e é substituta da carne bovina.
} 


$$
A_{t} s=\min \left\{F_{t} / \mu, C_{t} / \delta\right\}
$$

onde :

$\mu, \delta>0$.

O preço de venda do atacadista ao varejista, obtido de (54), é :

$$
a_{t}=(1 / \alpha)\left(v_{t}-\beta b_{t}\right)
$$

Mas o atacadista espera receber, em $(t)$, o preço verificado em $(t-1)$ :

$$
a_{t}^{e}=a_{t-1}=(1 / \alpha)\left(v_{t-1}-\beta b_{t-1}\right)
$$

\subsection{3 - Produtor}

A oferta de frango pelo produtor é considerada como uma função linear do próprio preço ao produtor e dos insumos de produção no período anterior :

$$
\mathrm{F}_{\mathrm{t}} \mathbf{s}=\theta_{\mathrm{o}}+\theta_{1} \mathrm{f}_{\mathrm{t}}+\theta_{2} \mathrm{~g}_{\mathrm{t}-1}
$$

onde :

$\theta_{1}>\mathbf{0}$ e $\theta_{2}<0$

\subsection{4 - Maximização de lucro}

O custo médio esperado para o atacadista é :

$$
\mathrm{CM}_{\mathrm{t}} \mathrm{e}=\mu \mathrm{f}_{\mathrm{t}}+\delta \mathrm{c}_{\mathrm{t}}
$$


onde $\boldsymbol{c}_{\mathbf{t}}$ representa o custo de comercialização, no atacado, no tempo $\mathbf{t}$, pois os atacadistas levam em consideração na tomada de decisões os custos de reposição, não interessando para os mesmos os custos em um período anterior.

Considerando (58) :

$$
\mathrm{CM}_{\mathrm{t}} \mathrm{e}=\left(\mu / \theta_{1}\right)\left[\mathrm{F}_{\mathrm{t}}-\left(\theta_{\mathrm{o}}+\theta_{2} \mathrm{~g}_{\mathrm{t}-1}\right)\right]+\delta c_{\mathrm{t}}
$$

O Custo Total esperado é:

$$
\mathrm{C}_{\mathrm{t}} \mathrm{e}=\left(\mu / \theta_{1}\right)\left[\mathrm{F}_{\mathrm{t}}^{2}-\left(\theta_{\mathrm{o}}+\theta_{2} \mathrm{~g}_{\mathrm{t}-1}\right) \mathrm{F}_{\mathrm{t}}\right]+\delta \mathrm{c}_{\mathrm{t}} \mathrm{F}_{\mathrm{t}}
$$

O Custo Marginal esperado é :

$$
\mathrm{CMa}_{\mathrm{t}} \mathrm{e}=2 \mu \mathrm{F}_{\mathrm{t}} / \theta_{1}-\left[\left(\theta_{\mathrm{o}}+\theta_{2} \mathrm{~g}_{\mathrm{t}-1}\right) \mu\right] / \theta_{1}+\delta \mathrm{c}_{\mathrm{t}}(62)
$$

Igualando (57) com (62), tem-se o ponto onde o atacadista maximiza o lucro, ou seja, onde iguala o preço com o custo marginal esperado :

$$
\begin{aligned}
& a_{t} e=\mathrm{CMa}_{t} e^{e} \quad \text { ou, } \\
& (1 / \alpha)\left(v_{t-1}-\beta b_{t-1}\right)=2 \mu F_{t} / \theta_{1}-\left[\left(\theta_{o}+\theta_{2} g_{t-1}\right) \mu\right] / \theta_{1}+\delta c_{t}
\end{aligned}
$$

de onde tem-se :

$$
\mathrm{F}_{\mathrm{t}}^{*}=\frac{\theta_{0}}{2}+\frac{\theta_{2}}{2} g_{t-1}-\frac{\delta \theta_{1}}{2 \mu} c_{t}+\frac{\theta_{1}}{2 \alpha \mu} v_{t-1}-\frac{\beta \theta_{1}}{2 \alpha \mu} b_{t-1}
$$

que é a quantidade efetiva de frango vivo a ser adquirida, pelos atacadistas, junto aos produtores (demanda derivada) e a ser ofertada, pelos atacadistas, aos varejistas. De 
modo a determinar o preço efetivo a ser recebido pelos produtores e varejistas, substituise $\mathbf{F}_{\mathbf{t}}{ }^{*}$ nas respectivas equações de oferta.

A partir de (58), obtém-se :

$$
f_{t}=1 / \theta_{1}\left(F_{t}^{*}-\theta_{0}-\theta_{2} g_{t-1}\right)
$$

com base em (63), o preço efetivamente pago ao produtor é :

$$
\mathrm{f}_{\mathrm{t}}=\frac{\theta_{0}}{2 \theta_{1}}-\frac{\theta_{2}}{2 \theta_{1}} g_{t-1}-\frac{\delta}{2 \mu} c_{t}+\frac{1}{2 \alpha \mu} v_{t-1}-\frac{\beta}{2 \alpha \mu} b_{t-1}
$$

Enquanto a equação (56) é o preço efetivamente recebido pelos atacadistas, o preço referente aos varejistas é obtido das equações (52) e (55) e da hipótese ( e ) do modelo, que considera a existência de equilíbrio instantâneo neste nível de mercado, resultando em :

$$
\mathrm{v}_{\mathrm{t}}=\frac{1}{\gamma_{1}}\left[\frac{F_{t}^{*}}{\alpha \mu}-\left(\gamma_{0}+\gamma_{2} X_{t}+\gamma_{3} z_{t}\right)\right]
$$

que é quanto recebe o varejista com base na oferta que lhe é dada por $\mathbf{F}_{\mathbf{t}}{ }^{*}$.

Estabelece-se assim, a seguinte estrutura dinâmica do modelo monopsonista :

$$
\begin{aligned}
& f_{t}=f\left(g_{t-1}, c_{t}, v_{t-1}, b_{t-1}\right) \text { pela equação }(64) \\
& v_{t}=v\left(g_{t-1}, c_{t}, v_{t-1}, b_{t-1}, X_{t}, z_{t}\right) \text { pela equação (65) } \\
& a_{t}=a\left(v_{t}, b_{t}\right) \text { pela equação }(56) .
\end{aligned}
$$


Esta estrutura procura explicar a formação e o comportamento dos preços no mercado de frango com características monopsonísticas no nível de produtor, e concorrenciais nos níveis de atacado e varejo.

O modelo apresentado pode ser melhor interpretado com o auxílio da Figura 9. Nesta, por simplificação, as funções são consideradas lineares e o cenário ilustrado com os custos e condições de oferta e demanda constantes. As quantidades são dadas por unidades equivalentes. Verifica-se que o atacadista maximiza lucro igualando o seu custo marginal com o seu preço que, conforme o modelo, depende da demanda derivada ao atacado, determinando, assim, os pontos $\mathbf{B}$ e $\mathbf{C}$, que representam, respectivamente, os preços no atacado e ao produtor referentes à quantidade $\mathbf{F}_{\mathbf{t}}{ }^{*}$. No modelo, o preço no varejo é determinado através de um "markup" sobre os custos de comercialização e de aquisição do produto junto aos atacadistas. Este preço é representado pelo ponto A, onde ocorre a interseç̧ão da curva de oferta derivada do varejista com a demanda primária, para a quantidade determinada previamente pelo atacado $\left(\mathbf{F}_{\mathbf{t}}{ }^{*}\right)$. 
Figura 9 - Representação gráfica do modelo monopsonista.

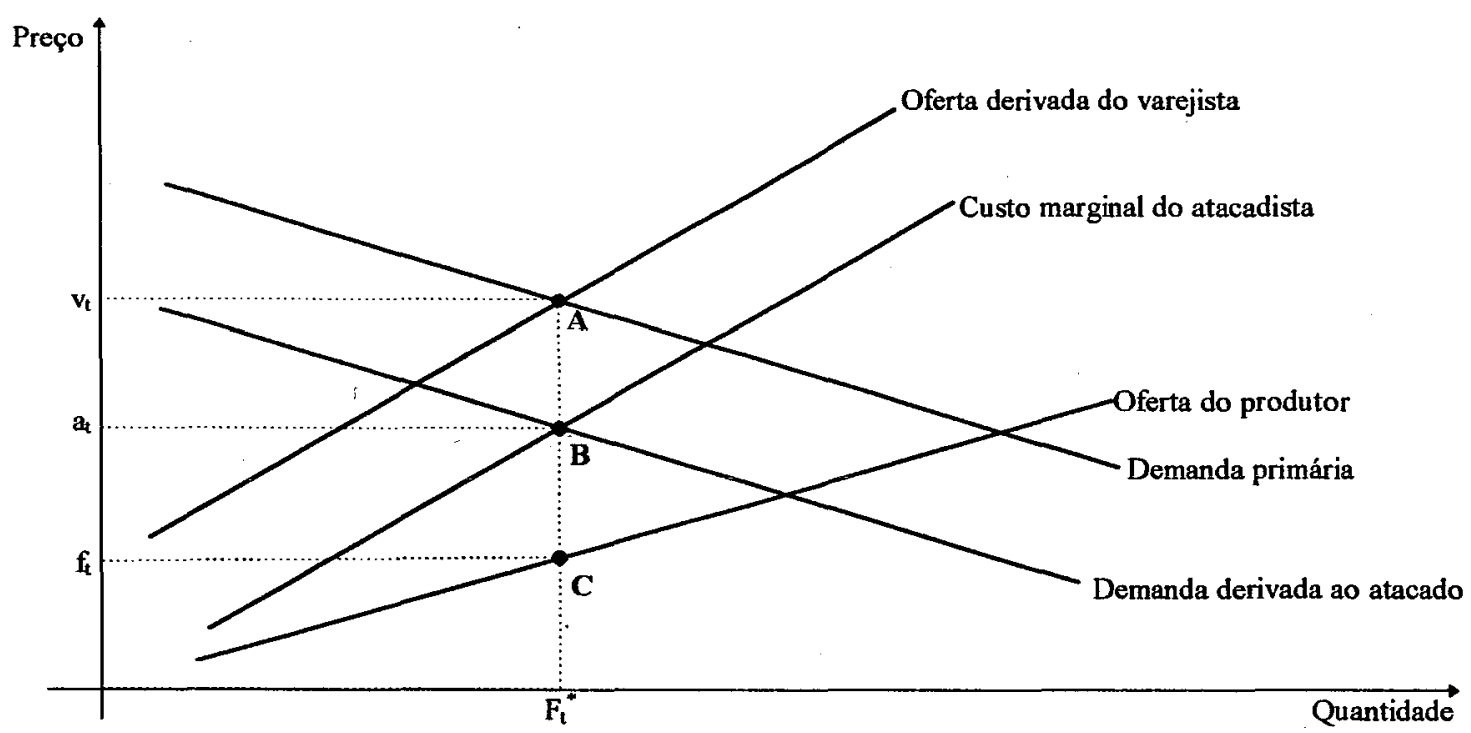

De acordo com a figura o atacadista decide considerando o preço que o varejista poderia praticar conforme o observado no período (t-1). A curva de oferta do varejista é paralela à de custo marginal do atacadista devido à política de "markup" praticada, pois o preço de varejo é exatamente o preço de atacado acrescido dos custos de comercialização no varejo. 
55.

\section{4 - DADOS E PROCEDIMENTOS}

\section{1 - Aspectos gerais}

Após a exposição sobre o desempenho, a longo prazo, do mercado de frango e dos modelos teóricos de formação de preços, parte-se agora para a exposição dos métodos econométricos a serem utilizados para se alcançar os objetivos previamente estabelecidos, que visam um melhor entendimento do funcionamento do mercado de frango.

As análises serão feitas considerando-se o período de janeiro de 1985 a dezembro de 1993, que seria um período em que as inovações tecnológicas, devido às integrações, foram responsáveis por rápida evolução da avicultura paulista ${ }^{9}$. Além disso, em 1984 houve uma grande crise interna e externa no setor, justificando assim a não utilização de dados de período anterior ao considerado.

BESSLER \& COVEY (1993) tratam de problemas encontrados na determinação da estrutura econômica em modelos econométricos e de problemas estruturais que decorrem da omissão de variáveis nas estimações. Segundo estes autores, a literatura de economia agrícola está repleta de exemplos de estimativas de coeficientes

\footnotetext{
9 No caso da avicultura, os principais componentes de mudança estrutural no período considerado (1985-1993) são a tecnologia de produção e a tecnologia de processamento do produto, todas como consequência do processo de integração.
} 
que mudam quando a mesma relação estrutural é ajustada para diferentes períodos de tempo. Em uma revisão de literatura efetuada pelos autores nos periódicos "American Journal of Agricultural Economics" e "Journal of Farm Economics", desde 1960, foram encontrados 63 trabalhos que mostravam evidências de mudanças nos parâmetros estimados; em apenas 9 não se observou evidência de tal fato.

Um outro exemplo desta natureza pode ser constatado em CHAVAS (1983), que verificou significantes reduções nas elasticidades de preço e renda da demanda de carne bovina e aumentos na elasticidade-renda de carne de aves durante os anos 70 . $\mathrm{O}$ autor sugere que mudanças nas preferências do consumidor e no âmbito estrutural possam ser responsáveis pela mudança estrutural ocorrida.

Segundo RAVALLION (1986), a utilização de modelos dinâmicos permite o estudo de mercados que, mesmo separados espacialmente, possuem uma conexão através de diferenciais de preços onde cada série de preço local tem a sua própria estrutura dinâmica interagindo com a de outros mercados locais. Estes modelos permitem também verificar se o mercado em estudo é um mercado integrado instantaneamente, como se cogitou no parágrafo anterior, ou se a integração ocorre gradativamente no processo dinâmico de ajuste.

GOODWIN \& SCHROEDER (1991) chegam a algumas conclusões importantes de que mercados não interligados podem obter informações imprecisas de preços, podendo distorcer as decisões de produção do mercado e contribuir para movimentos ineficientes de produtos. Daí a importância de se estudar os mercados de frango nas regiões Sul e Sudeste.

Este capítulo tem por objetivo apresentar, por um lado, os dados a serem utilizados e sua origem, e, por outro, a metodologia a ser aplicada aos mesmos. 


\section{2 - Dados}

Foram utilizados dados referentes às seguintes variáveis econômicas: renda da população (índice de produção industrial); preços de frango ao produtor, atacado e varejo em São Paulo; preços de frango ao produtor no Paraná e Santa Catarina; preço da carne bovina no varejo, preços de milho e soja ao produtor e taxa de juros real.

\section{Frango em São Paulo}

Para o mercado de frango em São Paulo, os preços médios correntes recebidos ao nível de produtor, atacado e varejo, em $\mathrm{Cr} \$ / \mathrm{kg}$, foram obtidos junto a Informações Econômicas, publicação do Instituto de Economia Agrícola (IEA) da Secretaria de Agricultura do Governo do Estado de São Paulo.

\section{Frango no Paraná e em Santa Catarina}

Destes estados obteve-se apenas o preço médio corrente a nível de produtor, em $\mathrm{Cr} \$$ / kg, no Departamento de Economia Rural (DERAL) da Secretaria da Agricultura do Governo do Estado do Paraná e no Instituto CEPA da Secretaria da Agricultura do Governo do Estado de Santa Catarina, respectivamente. 


\section{Carne bovina em São Paulo}

Foram coletados também os preços médios correntes de boi gordo, ao nível de varejo, junto ao Instituto de Economia Agrícola (IEA), em $\mathrm{Cr} \$ /$ @, os quais foram convertidos para $\mathrm{Cr} \$ / \mathrm{kg}$.

\section{Milho e soja em São Paulo}

Os preços utilizados de milho e soja foram preços médios correntes recebidos pelos produtores no estado, em $\mathrm{Cr} \$ / 60 \mathrm{~kg}$ (obtidos no Instituto de Economia Agrícola), os quais foram convertidos em $\mathrm{Cr} \$ / \mathrm{kg}$. Estes dois preços constituem um indice de custo de produção utilizado na proporção de : $0,7 \times \mathbf{P}_{\mathbf{M L}}+0,3 \times \mathbf{P S O}^{10}$, onde $\mathbf{P}_{\mathbf{M L}}$ é o preço do kg de milho e PSO é o preço do kg de soja. Este índice se deve ao fato destes dois produtos constituirem quase que a totalidade da composição das rações utilizadas na avicultura, além do que as rações são responsáveis por cerca de 60 a $70 \%$ dos custos de produção.

\section{Taxa de juros real}

Os dados de taxa de juros real foram obtidos da publicação Taxa de Juros no Brasil do Banco Central, cuja série utilizada foi a da taxa de juros do "overnight", e servirão como proxy do custo dos insumos de comercialização no atacado e varejo, conjuntamente.

10 Este fator de ponderação é baseado na composição média das raçðes de frango de corte em VELASCO, A.M.; GALAN, V.B. e BACHA, C.J.C. (1994). 
59.

\section{Índice de produção industrial}

Os dados de índice de produção industrial que servirão de variável proxy da renda da população, foram obtidos na publicação Conjuntura Econômica da Fundação Getúlio Vargas (FGV).

Todos os dados coletados foram deflacionados pelo IGP - DI (Índice geral de preços - disponibilidade interna) da Fundação Getúlio Vargas (FGV), convertidos para valores de junho de 1994, e transformados em logaritmos para se obter as respostas das variáveis a choques em termos de elasticidade. O período coletado foi de janeiro de 1985 a dezembro de 1993.

\section{3 - Procedimentos}

Neste item constam os principais testes e modelos econométricos utilizados com o objetivo de esclarecer e justificar o uso de tais instrumentais nas estimações executadas.

A análise empírica se divide em : 1) testes de estacionariedade das séries temporais, bem como testes de cointegração e 2) utilização de modelos de autoregressão vetorial (VAR), com correção de erro, se necessário, para captar as relações dinâmicas entre as variáveis do modelo proposto no capítulo 3 . 
60.

\subsection{1 - Testes de estacionariedade e de cointegração}

\subsubsection{1 - Séries de tempo estacionárias e não-estacionárias}

Em PINDYCK \& RUBINFELD (1991), tem-se que as séries de tempo são geradas por um processo estocástico onde as variáveis associadas possuem uma distribuição aleatória conjunta, isto é, existe alguma função de distribuição de probabilidade $\mathbf{p}\left(\mathbf{y}_{1}, \mathbf{y}_{2}, \ldots, \mathbf{y}_{\mathbf{T}}\right)$ que atribui probabilidades a todas combinações possíveis de valores de $\mathbf{y}_{1}, \ldots, \mathbf{y}_{\mathbf{T}}$. Este processo estocástico que gera as séries pode ser assumido como estacionário se as suas características não se alterarem ao longo do tempo. Ocorrendo o contrário, as séries são ditas não - estacionárias.

Conforme definição de GREENE (1993), um processo estocástico yt é estacionário se satisfaz os seguintes itens :

$1-\mathbf{E}\left[\mathbf{y}_{\mathbf{t}}\right]$ é independente de $\mathbf{t}$.

2 - Var [yt] é uma constante, independente de t.

3 - Cov $\left[y_{t}, y_{s}\right]$ é uma função de $t-s$, mas não de $t$ ou s.

Nos modelos dinâmicos de séries temporais que serão utilizados, exige-se que as séries sejam estacionárias de modo a se poder fazer inferências e testes estatísticos que sejam válidos, além de permitir a operacionalização dos modelos ${ }^{11}$.

Os modelos econométricos utilizados, de modo geral, pressupõem estacionariedade dos dados para que os resultados obtidos e as inferências feitas sejam válidos. Quando se analisa dados não-estacionários sem alguma transformação dos mesmos em estacionários, se está incorrendo em erro, ficando os resultados de regressões sem nenhum significado. Conforme GRANGER \& NEWBOLD (1974) (em

\footnotetext{
$"$ Em uma série estacionária, as condições de invertibilidade de um processo autoregressivo (AR) em outro de média móvel (MA) está garantida, o que não ocorre quando a série é não-estacionária, conforme GRANGER \& NEWBOLD (1974); PINDYCK \& RUBINFELD (1991); MORETTIN e TOLOI (1985) ; e GREENE (1993).
} 
GRIFFITHS, HILL \& JUDGE (1993)), GRANGER \& NEWBOLD (1986) e PHIILLIPS (1986) esses resultados são chamados de "regressões espúrias" ; por exemplo, regressões em nível com processos integrados de primeira ordem são "espúrias". Estes autores ainda chegaram à conclusão de que os estimadores obtidos são ineficientes e apresentam viés. Segundo HENDRY (1986), as regressões estimadas não convergem em probabilidade, com a gravidade do problema não diminuindo com o aumento do tamanho da amostra.

\subsubsection{2 - Testes de estacionariedade ou raizes unitárias ${ }^{12}$}

Uma vez verificada a importância de se trabalhar com dados que apresentam comportamento estacionário, pode-se agora tratar dos testes empregados para se determinar se uma série é ou não estacionária.

MADDALA (1988) diz que as variáveis são não-estacionárias em nível quando existe pelo menos uma raiz unitária no processo que descreve a série temporal.

Segundo DOLADO , JENKINSON \& SOSVILLA-RIVERO (1990) e BOX \& JENKINS (1970), algumas séries de tempo necessitam ser apropriadamente diferenciadas para se tornarem estacionárias.

Daí vem a definição de integração feita por ENGLE \& GRANGER (1987), de que uma variável $\mathbf{y}_{\mathbf{t}}$ com representação ARMA é dita ser integrada de ordem [d], $\left[\mathrm{y}_{\mathrm{t}} \sim \mathrm{I}(d)\right]$ se ela é estacionária, invertível, sem componente determinístico, depois de ser diferenciada $d$ vezes.

12 No presente trabalho será considerada por simplificação apenas uma raiz unitária, sendo que o problema de mais de uma raiz unitária é tratado com mais detalhes em DICKEY \& PANTULA (1987) e PANTULA (1989). 
62.

Supondo que o processo seja um passeio aleatório ("Random Walk") :

$$
x_{t}=x_{t-1}+e_{t}
$$

após substituições sucessivas tem-se :

$$
\mathrm{x}_{\mathrm{t}}=\sum_{j=1}^{t} e_{j} \quad \text { se } \mathrm{x}_{\mathrm{o}}=0
$$

onde $\mathbf{x}_{\mathbf{t}}$ é a somatória de $\mathbf{e}_{\mathbf{t}}, \mathrm{e} \Delta \mathbf{x}_{\mathbf{t}}=\mathbf{e}_{\mathbf{t}}$ é integrada de ordem zero : I (0). Deste modo tem-se que $\mathbf{x}_{t}$ é I (1), pois uma diferença foi suficiente para que o processo se tornasse estacionário.

Existem autores que criticam esta transformação das séries, como NERLOVE, GRETHER \& CARVALHO (1979), HENDRY (1986) e até mesmo ENGLE \& GRANGER (1987), pois em se diferenciando as séries perdem-se as informações de longo prazo. Conforme estes últimos autores, tem-se também, que a diferenciação dos dados pode levar a sérios problemas de especificação quando não se consideram componentes teoricamente relevantes de longo prazo.

Para solucionar este problema existe um outro conceito chamado de "cointegração ${ }^{13}$ " que será abordado adiante, o qual relaciona variáveis não-estacionárias cuja combinação linear é estacionária. Esta combinação, que é o próprio resíduo, é usada na estimação do modelo econométrico previamente estabelecido, chamado de modelo de correção de erro, o qual recupera as informações de longo prazo, entre as variáveis.

${ }^{13} \mathrm{O}$ conceito de cointegração é importante no estudo do mercado de frango porque, segundo GOODWIN \& SCHROEDER (1991), há um acréscimo no grau de cointegração à medida que o tempo passa, ou seja, à medida que os mercados se desenvolvem e a concentração industrial e o grau de integração aumentam. 
63.

Mas antes há a necessidade de se verificar se as séries são ou não estacionárias, pois a maior parte dạs séries econômicas de dados são não-estacionárias, conforme GRANGER (1966) ; NELSON \& PLOSSER (1982); PALASKAS \& VARANGIS (1989); ZINI (1990) ; BURNQUIST (1992) e BACCHI (1994), entre outros.

Primeiramente utilizam-se alguns dos vários procedimentos para detectar a presença de raiz unitária nos dados, como os de FULLER (1976) e DICKEY \& FULLER $(1979,1981)$.

Considerando que o processo seja do tipo :

$$
\mathrm{x}_{\mathrm{t}}=\alpha+\beta_{1} \mathrm{~T}+\rho \mathrm{x}_{\mathrm{t}-1}+\mathrm{e}_{\mathrm{t}}
$$

esta equação pode ser reescrita da seguinte maneira :

$$
\Delta \mathrm{x}_{\mathrm{t}}=\alpha+\beta_{1} \mathrm{~T}+\gamma \mathrm{x}_{\mathrm{t}-1}+\mathbf{e}_{\mathrm{t}}
$$

sendo que $\gamma=\rho-1$. O teste de raiz unitária consiste em se testar, na equação (67), a hipótese de que $\gamma=0$ que é equivalente a testar não-estacionariedade contra estacionariedade. $O$ teste referente a equação (67) é implementado com a utilização da usual estatística, $\mathbf{t}^{14}$, e é chamado estatística $\tau_{\tau}$ de FULLER (1976), sendo que o mesmo teste é chamado de estatística $\tau_{\mu}$ e $\tau$ se, em (67), se exclui, respectivamente, a variável tendência e a variável tendência mais a constante.

As estatísticas utilizadas para os mesmos possuem distribuições assintóticas tabuladas em FULLER (1976) e DICKEY \& FULLER (1981), sendo que no apêndice 1 as mesmas se encontram reproduzidas na Tabela 1.1.

Utilizam-se, também, outros testes que são mais rígidos, os chamados testes expandidos com os mesmos valores críticos dos testes $\tau_{\tau}, \tau_{\mu}$ e $\tau$. Estes consistem do

\footnotetext{
${ }^{14}$ As distribuições, porém, não são distribuições padrão.
} 
mesmo procedimento anterior, com alteração apenas na equação básica utilizada, da seguinte forma :

$$
\Delta \mathrm{x}_{\mathrm{t}}=\alpha+\beta_{1} \mathrm{~T}+\gamma_{1} \mathrm{x}_{\mathrm{t}-1}+\sum_{\mathrm{i}=1}^{\mathrm{n}-1} \lambda_{\mathrm{i}} \Delta \mathrm{x}_{\mathrm{t}-\mathrm{i}}+\mathrm{e}_{\mathrm{t}}
$$

onde:

$$
\lambda_{i}=-\sum_{j=i+1}^{\mathrm{n}} \rho_{\mathrm{j}}
$$

Os testes $\tau_{\tau}, \tau_{\mu}$ e $\tau$ foram baseados na hipótese de que os erros não são dependentes serialmente, mas caso o sejam utilizam-se os testes propostos por PHILLIPS (1987) e PHILLIPS \& PERRON (1988), os quais são testes não-paramétricos que permitem esta dependência dos erros aleatórios.

Para se saber a ordem de integração das séries procede-se à execução dos testes descritos até que a hipótese nula de raiz unitária seja rejeitada. A ordem de integração é igual ao número de diferenças necessárias aos dados para que isso ocorra (rejeição da hipótese).

Esses testes de Dickey \& Fuller e outros utilizados para o mesmo fim são criticados por vários autores, entre eles COCHRANE (1991), que enfatiza o baixo poder que estes testes possuem, principalmente em pequenas amostras. $O$ autor mostra também que procedimentos alternativos não demonstram resultados muito melhores estatisticamente e que também possuem baixo poder.

\subsubsection{3 - Testes de cointegração e mecanismo de correção de erro}

A relação entre processos não-estacionários e o conceito de equilíbrio de longoprazo foi introduzido por GRANGER $(1981$, 1986). Esta relação se resume no conceito de cointegração. 
Segundo BANERJEE, DOLADO, HENDRY \& SMITH (1986); ENGLE \& GRANGER (1987) e CAMPBELL \& PERRON (1991), se duas séries de tempo y $\mathbf{t}$ e $\mathbf{x}_{\mathbf{t}}$ são I (1), então em geral a combinação linear

$$
\mathrm{y}_{\mathrm{t}}-\alpha-\beta \mathrm{x}_{\mathrm{t}}=\varepsilon_{\mathrm{t}}
$$

é também I (1), mas pode ocorrer que a combinação seja I(0). De (69) tem-se um vetor de cointegração $(1,-\beta)^{\prime}$ se $\varepsilon_{t}$ é estacionário, ou I (d-b), b $>0$. Neste caso yt e $x_{t}$ são consideradas cointegradas. Assim um par de variáveis é definido como cointegrado se as variáveis são I (d) e I (b), e existe uma combinação linear delas que seja I (0).

Existem vários procedimentos para determinação das relações de cointegração entre variáveis, mas os dois mais utilizados são os métodos de Engle \& Granger e o de Johansen, os quais são expostos a seguir.

\subsubsection{1 - Método de Engle \& Granger}

$O$ conceito de cointegração trata da existência de um equilíbrio para onde o sistema econômico converge ao longo do tempo. Se, por exemplo, a teoria econômica sugere a seguinte relação de longo prazo entre $x_{t}$ e $y_{t}$ :

$$
\mathrm{y}_{\mathrm{t}}=\alpha-\beta \mathrm{x}_{\mathrm{t}}+\varepsilon_{\mathrm{t}}
$$

então, $\varepsilon_{t}$ pode ser interpretado como um desvio do equilíbrio, isto é, a distância que o sistema está do equilíbrio de longo prazo em um ponto do tempo. Havendo uma relação de equilíbrio no longo prazo, pode-se assumir que as variáveis movem-se juntas, que $\varepsilon_{\mathbf{t}}$ é estacionário e que as variáveis são cointegradas.

Foi visto que ao se diferenciar os dados para se obter séries estacionárias, perdese as informações de longo prazo entre as variáveis, se a relação de longo prazo entre as 
variáveis existe, fazendo com que se obtenha estimativas viesadas dos parâmetros, além de testes inválidos estatisticamente. Este problema é solucionado com a inclusão de um componente que recupera este desvio da trajetória de longo prazo das variáveis, chamado de mecanismo de correção de erro. Éste mecanismo nada mais é que o resíduo da regressão da equação de cointegração, o qual é incluído como uma variável determinística na estimação do modelo econométrico principal, dando origem ao modelo com correção de erro ${ }^{15}$ do qual se obtém estimativas "superconsistentes", segundo STOCK (1987). Abaixo tem-se mais detalhes em relação a estes conceitos.

Após se verificar a existência de raizes unitárias de mesma ordem entre as variáveis, o teste de cointegração consiste em se testar se $\varepsilon_{t}$, em uma equação de cointegração semelhante a (70), é ou não estacionário. Isto também é feito através de testes de raiz unitária, sendo o teste ADF ( Dickey \& Fuller expandido) o mais utilizado. Este consiste em se testar se o coeficiente de $\varepsilon_{t-1}$ na equação abaixo é estatisticamente diferente de zero :

$$
\Delta \varepsilon_{t}=\phi \varepsilon_{t-1}+\sum_{j=1}^{n} \delta_{j} \Delta \varepsilon_{t-j}+u_{t}
$$

o que equivale a testar a hipótese nula de que u ú I (1), ou seja, de que as variáveis não são cointegradas, contra a hipótese alternativa de que há cointegração entre elas e o erro $u_{t}$ é estacionário.

A relação entre cointegração e o mecanismo de correção de erros foi estabelecida por ENGLE \& GRANGER (1987), que provaram existir, através do Teorema de Representação de Granger, um mecanismo de correção de erro para cada

15 Este modelo será visto na próxima seção, quando será exposto o modelo de Auto Regressão Vetorial (VAR) e a inclusão do termo de correção de erro neste,dando origem ao modelo VAR com correção de erro. 
67.

relação de cointegração constatada, e vice-versa. Sugeriram então a utilização de um método de dois estágios ao lidar com o mecanismo de correção de erros.

( i ) No primeiro estágio estima-se a equação (70), obtém-se o resíduo $\varepsilon_{t}$ e testa-se a cointegração de acordo com a equação (71), onde, rejeitando a hipótese de que as variáveis não são cointegradas, estima-se o mecanismo de correção de erro no estágio seguinte.

( ii ) No segundo estágio, os resíduos, ou o termo (mecanismo) de correção de erro, obtidos no primeiro estágio, são usados em uma equação de diferenças para se obterem os coeficientes de impacto, sendo incorporada a estrutura dinâmica através do termo de correção de erro. Um exemplo de modelo de correção de erro segundo as equações (70) e (71) é :

$$
\Delta \mathrm{y}_{\mathrm{t}}=\varphi \Delta \mathrm{x}_{\mathrm{t}}+\pi\left(\mathrm{y}_{\mathrm{t}}-\alpha-\beta \mathrm{x}_{\mathrm{t}}\right)+\mathrm{v}_{\mathrm{t}}
$$

que somente é válida se as séries são I (1) e as suas diferenças são I (0), e se o termo em parêntese também é I (0). Esta equação representa a dinâmica de curto prazo, e a equação (70) a relação de longo prazo.

De acordo com DOLADO, JENKINSON \& SOSVILLA-RIVERO (1990), VALLS PEREIRA (1991), PORTUGAL (1992) e MOOSA (1992), o método de Engle e Granger tem alguns problemas com respeito à direção de normalização : ( a ) a escolha da variável independente e ( b ) parte do pressuposto de que só existe uma relação de çointegração entre as variáveis, ou seja, só um vetor de cointegração.

$\mathrm{Na}$ tentativa de solucionar estes problemas surgiu uma metodologia, de JOHANSEN $(1988,1991)$ e JOHANSEN \& JUSELIUS $(1990)$, que é um procedimento de estimação por máxima verossimilhança e que é particularmente importante quando se 
testa cointegração entre mais de duas variáveis, conforme ALEXANDER \& WYETH (1994).

Mas o método de Engle e Granger não é absolutamente errôneo ou ultrapassado, mas sim um método que possui algumas simplificações de modo que possa ser operacionalizado mais facilmente, além de conseguir em um sistema de variáveis cointegradas com a hipótese implícita de haver apenas uma relação de cointegração, obter uma trajetória de longo prazo satisfatória para se entender como as variáveis se relacionam. E apesar das vantagens aparentes do método de Johansen, não se pode descartar completamente o método de Engle e Granger, pois algumas pesquisas têm mostrado que estas vantagens aparentes não são tão significativas ou não têm mostrado resultados muito melhores, como em PORTUGAL (1992).

Outros autores contemporâneos de Johansen e Juselius preferiram utilizar o método de Engle e Granger para suas pesquisas, como ROBERTSON \& ORDEN (1990), ZAPATA \& GARCIA (1990), GOODWIN \& SCHROEDER (1991), ROSSI (1991), HALLAM, MACHADO, \& RAPSOMANIKIS (1992), LLOYD \& RAYNER (1993), BACCHI (1994), entre outros.

\subsubsection{2 - Método de Johansen}

O método de máxima verossimilhnça foi proposto por JOHANSEN $(1988,1991)$ e JOHANSEN \& JUSELIUS (1990) com o propósito de se obter estimativas melhores, de testar a presença de mais de um vetor de cointegração, além de prover testes de razão de verossimilhança sobre os vetores de cointegração, tudo sob a ótica de sistema de variáveis, o que não é o caso do método de Engle \& Granger. 
Primeiramente, considera-se uma representação VAR de ordem $\boldsymbol{k}$, não restrito, $\operatorname{de} \mathbf{X}_{\mathbf{t}}$ :

$$
X_{t}=\mu+\Pi_{1} X_{t-1}+\Pi_{2} X_{t-2}+\ldots+\Pi_{k} X_{t-k}+\varepsilon_{t}
$$

onde $X_{t}$ é um vetor $\mathbf{p} \times 1$ de variáveis I (1); $\Pi_{\mathbf{i}}$ são matrizes $\mathbf{p} \times \mathbf{p}$ de parâmetros; $\boldsymbol{\mu}$ é um vetor $\mathbf{p} \times 1$ de termos constantes e $\varepsilon_{t}$ é um vetor $\mathbf{p} \times 1$ de erros aleatórios.

Seguindo procedimento similar ao dos testes de raiz unitária, pode-se reparametrizar a equação (73) :

$$
\Delta X_{t}=\mu+\Gamma_{1} \Delta X_{t-1}+\Gamma_{2} \Delta X_{t-2}+\ldots+\Gamma_{k-1} \Delta X_{t-k+1}+\ldots-\Pi X_{t-k}+\varepsilon_{t}
$$

onde $\Gamma_{\mathbf{i}}=-\mathbf{I}+\Pi_{1}+\Pi_{2}+\ldots+\Pi_{\mathbf{i}}$ e $(\mathbf{i}=1, \ldots, \mathbf{k}-1)$; e $-\Pi=I-\Pi_{1}-\Pi_{2}-\ldots-\Pi_{k}$.

É interessante notar que a expressão (74) é a representação tradicional de um modelo VAR nas diferenças exceto pelo termo $\Pi \mathbf{\Pi} \mathbf{X}_{\mathbf{t}-\mathbf{k}}$. Este método consiste em testar se os coeficientes da matriz $\Pi$ contém informações sobre as relações de longo prazo entre as variáveis envolvidas. Há três casos possíveis de acordo com o posto (r) da matriz $\Pi$ :

(i) posto $(\Pi)=p$, isto é, a matriz tem posto completo indicando que $\mathbf{X}_{t}$ é um processo estacionário e um modelo VAR em nível é apropriado.

(ii ) posto $(\Pi)=0$, isto é, a matriz é nula e $\mathbf{X}_{\mathbf{t}}$ é um processo integrado onde um modelo VAR nas diferenças é apropriado.

( iii ) $0<$ posto $(\Pi)=\mathbf{r}<\mathbf{p}$, isto é, há cointegração e a matriz $\Pi$ pode ser representada pelo produto de duas matrizes $\mathbf{p} \times \mathbf{r}, \alpha$ e $\beta$, de modo que $\Pi=\alpha \beta^{\prime}$. Onde $\beta$ contém os vetores de cointegração e $\alpha$ é o vetor de ponderação. 
Os vetores de cointegração de $\boldsymbol{\beta}$ têm a propriedade de tornar $\boldsymbol{\beta}^{\prime} \mathbf{X}_{\mathbf{t}}$ estacionário, onde tem-se que $\mathbf{X}_{\mathbf{t}}$ é não estacionário. Desta maneira a expressão (74) representa um modelo VAR com correção de erro como o obtido no método de Engle \& Granger, mas somente quando há apenas um equilibrio de longo prazo $(r=1)$.

A estimação de máxima verossimilhança de $\Pi$ consiste de dois conjuntos de regressões : a) obtém-se os resíduos $\mathbf{R}_{\mathbf{0 t}}$ da regressão de $\Delta \mathbf{X}_{\mathbf{t}}$ contra $\Delta \mathbf{X}_{\mathbf{t}-1}, \ldots, \Delta \mathbf{X}_{\mathbf{t}}$ $\mathbf{k + 1}$; e b) obtém-se os resíduos $\mathbf{R}_{\mathbf{k t}}$ da regressão de $\mathbf{X}_{\mathbf{t}-\mathbf{k}}$ contra $\Delta \mathbf{X}_{\mathrm{t}-1}, \ldots, \Delta \mathbf{X}_{\mathbf{t}-\mathbf{k}+1}$. Estas regressões são importantes para se inferir sobre $\Pi$ por meio de métodos de verossimilhança. Os resíduos obtidos são na verdade $\Delta \mathbf{X}_{\mathbf{t}}$ e $\mathbf{X}_{\mathbf{t}-\mathbf{k}}$ livres da influência das demais variáveis envolvidas.

A função de verossimilhança concentrada a ser maximizada para um dado valor de $\beta$ e sob a hipótese $\mathbf{H}_{2}: \Pi=\alpha \beta^{\prime}$ é :

$$
L(\beta)=|\Omega(\beta)|^{-\mathrm{T} / 2}=\left|S_{o o}-S_{o k} \beta\left(\beta^{\prime} S_{k k} \beta\right)^{-1} \beta^{\prime} S_{k o}\right|^{-T / 2}
$$

onde $\mathbf{S}_{\mathbf{0 o}}, \mathbf{S}_{\mathbf{0 k}}, \mathbf{S}_{\mathbf{k o}}$ e $\mathbf{S}_{\mathbf{k k}}$ são as matrizes dos momentos do produto dos resíduos; $\boldsymbol{\Omega}$ é a matriz de variância e covariância dos resíduos; e $\mathbf{T}$ é o número de observações. Sendo que $S_{i, j}=T^{-1} \sum_{t=1}^{T} R_{i t} R_{j t}{ }^{\prime}$ para $\mathbf{i}, \mathbf{j}=\mathbf{0}, \mathbf{k}$. As estimativas para $\alpha$ e $\Omega$ pela regressão de $\mathbf{R}_{\mathbf{o t}}$ contra $\boldsymbol{\beta}^{\prime} \mathbf{R}_{\mathbf{t}-\mathbf{k}}$ são :

$$
\begin{aligned}
& \alpha(\beta)=S_{0 k} \beta\left(\beta^{\prime} S_{k k} \beta\right)^{-1} \\
& \Omega(\beta)=S_{00}-S_{0 k} \beta\left(\beta^{\prime} S_{k k} \beta\right)^{-1} \beta^{\prime} S_{k 0}
\end{aligned}
$$

A maximização da expressão (75) é equivalente a minimização de $|\Omega(\beta)|$. Esta minimização permite se obter o estimador de $\beta$, que por sua vez, equivale a resolver a seguinte equação característica : 
71.

$$
\left|\lambda I-C^{-1} S_{k 0} S_{00}{ }^{-1} S_{0 k} C^{\prime-1}\right|=0
$$

onde $\mathbf{C}$ é uma matriz pxp utilizada para a decomposição de Cholesky, $\mathbf{S}_{\mathbf{k k}}=\mathbf{C}^{\prime} \mathbf{C} ; \boldsymbol{\lambda}$ é um vetor de autovalores cujos autovetores podem ser normalizados por $\mathbf{v}_{\mathbf{i}}=\mathbf{C}^{\mathbf{- 1}} \mathbf{e}_{\mathbf{i}}$, onde e são os autovetores de (78).

A escolha de $\boldsymbol{\beta}$ é dependente de :

$$
\beta=\left(v_{1}, v_{2}, \ldots, v_{r}\right)
$$

a qual resulta na função de máxima verossimilhança a ser maximizada :

$$
L_{\max }^{-2 / T}\left(\Pi=\alpha \beta^{\prime}\right)=\left|S_{00}\right| \prod_{i=1}^{r}\left(1-\lambda_{i}\right)
$$

A hipótese nula de que existem $\mathbf{r}$ vetores cointegrados é testada usando-se dois testes de razão de verossimilhança, os chamados testes do traço e teste do máximo autovalor $\left(\lambda_{\text {máx. }}\right)$. Estes testes, contendo no máximo $\mathbf{r}$ vetores de cointegração, são aplicados sequencialmente para valores decrescentes de $\mathbf{r}$. Os valores críticos destes testes se encontram em JOHANSEN \& JUSELIUS (1990) e suas distribuições assintóticas não seguem a distribuição chi-quadrado padrão, mas representam versões multivariadas da distribuição Dickey-Fuller, e estão reproduzidos na Tabela 1.2 do apêndice 1.

Estes testes são baseados em duas hipóteses básicas :

a) $\mathrm{H}_{1}: \Delta X_{t}=\sum_{j=1}^{k-1} \Gamma_{j} \Delta X_{t-j}+\Pi X_{t-k}+\mu+\varepsilon_{t}$;

b) $\mathrm{H}_{2}: \Pi=\alpha \beta^{\prime}$.

O teste do traço testa a razão de verossimilhança para a hipótese $\mathbf{H}_{2} \mathrm{em} \mathbf{H}_{1}$, desde que $\mathbf{H}_{1}$ seja um caso especial de $\mathbf{H}_{2}$ para $\mathbf{r}=\mathbf{p}$, o teste do traço é definido por: 


$$
-2 \ln \left(Q ; H_{2} / H_{1}\right)=-T \sum_{i=r+1}^{p} \ln \left(1-\lambda_{i}\right)
$$

De maneira similar a estatística do máximo autovalor é definida pelo teste de $\mathbf{H}_{2}(\mathbf{r})$ em $\mathbf{H}_{2}(\mathbf{r}+\mathbf{1})$, que é dado por :

$$
-2 \ln (Q ; r / r+1)=-T \ln \left(1-\lambda_{r+1}\right)
$$

O método de Johansen também permite testar hipóteses lineares expressas em termos dos coeficientes $\mu, \alpha$ e $\beta$. Os testes de razão de verossimilhança podem ser também utilizados para se testar uma variedade de restrições lineares em $\alpha$ e $\beta$. Com ajuda da teoria econômica e de uma abordagem empírica, estas restrições podem ser formuladas. Estas restrições essencialmente limitam o espaço $\mathbf{r}$ dos vetores de cointegração em um espaço s-dimensional. Se $\mathbf{s}=\mathbf{r}$, então o espaço de cointegração é dito ser completamente especificado, segundo JOHANSEN (1991).

O método a ser empregado neste trabalho será o de Johansen, pois além de ser mais completo que o de Engle \& Granger, não possui as sérias limitações no contexto multivariado que aquele. Apesar disso, serão apresentados no próximo capítulo os testes de raiz unitária (Dickey-Fuller) a título de comparação, pois o método de Johansen dispensa qualquer teste prévio de estacionariedade, haja vista que o método já possui algo semelhante em seu algoritmo.

SARKER (1993) utilizou o método de Johansen, por este lhe possibilitar a estimação de intervalos de confiança e testes de hipóteses para os parâmetros dos vetores de cointegração. Mas outros autores utilizaram este método para determinação de relações de cointegração, como WILLIAMS \& BEWLEY (1991); MELLANDER, 
VREDIN \& WARNE (1992); LIMA, LOPES, MOREIRA \& VALLS PEREIRA (1993); WILLIAMS \& BEWLEY (1993); ENGLE \& ISSLER (1994); FERREIRA \& ISSLER (1994) entre outros.

Mas este método não é absoluto, pois como todo modelo econométrico é uma aproximação da realidade e possui um erro aleatório no qual está tudo aquilo que o modelo não consegue explicar, sempre hão de surgir outros modelos que captam uma parcela um pouco maior deste erro aleatório e que possuam características estatísticas melhores.

Devido a isto, CHOI (1994) chegou à conclusão de que outros testes de cointegração, como o teste de Durbin-Hausman por exemplo, podem ser utilizados em séries temporais, obtendo-se até melhores resultados que os convencionais, mas não os descarta.

\subsection{2 - Modelos VAR com correção de erro}

Os modelos de autoregressão vetorial são muito utilizados pela pesquisa econômica desde que foram introduzidos por SIMS (1980), como alternativa aos modelos econométricos usuais, permitindo análises dinâmicas sem o problema de identificação de que os modelos de equações simultâneas necessitam. Mas há necessidade de uma estrutura econômica relacionando as variáveis entre si, pois na estimação de um modelo VAR não existem variáveis explicitamente exógenas, a não ser que sejam assim definidas previamente. Assim, os modelos VAR podem ser utilizados para aqueles casos em que não se tem certeza da especificação correta da teoria supostamente responsável pelo comportamento dinâmico das variáveis envolvidas. 
Os objetivos, segundo BABULA \& BESSLER (1990), do uso de modelos VAR é o de se obter as seguintes relações dinâmicas : a) o tempo de reação das respostas a choques; b) direção, padrão e duração das respostas; c) semelhança das respostas dos preços através dos setores ou níveis de mercado; e d) a força de interação entre os preços nos diferentes setores da economia.

Existem dois tipos de modelos VAR : o modelo convencional e o Modelo de Monopsônio (tipo Bernanke). Neste último não existe a restrição da recursividade, podendo algumas variáveis se relacionar apenas contemporaneamente.

\subsubsection{1 - Modelos VAR convencionais}

Segundo HAKKIO \& MORRIS (1984), BRANDÃO (1985), GIANNINI \& MOSCONI (1987) e AUBONE (1988) um modelo VAR ( p ) é representado por:

$$
\mathrm{x}_{\mathrm{t}}=\mathrm{B}_{1} \mathrm{x}_{\mathrm{t}-1}+\ldots+\mathrm{B}_{\mathrm{p}} \mathrm{x}_{\mathrm{t}-\mathrm{p}}+\varepsilon_{\mathrm{t}}=\sum_{j=1}^{p} B_{j} x_{t-j}+\varepsilon_{t}
$$

onde $\mathbf{x}_{\mathbf{t}}$ é uma matriz 1 x $\mathbf{n}$ das variáveis do modelo; $\mathbf{B}_{\mathbf{j}}$, sendo $\mathbf{j}=1, \ldots, P$, são matrizes $\mathbf{n}$ $\mathbf{x} \mathbf{n}$ de coeficientes que relacionam os valores defasados com os valores correntes das variáveis; e $\varepsilon_{\mathbf{t}}$ é uma matriz $1 \times \mathbf{~} \mathbf{n}$ de erros do tipo ruído branco ${ }^{16}$.

A equação (83) pode ser reescrita da seguinte forma :

$$
B(L) x_{t}=\varepsilon_{t}
$$

\footnotetext{
16 Ruido branco significa que o processo estocástico $\varepsilon_{t}$ possui média zero, matriz de variânciacovariância finita e é não autocorrelacionado.
} 
onde $\mathbf{L}$ é um operador de defasagem definido por $\mathbf{L P}^{\mathbf{P}} \mathbf{z}_{\mathbf{t}}=\mathbf{z} \mathbf{t}-\mathbf{P}$, com $\mathbf{s}$ inteiro; e $\mathbf{B}$ (L) é um polinômio dado por :

$$
B(L)=B_{0}-B_{1} L-B_{2} L^{2}-\ldots-B_{P} L^{P}
$$

onde $\mathbf{P}=1, \ldots, \infty$.

Sendo $\mathbf{x}_{\mathbf{t}}$ um processo estocástico estacionário, as condições de invertibilidade são observadas e de acordo com o Teorema de Wold, pode-se obter a seguinte representação de Média Móvel Vetorial (VMA) :

$$
\mathrm{x}_{\mathrm{t}}=\mathrm{A}(\mathrm{L}) \varepsilon_{\mathrm{t}}
$$

onde $\mathbf{A}(\mathbf{L})=\mathbf{A}_{0}+\mathbf{A}_{1} \mathbf{L}+\mathbf{A}_{2} \mathbf{L}^{2}+\ldots+\mathbf{A}_{\mathbf{P}} \mathbf{L}$, sendo que $\mathbf{P}=1, \ldots, \infty$

De acordo com (84) e (86), tem-se que a seguinte relação é satisfeita :

$$
A(L) B(L)=I
$$

O número de defasagens $\mathbf{P}$ a ser utilizado na análise dos modelos de autoregressão vetorial (VAR), pode ser obtido de várias maneiras, mas serão utilizados os mesmos procedimentos de Akaike e Schwartz utilizados nos testes de raiz unitária e de cointegração.

Através da equação (83) pode-se obter :

(i) as estimativas dos coeficientes.

(ii ) as respostas a choques, através das funções de impulso-resposta na representação de média móvel (86). 
( iii ) a decomposição da variância do erro de previsão.

As estimativas do item ( i ) são facilmente obtidos por mínimos quadrados ordinários.

Quanto ao item ( ii ), para se obter as respostas de todas as variáveis a choques de um desvio-padrão em uma variável, deve-se reescrever (86) :

$$
\mathrm{x}_{\mathrm{t}}=\varepsilon_{\mathrm{t}}+\mathrm{A}_{1} \varepsilon_{\mathrm{t}-1}+\mathrm{A}_{2} \varepsilon_{\mathrm{t}-2}+\ldots+\mathrm{A}_{\mathrm{k}} \varepsilon_{\mathrm{t}-\mathrm{k}}
$$

Assim, tem-se que a i-ésima coluna de $\mathbf{A}_{\mathbf{k}}$ mede o efeito de um choque (ou inovação) unitário no i-ésimo componente do vetor de inovações no período t-k sobre $\mathbf{x}_{n}$ no período $\mathbf{t}$. Uma maneira de visualizar isto é verificando que a primeira coluna de $\mathbf{A}_{\mathbf{k}}$ é a resposta de $\mathbf{x}_{\mathbf{n}}$ a choques no primeiro componente do vetor de inovações. Desta forma, com a estimação de (88) pode-se analisar o comportamento dinâmico das variáveis em resposta a choques em qualquer dos componentes do sistema.

Mas como se trabalha com processos vetoriais, surge um problema no que tange à análise de choques individuais sobre a dinâmica do sistema, pois em geral a matriz de variância - covariância de $\varepsilon_{t}(\Sigma)$ não é diagonal. É que os choques na matriz de inovações podem ocorrer simultaneamente, como o caso de um choque em uma variável sendo acompanhado de variações contemporâneas nas demais, inviabilizando a previsão de respostas a choques em uma das séries consideradas sobre as demais.

Para que se verifique o choque em apenas uma das variáveis sobre o sistema, necessita-se que a matriz de variância - covariância seja diagonalizada. $\mathrm{E}$ o procedimento usual para esta diagonalização é efetuar uma decomposição de Cholesky.

Admitindo que $\Sigma$ seja não singular, existe uma matriz $C$, triangular inferior e não singular, tal que $\Sigma=C C^{\prime}$, sendo que : 
$C^{-1} \sum\left(C^{1}\right)^{-1}=\mathrm{I}$

E definindo-se então $\eta_{t}=C^{-1} \varepsilon_{t}$, tem-se que $E\left[\eta_{t} \eta_{t}{ }^{\prime}\right]=I^{17}$.

Pré-multiplicando-se (84) por $C^{-1}$ tem-se :

$$
C^{-1} \mathrm{~B}_{0} \mathrm{x}_{\mathrm{t}}-C^{-1} \mathrm{~B}_{1} \mathrm{x}_{\mathrm{t}-1}-C^{-1} \mathrm{~B}_{2} \mathrm{x}_{\mathrm{t}-2}-\ldots=\mathrm{H}(\mathrm{L}) \mathrm{x}_{\mathrm{t}}=\eta_{\mathrm{t}}
$$

onde $H(L)=C^{-1} B(L)=C^{-1} A(L){ }^{-1}$. Na representação de médias - móveis temos:

$$
x_{t}=G(L) \eta_{t}
$$

onde $\mathbf{G}(\mathbf{L})=\mathbf{A}(\mathbf{L}) \dot{C}$.

A equação (89) mede o efeito de um choque unitário de um desvio-padrão em apenas uma das variáveis do sistema sobre todas as outras, período a período. Deste modo temos que a um choque de um desvio-padrão na variável i em t-j , tem-se o impacto sobre x no período $t$ através da $\mathbf{i}$ - ésima coluna de $\mathbf{G}_{\mathbf{j}}{ }^{18}$.

Segundo GUIMARÃES (1990), esta representação permite duas observações :

1) as inovações na primeira variável afetam contemporaneamente as variáveis posteriores, mas a primeira variável não é afetada por nenhuma das demais. Deste modo a segunda variável irá impactar as demais com exceção da primeira e não será influenciada

${ }_{17} \mathrm{E}\left[\eta_{\mathrm{t}} \eta_{\mathrm{t}}\right]=\mathrm{E}\left[C^{-1} \varepsilon_{\mathrm{t}} \varepsilon_{\mathrm{t}}{ }^{\prime}\left(C^{\prime}\right)^{-1}\right]=\left[C^{-1} \Sigma\left(C^{\prime}\right)^{-1}\right]=\mathbf{I}$

18 Notar que $x_{t}=G(L) \eta_{t}=\left[A(L) C \mid \eta_{t}\right.$, e se o i - ésimo componente de $\eta_{t}$ é igual a um e os demais são nulos, teremos $C \eta_{\mathbf{t}}=C_{\mathbf{i}}$, sendo $C_{\mathbf{j}}$ a $\mathbf{i}$ - ésima coluna de $C$, conforme BRANDÃO (1985). 
contemporaneamente por nenhuma delas; a terceira idem com exceção da primeira e da segunda, e assim por diante.

2) a ordem pela qual as variáveis são arranjadas no sistema afeta os resultados, daí a importância de uma estrutura econômica para se determinar com embasamento teórico, a ordem que as variáveis devem ocupar no vetor de variáveis do sistema. Apesar dos modelos VAR terem sido propostos no sentido de os dados mostrarem livremente as relações entre as variáveis, o modelo econômico torna-se útil na definição da ordem das variáveis, conforme SIMS (1989).

O item ( iii ) diz respeito à decomposição da variância do erro de previsão de $\mathbf{k}$ períodos a frente, onde o erro de previsão de $\mathbf{k}$ períodos a frente é definido por

$$
\varepsilon_{t+k}=x_{t+k}-E\left[x_{t+k} \backslash x_{t}, x_{t-1}, \ldots\right]
$$

e onde temos ainda $\mathbf{E}\left[\varepsilon_{\mathbf{t}} \varepsilon_{\mathbf{t}^{\prime}}\right]=\Sigma=C C^{\prime}$. Tem-se então que os elementos da diagonal principal são soma de quadrados, o que permite atribuir-se à variância de cada uma das inovações a parcela que se deve à própria inovação e as parcelas devidas às demais.

$$
\begin{aligned}
& \text { De (89) e (90) temos que : } \\
& x_{t+k}=G_{0} \eta_{t+k}+G_{1} \eta_{t+k-1}+\ldots+G_{k-1} \eta_{t+1}+G_{k} \eta_{t}+G_{k+1} \eta_{t-1}+\ldots
\end{aligned}
$$

Desta equação (91) tem-se que o erro de previsão $\mathbf{k}$ - períodos a frente é :

$$
\varepsilon_{\mathrm{t}+\mathrm{k}}=\sum_{j=0}^{k-1} G_{j} \eta_{t+k-j}
$$


79.

Sendo que a matriz de variância e covariância $\mathbf{K}$ - periodos à frente é dada por :

$$
\sum_{j=0}^{k-1} A_{j} \sum A_{j}=\sum_{j=0}^{k-1}\left(A_{j} C\right)\left(A_{j} C\right)^{\prime}
$$

A introdução do mecanismo de correção de erro nos modelos VAR ocorre após a estimação deste mecanismo através do método descrito anteriormente. Tem-se inicialmente um modelo VAR semelhante a (83), conforme WILLIAMS \& BEWLEY $(1991,1993)$ :

$$
\mathrm{Y}_{\mathrm{t}}=\alpha+\sum_{i=1}^{p} A_{i} Y_{t-1}+V_{t}
$$

onde $\mathbf{Y}_{\mathbf{t}}$ é um vetor $\mathbf{n} \times 1$ dos logaritmos das variáveis; $\alpha$ é um vetor $\mathbf{n} \times 1$ das constantes; $\mathbf{A}_{\mathbf{i}}$ é uma matriz $\mathbf{n} \times \mathbf{n}$ dos parâmetros e $\mathbf{V}_{\mathbf{t}}$ é um vetor $\mathbf{n} \times \mathbf{1}$ dos erros ruído branco.

Com utilização deste modelo em séries que apresentam problemas de não estacionariedade, tem-se, segundo alguns autores, soluções das mais diversas para este problema nas análise com modelos VAR. SIMS (1980), BESSLER (1984), entre outros, propõem a inclusão de um componente de tendência na equação (76). Outra proposta é a de se diferenciar as séries para induzir à estacionariedade conforme BAILEY \& BRORSEN (1985) e SCHROEDER \& GOODWIN (1990).

Mas nenhum destes procedimentos, como já foi exposto, proporciona resultados analitica e estatisticamente satisfatórios, pois tem-se que ater também às relações de longo prazo (cointegração) entre as variáveis.

Em modelos VAR em nível, com a presença de séries não - estacionárias, tem-se problemas de estimação e de funções de impulso - resposta, além de vários outros problemas citados por PHILLIPS (1991). 
Já nas análises em diferenças tem-se o problema de eliminação das relações de longo prazo das variáveis, no caso de haver cointegração, fazendo com que se tenha regressões espúrias e estimativas viesadas dos coeficientes.

Devido a estes problemas WILLIAMS \& BEWLEY (1991, 1993) determinam uma reparametrização do modelo (94) :

$$
\Delta Y_{t}=\alpha+\sum_{i=1}^{p-1} B_{i} \Delta Y_{t-1}+D Y_{t-1}+V_{t}
$$

onde $\quad D=\left[\sum_{i=1}^{p} A_{i}-I\right] \quad$ e $\quad B_{i}=-\sum_{j=i+1}^{p} A_{j}$

Caso exista cointegração entre as variáveis, parte-se para o modelo VAR com correção de erro a seguir :

$$
\Delta Y_{t}=\alpha+\sum_{i=1}^{p-1} B_{i} \Delta Y_{t-1}+\pi \varepsilon_{t-1}+V_{t}
$$

onde $\pi$ é a matriz dos coeficientes de longo prazo; e $\varepsilon_{t-1}$ é o resíduo da equação de cointegração, ou também chamado mecanismo ou termo de correção de erro, que inclui o vetor de cointegração $\beta$ definido em (74).

Segundo LUTKEPOHL (1991), a relação de cointegração deve ser especificada de modo a incluir o(s) vetor(es) de cointegração que mede(m) o desvio em relação ao equilíbrio de longo prazo, sem o que a equação ou o modelo a ser utilizado não é corretamente especificado. É por este motivo que modelos VAR descritos acima, sem o termo de correção de erro quando as variáveis são cointegradas, são mal especificados. Conclusão semelhante é encontrada em ROBERTSON \& ORDEN (1990), VALLS PEREIRA (1991), BRAUN \& MITTNIK (1993), entre outros. 
Assim, um modelo VAR só irá conter o termo de correção de erro se for constatada a presença de cointegração, pois do contrário as séries estarão em nível ou nas diferenças, respectivamente se houver ou não estacionariedade. E, conforme ENGLE \& YOO (1987), um VAR em nível na presença de cointegração produz previsões de longo prazo que são consistentes mas são ineficientes.

\subsubsection{2 - Modelos VAR estruturados}

Segundo BARROS (1991), BURNQUIST (1992) e AGUIAR (1994) estes modelos se diferenciam dos convencionais por considerarem hipóteses estruturais não necessariamente recursivas, as quais facilitam a interpretação econômica dos resultados do modelo. No modelo VAR convencional tem-se uma estrutura recursiva bastante restritiva que pode resultar em interpretações conflitantes com a teoria.

Para se contornar o problema da recursividade, pode-se concentrar as restrições nas interações contemporâneas e não nas variáveis defasadas. Conforme ORDEN \& FACKLER (1989), este procedimento se justifica pelo simples fato de a teoria econômica definir melhor as relações contemporâneas em comparação com as de defasagens. Os valores passados das variáveis são geralmente de conhecimento dos agentes econômicos, sendo úteis na formulação de expectativas, que, por sua vez, fornecem uma ligação entre passado e presente das variáveis do modelo, sobre o que a teoria econômica tem pouco a dizer.

No modelo convencional, a simples ordenação das variáveis já representa uma forma de identificação. Já um modelo VAR estruturado exige a formulação de uma estrutura ou modelo econômico para identificação, como, por exemplo, o modelo monopsonista formulado no capítulo 3 , que possa servir como referência para a construção de restrições em uma matriz de interações contemporâneas que pré-multiplica o vetor de variáveis, originando a forma geral : 


$$
\Gamma x_{t}=\sum_{j=1}^{p} B_{j} x_{t-j}+\varepsilon_{t}
$$

onde $\Gamma$ representa a matriz $\mathbf{n} \mathbf{x} \mathbf{n}$ de coeficientes de relações contemporâneas das variáveis, e os demais vetores e matrizes são os mesmos definidos na equação que representa o VAR convencional, dado por (83).

A expressão estrutural (97) pode ser reescrita na forma reduzida, com a multiplicação de (97) pela matriz inversa dos coeficientes de interações contemporâneas $\left(\Gamma^{-1}\right)$. Esta forma reduzida (98) é importante para a obtenção das estimativas dos parâmetros de $\Gamma$ :

$$
\mathrm{x}_{\mathrm{t}}=\sum_{j=1}^{p} \Gamma^{-1} B_{j} x_{t-j}+\Gamma^{-1} \varepsilon_{t}
$$

A matriz de variância e covariância dos resíduos $\Gamma^{-1} \varepsilon_{t}$ de $(98), \Psi$, será utilizada na estimação $\operatorname{de} \Gamma^{-1}$. Esta matriz possui $n(n+1) / 2$ parâmetros livres, que é o número máximo de parâmetros que podem ser estimados em $\Gamma$, sendo que $n(n-1) / 2$ o número mínimo de restrições que precisam ser impostas para identificação ${ }^{19}$. Havendo um número menor de restrições, tem-se um $_{\text {p }}$ modelo subidentificado, e com um número maior, um modelo superidentificado.

Para estimação de (97), utiliza-se o procedimento Bernanke incorporado ao programa RATS 4.0. Após a estimação de (98) por quadrados mínimos ordinários, num segundo estágio, maximiza-se a função logarítmica de verossimilhança, dada por:

$$
\ln L=-T(0,5 n) \ln (2 \pi)+T(|\ln \Gamma|-0,5 \ln |D|)-0,5 T \operatorname{tr}\left(D^{-1} \Gamma \Psi \Gamma^{\prime}\right)
$$

\footnotetext{
19 O modelo VAR convencional é exatamente identificado, pois a matriz $\Gamma$ é triangular inferior com $\mathbf{n}(\mathbf{n}+1) / 2$, e a fatoração de Cholesky é feita pela matriz triangular inferior $\mathbf{C}$.
} 
sendo a matriz diagonal de variância e covariância dos erros do modelo igual a

$\mathbf{D}=\operatorname{Cov}\left[\Gamma^{-1} \varepsilon_{t}\right]$ e $\mathbf{T}$ é igual ao número de observações. Neste procedimento de Bernanke, a matriz de variância e covariância da forma reduzida, $\Psi$, é substituída por $\mathbf{T}$ multiplicado pela matriz de produtos residuais cruzados.

Após a estimação dos coeficientes de $\Gamma$ e $\mathbf{D}$, podem ser feitas as análises de respostas a choques das variáveis e a decomposição da variância do erro de previsão, de modo semelhante ao dos modelos VAR convencionais.

O modelo autoregressivo pode ser expresso na forma de médias-móveis :

$$
x_{t}=\sum_{j=1}^{\infty} C_{j} \Gamma^{-1} \varepsilon_{t}
$$

onde $\mathbf{C} \mathrm{j}$ são as matrizes que medem os impactos do vetor de erros.

A expressão (100) pode ser reescrita da seguinte forma :

$$
x_{t}=\sum_{j=1}^{\infty} C_{j} \Gamma^{-1} D^{1 / 2} \varepsilon_{t}
$$

onde os choques unitários em $\varepsilon_{t}$ multiplicados pela raiz quadrada de $D$, são equivalentes a choques de um desvio-padrão. Esta expressão também será usada para obtenção da decomposição da variância de previsão.

\subsubsection{1 - Estrutura do modelo VAR}

A busca da estrutura econômica ideal para um VAR é abordada por MOUNT (1989), que testa um procedimento para identificar a estrutura correta nas análises de políticas.

Mas as análises de choques de políticas têm sido criticadas por COOLEY \& LE ROY (1985), estabelecendo que os desenvolvimentos obtidos com estas análises são baseados em análises incorretas, e que como aproximações estruturais os modelos VAR 
convencionais não tem sido vistos como muito acurados. Segundo ORDEN \& FACKLER (1989), esta identificação dos modelos VAR convencionais é obtida implicitamente pela escolha de uma decomposição de Cholesky da matriz de variância covariância dos erros de previsão, que é equivalente a impor uma estrutura recursiva para a economia. Mas BERNANKE (1986) citado por ORDEN \& FÁCKLER (1989), coloca que esta ordem recursiva é baseada em um conjunto de hipóteses prévias nas quais o analista se baseia, mas não tem certeza da ordem em que as variáveis devem ser arranjadas.

ORDEN \& FACKLER (1989) chegam à conclusão de que para se obter a correta identificação da estrutura econômica para um modelo VAR, deve-se considerar dois aspectos : a) a omissão de variáveis relevantes; e b) a presença de raízes unitárias e de cointegração.

A estrutura econômica descrita no capítulo 3 é uma tentativa de se dispor de um modelo VAR bem especificado, e que proporcione os melhores resultados esperados para se atender aos objetivos.

As estimações dos modelos VAR serão feitas através de dois modelos distintos:

1 -Modelo da Integração - estimação com as variáveis preços ao produtor de frango nos estados de São Paulo, Santa Catarina e Paraná através de um modelo VAR convencional. 2 - Modelo de Monopsônio - estimação de modelo envolvendo preços do estado de São Paulo referentes a frango ao produtor, carne bovina ao varejo, índice de custo de produção de frango, renda (índice de produção industrial) e variável proxy de custo de comercialização (taxa de juros real) utilizando um modelo VAR estruturado segundo estrutura do modelo monopsonista do capítulo 3.

Toda a metodologia descrita neste capítulo utilizará o método dos mínimos quadrados generalizados através dos seguintes softwares : RATS 3.0 (DOAN \& 
LITTERMAN, 1990) com rotina CATS (JUSELIUS, 1991); RATS 4.0 (DOAN \& LITTERMAN, 1992) e MICRO TSP 6.5 (LILIEN \& HALL, 1989).

A determinação do número de defasagens utilizado tanto para os testes de raiz unitária quanto para os testes de cointegração e para o VAR é um problema que será contornado com a utilização de dois diferentes procedimentos para se obter o número de defasagens: o primeiro se refere ao uso do número de 12 defasagens para os testes de raiz unitária, devido ao uso de séries de dados mensais; o segundo critério é a determinação destas defasagens através dos procedimentos de Akaike e Schwarz, os quais indicarão o número de defasagens a serem utilizados nos testes de raiz unitária, cointegração e nos modelos VAR.

Os critérios de Akaike (AIC) e Schwarz (SC) para determinação do número de defasagens para os testes de raiz unitária consiste segundo JUDGE et alii (1988) em determinar $\mathbf{n}$ que minimiza as funções :

$$
\begin{aligned}
& A I C(n)=\ln \sigma_{n}^{2}+\frac{2 n}{T} \\
& S C(n)=\ln \sigma_{n}^{2}+\frac{n \ln T}{T}
\end{aligned}
$$

onde $\mathbf{n}$ é o número de defasagens ; $\boldsymbol{\sigma}^{2}$ é a estimativa da variância residual que é igual a soma de quadrados do erro divididos pelo tamanho da amostra (SSE/T) e T é o tamanho da amostra.

Para a seleção da ordem do VAR a ser utilizado no método de Johansen e no VAR com ou sem correção de erro segundo JUDGE et alii (1988), os critérios AIC e SC sofrem respectivamente algumas modificações devido à análise nestes casos ser multivariada, resultando em : 


$$
\begin{aligned}
& A I C(n)=\ln \operatorname{det}\left(\Sigma_{n}\right)+\frac{2 M^{2} n}{T} \\
& S C(n)=\ln \operatorname{det}\left(\Sigma_{n}\right)+\frac{M^{2} n \ln T}{T}
\end{aligned}
$$

onde $\mathbf{M}$ é o número de variáveis no sistema, $\mathbf{T}$ é o tamanho da amostra, $\mathbf{n}$ é o número de defasagens que minimiza as funções acima e $\Sigma$ é a estimativa da matriz de covariância residual. 
87.

\section{5 - RESULTAdOS E DISCUSSĀo}

Este capítulo é dividido em 2 partes, sendo que cada uma delas contém os resultados dos testes de raiz unitária, testes de cointegração e do modelo VAR com correção de erro. A primeira trata dos resultados do Modelo da Integração que relaciona as variáveis preço de frango ao produtor nos estados de São Paulo, Santa Catarina e Paraná. A segunda mostra os respectivos resultados do Modelo de Monopsônio que relaciona os preços de frango no estado de São Paulo aos níveis de produtor, atacado e varejo, índice de produção industrial, taxa de juros, preço da carne bovina em São Paulo e índice do custo de produção.

A seguir tem-se uma Tabela relacionando as variáveis e estatísticas utilizadas e suas respectivas descrições. 
88.

Tabela 12 - Variáveis utilizadas na pesquisa

\begin{tabular}{cl}
\hline Variáveis & \multicolumn{1}{c}{ Significado } \\
\hline PpSP & logaritmo do preço real ao produtor de frango em SP \\
PpSC & logaritmo do preço real ao produtor de frango em SC \\
PpPR & logaritmo do preço real ao produtor de frango no PR \\
PaSP & logaritmo do preço real ao atacado de frango em SP \\
PvSP & logaritmo do preço real ao varejo de frango em SP \\
PcBov & logaritmo do preço real ao produtor de boi gordo em SP \\
IProd & logaritmo do preço real pago pelos produtores de frango pelo kg do insumo de \\
& produção em SP \\
Tj & logaritmo da taxa de juros real \\
$\mathrm{X}$ & logaritmo do índice de produção industrial \\
\hline
\end{tabular}

\section{1 - Modelo da Integração}

\subsection{1 - Testes de raiz unitária ${ }^{20}$}

Os modelos utilizados para testar a presença de raizes unitárias nas variáveis utilizadas, PpSP, PpSC e PpPR, foram ajustados com defasagens obtidas de acordo com os critérios de informação de Akaike e Schwarz. Nem sempre estes critérios chegaram às mesmas defasagens, justificando assim, em alguns casos, o uso de mais de uma defasagem para cada série de preços.

As Tabelas 13 e 14, mostram que, para o teste sem constante e sem tendência ( $\tau$ ), rejeita-se a hipótese das variáveis serem integradas de ordem 2 . Indicando que basta diferenciar as séries uma única vez para que estas se tornem estacionárias.

20 Os testes de raiz unitária são realizados comparando-se o valor da estatistica t de Student com os valores críticos de FULLER (1976) que se encontram na Tabela 1.1 do apêndice 1. 
Tabela 13 - Testes de raiz unitária, modelo sem constante e sem tendência ( $\tau$ )

\begin{tabular}{lcccc}
\hline & $\Delta x_{t}=\gamma_{1} x_{t-1}+\sum_{j=2}^{n} \gamma_{j} \Delta x_{t-j-1}+e_{t}$ & Ho : $\gamma_{1}=0$ \\
Modelo : & Defasagens & Valor da Estatística $t$ & Q & (G.L.) \\
Variáveis & 12 & $-1,327$ & 20,79 (27) \\
\hline PpSP & 7 & $-1,235$ & 27,99 (30) \\
PpSC & 12 & $-1,415$ & $22,04 \quad(27)$ \\
& 2 & $-0,485$ & $30,66 \quad(30)$ \\
PpPR & 12 & $-1,408$ & $22,74 \quad(27)$ \\
\hline
\end{tabular}

Fonte: Dados da pesquisa.

Tabela 14 - Testes de raíz unitária, modelo sem constante e sem tendência $(\tau)$

\begin{tabular}{|c|c|c|c|c|}
\hline Modelo : & $\Delta \Delta x_{t}=o$ & $\sigma_{j} \Delta \Delta x_{t-j-1}+e_{t}$ & Ho: $\sigma_{1}$ & $=0$ \\
\hline Variáveis & Defasagens & Valor da Estatística t & $Q$ & (G.L.) \\
\hline PpSP & 12 & $-3,137 *$ & 15,67 & (27) \\
\hline \multirow[t]{2}{*}{ PpSC } & 7 & $-5,180^{*}$ & 21,57 & (27) \\
\hline & 12 & $-3,137 *$ & 16,17 & (27) \\
\hline \multirow[t]{2}{*}{ PpPR } & 2 & $-7,347 *$ & 28,56 & (30) \\
\hline & 12 & $-3,345 *$ & 17,36 & (27) \\
\hline
\end{tabular}

* significativo a $1 \%$ de probabilidade

** significativo a $2,5 \%$ de probabilidade

*** significativo a $5 \%$ de probabilidade

Fonte: Dados da pesquisa.

De acordo com os resultados da estatística $(\tau)$ na Tabela 13 , não se rejeita a hipótese de haver raiz unitária, caso contrário, as séries seriam estacionárias. Na Tabela 
90.

14 rejeita-se a hipótese de raiz unitária nas primeiras diferenças, ou seja, rejeita-se a hipótese das séries serem integradas de ordem superior a 1, podendo-se concluir, então, que as séries são $\mathrm{I}(1)$.

Nas Tabelas 15 e 16 estão os resultados da estatística $\left(\tau_{\mu}\right)$, mostrando que as séries de frango em São Paulo, Paraná e Santa Catarina são I (1).

Tabela 15 - Testes de raiz unitária, modelo com constante e sem tendência $\left(\tau_{\mu}\right)$

\begin{tabular}{|c|c|c|c|c|}
\hline \multirow{2}{*}{$\begin{array}{l}\text { Modelo: } \\
\text { Variáveis }\end{array}$} & \multicolumn{2}{|c|}{$\Delta x_{t}=\alpha+\gamma_{1} x_{t-1}+\sum_{j=2}^{n} \gamma_{j} \Delta x_{t-j-1}+e_{t}$} & \multicolumn{2}{|c|}{ Ho: $\gamma_{1}=0$} \\
\hline & Defasagens & Valor da Estatística $t$ & $Q$ & (G.L.) \\
\hline \multirow[t]{2}{*}{ PpSP } & 9 & $-1,284$ & 21,80 & (27) \\
\hline & 12 & $-1,118$ & 19,78 & (27) \\
\hline \multirow[t]{2}{*}{$\mathrm{PpSC}$} & 2 & $-1,780$ & 27,22 & (30) \\
\hline & 12 & $-1,659$ & 22,81 & (27) \\
\hline \multirow[t]{2}{*}{ PpPR } & 2 & $-1,679$ & 27,41 & (30) \\
\hline & 12 & $-1,302$ & 21,09 & (27) \\
\hline
\end{tabular}

Fonte: Dados da pesquisa. 
Tabela 16 - Testes de raiz unitária, modelo com constante e sem tendência $\left(\tau_{\mu}\right)$

\begin{tabular}{lccc}
\hline Modelo : & $\Delta \Delta x_{t}=\alpha+\sigma_{1} x_{t-1}+\sum_{j=2}^{n} \sigma_{j} \Delta \Delta x_{t-j-1}+e_{t}$ & Ho : $\sigma_{1}=0$ \\
& Defasagens & Valor da Estatística $t$ & Q \\
Variáveis & 9 & $-4,447^{*}$ & 22,23 (27) \\
\hline PpSP & 12 & $-3,317^{* *}$ & $18,20(27)$ \\
& 2 & $-6,601^{*}$ & 27,31 (30) \\
PpSC & 12 & $-3,383^{* *}$ & $18,47(27)$ \\
PpPR & 2 & $-7,320^{*}$ & $28,88(30)$ \\
& 12 & $-3,517^{*}$ & $20,06(27)$ \\
\hline
\end{tabular}

* significativo a $1 \%$ de probabilidade

** significativo a $2,5 \%$ de probabilidade

*** significativo a $5 \%$ de probabilidade

Fonte: Dados da pesquisa.

As Tabelas 17 e 18 mostram os testes de raiz unitária com constante e tendência, estatística $\left(\tau_{\tau}\right)$, a qual confirma que as séries de frango nos três estados são I (1), ao nível de 2,5\% de significância. Mas para as variáveis PpSP e PpSC com 12 defasagens, verifica-se que estas podem ser integradas de ordem superior. Se houver relações de cointegração entre as três variáveis, todas são integradas de mesma ordem, do contrário, PpSP e PpSC podem, realmente, ser integradas de ordem superior a um. A definição só poderá ocorrer através do procedimento de Johansen a seguir. 
Tabela 17 - Testes de raiz unitária, modelo com constante e com tendência $\left(\tau_{\tau}\right)$

\begin{tabular}{|c|c|c|c|c|}
\hline \multirow{2}{*}{$\begin{array}{l}\text { Modelo: } \\
\text { Variáveis }\end{array}$} & \multicolumn{2}{|c|}{$\Delta x_{t}=\alpha+\beta_{1} T+\gamma_{1} x_{t-1}+\sum_{j=2}^{n} \gamma_{j} \Delta x_{t-j-1}+e_{t}$} & \multicolumn{2}{|c|}{ Ho : $\gamma_{1}=0$} \\
\hline & Defasagens & Valor da Estatística t & Q & (G.L.) \\
\hline \multirow[t]{2}{*}{ PpSP } & 9 & $-3,178$ & 20,29 & (27) \\
\hline & 12 & $-2,375$ & 20,52 & (27) \\
\hline \multirow[t]{2}{*}{ PpSC } & 2 & $-3,622 * * *$ & 24,42 & (30) \\
\hline & 12 & $-2,963$ & 16,80 & (27) \\
\hline \multirow[t]{2}{*}{ PpPR } & 4 & $-3,703 * * *$ & 28,18 & (30) \\
\hline & 12 & $-2,661$ & 21,02 & (27) \\
\hline
\end{tabular}

Fonte: Dados da pesquisa.

Tabela 18 - Testes de raiz unitária, modelo com constante e com tendência $\left(\tau_{\tau}\right)$

Modelo :

$$
\Delta \Delta x_{t}=\alpha+\beta_{1} T+\sigma_{1} x_{t-1}+\sum_{j=2}^{n} \sigma_{j} \Delta \Delta x_{t-j-1}+e_{t} \quad \text { Ho : } \sigma_{1}=0
$$

\begin{tabular}{lccc} 
Variáveis & Defasagens & Valor da Estatística $\mathrm{t}$ & $\mathrm{Q}$ (G.L.) \\
\hline PpSP & 9 & $-4,372 *$ & 22,27 (27) \\
& 12 & $-3,276$ & $18,46(27)$ \\
PpSC & 2 & $-6,569 *$ & $27,27(30)$ \\
& 12 & $-3,371$ & $18,90(27)$ \\
PpPR & 4 & $-6,509 *$ & $23,87(30)$ \\
& 12 & $-3,787^{* *}$ & $20,07(27)$ \\
\hline
\end{tabular}

* significativo a $1 \%$ de probabilidade

** significativo a $2,5 \%$ de probabilidade

*** significativo a $5 \%$ de probabilidade

Fonte: Dados da pesquisa. 
De acordo com os resultados sugeridos pelos testes acima, as variáveis são integradas de mesma ordem para defasagens inferiores a 12 , restando verificar se há relações de cointegração entre as mesmas, conforme o procedimento de Johansen.

\subsection{2 - Testes de cointegração}

De acordo com o que foi visto no capítulo 4, segundo o método de Johansen dois testes são usados para se determinar o número de relações de cointegração existentes entre as variáveis em estudo: o teste do Traço e do Máximo Autovalor ( $\left.\lambda_{\text {máx }}\right)$, os quais, para o modelo não estruturado, encontram-se na Tabela 19, com os respectivos valores críticos oriundos da Tabela 1.2 do apêndice 1.

Tabela 19 - Resultados dos testes para determinação do nủmero de relações de cointegração a

\begin{tabular}{ccccc}
\hline Hipótese Nula & Traço & Traço (95\%) & $\lambda_{\text {máx }}$ & $\lambda_{\text {máx }}(95 \%)$ \\
\hline$r \leq 2$ & 4,07 & 8,08 & 4,07 & 8,08 \\
$r \leq 1$ & 22,55 & 17,84 & 18,48 & 14,60 \\
$r=0$ & 57,54 & 31,26 & 35,00 & 21,28 \\
\hline
\end{tabular}

a Foi utilizado para estes testes um modelo VAR apenas com as 3 variáveis e uma constante.

O número de defasagens utilizada foi de 2 de acordo com os critérios de Akaike e Scwarz.

Fonte: Dados da pesquisa.

A Tabela 19 mostra claramente que em ambos os testes se rejeita, ao nível de 95\% de probabilidade, a hipótese $\mathbf{r} \leq 1$, de haver no máximo uma relação de cointegração, e não se rejeita a de $\mathbf{r} \leq \mathbf{2}$, o que significa dizer que estatísticamente devem existir duas relações de cointegração, ou seja, duas relações estáveis de longo prazo, confirmando que as três variáveis são integradas de mesma ordem, I(1), como indicaram 
os três testes de raiz unitária. Estas duas relações de cointegração podem ser obtidas da Tabela 20.

Tabela 20 - Estimativas dos autovalores $(\lambda)$, autovetores da matriz de cointegração $(\beta)$

\begin{tabular}{lccc}
\hline & \multicolumn{3}{c}{ AUTOVALORES $(\lambda)$} \\
\cline { 2 - 4 } & 0,281 & 0,160 & 0,038 \\
\hline AUTOVETORES $(\beta$ 's) & & & \\
PpSC & $-2,113$ & 8,596 & 3,116 \\
PpSP & $-16,115$ & $-3,969$ & $-0,886$ \\
PpPR & 18,344 & $-3,945$ & 1,857 \\
\hline
\end{tabular}

Fonte: Dados da pesquisa..

A partir da Tabela 20 , tem-se as duas relações de cointegração relevantes, as quais são representadas pelas duas primeiras colunas de autovetores $(\beta)$, resultando em :

$$
\begin{aligned}
& Z_{1 \mathrm{t}}=-2,113 \mathrm{PpSC}-16,115 \mathrm{PpSP}+18,344 \mathrm{PpPR} \\
& \mathrm{Z}_{2 \mathrm{t}}=8,596 \mathrm{PpSC}-3,969 \mathrm{PpSP}-3,945 \mathrm{PpPR}
\end{aligned}
$$

Estas equações representam relações estáveis do equilíbrio de longo prazo entre as variáveis, os chamados termos de correção de erro, os quais serão utilizados no período t -1 para a estimação do modelo VAR com correção de erro, de modo a se recuperar as informações de longo prazo perdidas nas diferenças das variáveis em estudo.

\subsection{3 - Modelo VAR com correção de erro}

Nesta análise utilizou-se o modelo VAR convencional, o qual admite uma relação recursiva entre as variáveis. Mas como estas variáveis apresentaram problemas de estacionariedade foram primeiramente diferenciadas nos logaritmos, de maneira que os 
resultados a seguir referem-se às taxas de crescimento dos preços e não aos preços propriamente ditos.

A Tabela 21 mostra as respostas a choques no preço do frango ao produtor em Santa Catarina bem como a dinâmica destas respostas em um horizonte de 24 meses.

A ordem com que as variáveis foram arranjadas foi pressuposta de acordo com a sua importância empírica no mercado. Outras ordenações mostraram resultados semelhantes nas respostas a choques nas variáveis e bem diferentes nas decomposições da variância dos erros de previsão, sendo que a primeira variável sempre mostrou-se exógena em relação às demais e importante na explicação da segunda e terceira variáveis do vetor. A terceira variável, por sua vez, sempre foi explicada pela primeira variável, mas algumas vezes pela segunda, além dela mesma. ${ }^{21}$

Segundo a Tabela 21, e Figuras 2.1, 2.2 e 2.3 do apêndice 2, um aumento no preço do frango ao produtor em Santa Catarina faria com que os preços nos estados de São Paulo e Paraná subissem imediatamente após este aumento. No segundo mês, após um aumento inicial de $1 \%$ no preço em SC, ter-se-ia um aumento neste de $0,09 \%$, e respectivamente de $0,43 \%$ e $0,34 \%$ nos estados de SP e PR. Nos meses seguintes a este aumento, o efeito nos preços dos três estados torna-se pequeno, passando a valores desprezíveis a partir do sétimo mês, convergindo a valores próximos de zero.

Uma variação no preço do frango em Santa Catarina contribuiria, então, para que houvesse variações também nos preços dos estados de São Paulo e Paraná até o nono mês após a variação inicial, não havendo nos meses seguintes, nenhum efeito significativo nos preços dos três estados.

${ }^{21}$ Como exemplo toma-se a ordenação PpSP, PpSC e PpPR, onde a decomposição dos erros de previsão mostrou que na explicação de PpSP, após 12 meses, a própria variável foi autoexplicativa em cerca de 92\%. PpSP explicou cerca de $18 \%$ da variação do erro de previsão de PpSC após 12 meses. E PpSP foi responsável por cerca de $61 \%$ dos erros de previsão de PpPR. 
Tabela 21 - Respostas a choque no preço do frango ao produtor em SC (PpSC) no Modelo da Integração*.

\begin{tabular}{|c|c|c|c|}
\hline Meses & $\mathrm{PpSC}$ & PpSP & PpPR \\
\hline 1 & 1 & 0,4628 & 0,4909 \\
\hline 2 & 0,0899 & 0,4288 & 0,3408 \\
\hline 3 & $-0,0727$ & $-0,1647$ & $-0,0807$ \\
\hline 4 & $-0,0870$ & $-0,1895$ & $-0,1515$ \\
\hline 5 & 0,0090 & $-0,0018$ & $-0,0090$ \\
\hline 6 & 0,0322 & 0,0690 & 0,0515 \\
\hline 7 & 0,0078 & 0,0215 & 0,0187 \\
\hline 8 & $-0,0094$ & $-0,0180$ & $-0,0126$ \\
\hline 9 & $-0,0058$ & $-0,0134$ & $-0,0106$ \\
\hline 10 & 0,0016 & 0,0023 & 0,0012 \\
\hline 11 & 0,0026 & 0,0055 & 0,0042 \\
\hline 12 & 0,0002 & 0,0009 & 0,0009 \\
\hline 13 & $-0,0009$ & $-0,0017$ & $-0,0012$ \\
\hline 14 & $-0,0004$ & $-0,0009$ & $-0,0007$ \\
\hline 15 & 0,0002 & 0,0003 & 0,0002 \\
\hline 16 & 0,0002 & 0,0004 & 0,0003 \\
\hline 17 & $-1,2 \mathrm{E}-05$ & $7,6 \mathrm{E}-06$ & $2,1 E-05$ \\
\hline 18 & $-7,2 \mathrm{E}-05$ & $-1,5 E-04$ & $-1,1 \mathrm{E}-04$ \\
\hline 19 & $-1,8 \mathrm{E}-05$ & $-5,0 \mathrm{E}-05$ & $-4,2 \mathrm{E}-05$ \\
\hline 20 & $2,0 \mathrm{E}-05$ & $3,8 \mathrm{E}-05$ & $2,7 \mathrm{E}-05$ \\
\hline 21 & $1,3 E-05$ & $3,0 \mathrm{E}-05$ & $2,4 \mathrm{E}-05$ \\
\hline 22 & $-3,2 \mathrm{E}-06$ & $-4,4 \mathrm{E}-06$ & $-2,2 \mathrm{E}-06$ \\
\hline 23 & $-5,7 \mathrm{E}-06$ & $-1,2 \mathrm{E}-05$ & $-9,2 E-06$ \\
\hline 24 & $-6,3 \mathrm{E}-07$ & $-2,2 \mathrm{E}-06$ & $-2,1 E-06$ \\
\hline
\end{tabular}

Fonte: Dados da pesquisa.

* Foram utilizados no ajustamento, dados do período 1985-93.

Com auxílio da Tabela 22, onde tem-se a decomposição da variância do preço de frango ao produtor em Santa Catarina, pode-se notar que este não é influenciado pelos preços de nenhum dos demais estados, pois os preços em São Paulo e Paraná explicam 
uma parcela muito pequena do erro de ṕrevisão, sendo portanto, uma variável exógena a qual apenas os componentes de oferta e demanda (nível tecnológico, exportações) peculiares ao estado catarinense são determinantes do seu preço, o que já era esperado, devido ao alto grau de integração e de nível tecnológico encontrado neste estado.

Tabela 22 - Decomposição da variância dos erros de previsão do preço do frango ao produtor em Santa Catarina (PpSC) no Modelo da Integração, em porcentagem*.

\begin{tabular}{cccc}
\hline Meses & PpSC & PpSP & PpPR \\
\hline 1 & 100 & 0,00 & 0,00 \\
2 & 98,09 & 1,86 & 0,05 \\
3 & 95,47 & 3,70 & 0,82 \\
4 & 95,06 & 4,11 & 0,83 \\
5 & 95,00 & 4,16 & 0,84 \\
6 & 94,90 & 4,25 & 0,85 \\
7 & 94,90 & 4,25 & 0,85 \\
8 & 94,89 & 4,26 & 0,85 \\
9 & 94,89 & 4,26 & 0,85 \\
10 & 94,89 & 4,26 & 0,85 \\
11 & 94,89 & 4,26 & 0,85 \\
12 & 94,89 & 4,26 & 0,85 \\
\hline
\end{tabular}

Fonte: Dados da pesquisa.

* Foram utilizados no ajustamento, dados do período 1985-93.

Segundo a Tábela 23 e Figuras 2.4, 2.5 e 2.6 do apêndice 2, após um choque de $1 \%$ no preço do frango ao produtor em São Paulo, no mês seguinte este sofrerá um efeito de variação de aproximadamente $0,16 \%$, passando a ter uma variação negativa nos dois meses seguintes, para a partir do sétimo mês após o choque o efeito tornar-se nulo. 
98.

Tabela 23 - Respostas a choque no preço do frango ao produtor em SP (PpSP) no Modelo da Integração*.

\begin{tabular}{|c|c|c|c|}
\hline Meses & $\mathrm{PpSC}$ & PpSP & PpPR \\
\hline 1 & 0,0000 & 1 & 0,6914 \\
\hline 2 & 0,1189 & 0,1589 & 0,1345 \\
\hline 3 & $-0,1222$ & $-0,2184$ & $-0,1738$ \\
\hline 4 & $-0,0596$ & $-0,1385$ & $-0,1060$ \\
\hline 5 & 0,0201 & 0,0349 & 0,0212 \\
\hline 6 & 0,0286 & 0,0606 & 0,0459 \\
\hline 7 & 0,0011 & 0,0070 & 0,0074 \\
\hline 8 & $-0,0098$ & $-0,0198$ & $-0,0144$ \\
\hline 9 & $-0,0035$ & $-0,0088$ & $-0,0072$ \\
\hline 10 & 0,0024 & 0,0044 & 0,0029 \\
\hline 11 & 0,0020 & 0,0045 & 0,0035 \\
\hline 12 & $-0,0002$ & $-0,0002$ & 0,0001 \\
\hline 13 & $-0,0008$ & $-0,0017$ & $-0,0013$ \\
\hline 14 & $-0,0002$ & $-0,0005$ & $-0,0004$ \\
\hline 15 & 0,0002 & 0,0005 & 0,0003 \\
\hline 16 & 0,0001 & 0,0003 & 0,0003 \\
\hline 17 & $-4,4 \mathrm{E}-05$ & $-6,7 \mathrm{E}-05$ & $-3,8 \mathrm{E}-05$ \\
\hline 18 & $-6,2 \mathrm{E}-05$ & $-1,3 \mathrm{E}-04$ & $-1,0 \mathrm{E}-04$ \\
\hline 19 & $-3,7 \mathrm{E}-06$ & $-1,8 \mathrm{E}-05$ & $-1,8 \mathrm{E}-05$ \\
\hline 20 & $2,1 \mathrm{E}-05$ & $4,3 E-05$ & $3,1 \mathrm{E}-05$ \\
\hline 21 & $8,0 E-06$ & $2,0 \mathrm{E}-05$ & $1,6 \mathrm{E}-05$ \\
\hline 22 & $-5,2 \mathrm{E}-06$ & $-9,2 E-06$ & $-6,1 \mathrm{E}-06$ \\
\hline 23 & $-4,5 \mathrm{E}-06$ & $-1,0 \mathrm{E}-05$ & $-7,9 E-06$ \\
\hline 24 & $4,4 \mathrm{E}-07$ & $1,6 \mathrm{E}-07$ & $-2,6 \mathrm{E}-07$ \\
\hline
\end{tabular}

Fonte: Dados da pesquisa.

* Foram utilizados no ajustamento, dados do período $1985-93$.

Com relação aos preços em SC e PR, o efeito de um choque no preço em SP tem comportamento semelhante. Em SC há uma variação positiva no segundo mês após o choque de $0,12 \%$. No PR há uma variação positiva de $0,69 \%$ já no primeiro mês e de 
$0,13 \%$ no segundo, sendo que nos dois meses seguintes o efeito nos dois estados torna-se negativo, passsando a nulo a partir do sétimo mês.

Por meio da Tabela 24, onde se encontra a decomposição da variância do preço do frango em São Paulo, verifica-se que este sofre influência apenas do preço do frango em Santa Catarina, devido à avicultura deste estado apresentar características de liderança nacional em produção, número de empresas integradoras, exportações, tecnologia, entre outras.

Tabela 24 - Decomposição da variância dos erros de previsão do preço do frango ao produtor em São Paulo (PpSP) no Modelo da Integração, em porcentagem*.

\begin{tabular}{cccc}
\hline Meses & PpSC & PpSP & PpPR \\
\hline 1 & 13,67 & 86,33 & 0,00 \\
2 & 22,23 & 77,44 & 0,33 \\
3 & 22,58 & 77,09 & 0,33 \\
4 & 23,66 & 75,81 & 0,54 \\
5 & 23,64 & 75,83 & 0,54 \\
6 & 23,75 & 75,68 & 0,57 \\
7 & 23,77 & 75,66 & 0,57 \\
8 & 23,78 & 75,65 & 0,57 \\
9 & 23,78 & 75,65 & 0,57 \\
10 & 23,78 & 75,65 & 0,57 \\
11 & 23,78 & 75,65 & 0,57 \\
12 & 23,78 & 75,65 & 0,57 \\
\hline
\end{tabular}

Fonte: Dados da pesquisa..

* Foram utilizados no ajustamento, dados do período 1985-93.

Quanto à análise das respostas nos preços devido a um choque de $1 \%$ no preço do frango no Paraná, tem-se, conforme a Tabela 25 e figuras 2.7, 2.8 e 2.9 do apêndice 2, que o efeito no preço nos três estados é negativo no mês seguinte ao choque, com 
variações de $-0,03 \%,-0,11$ e $-0,12 \%$, respectivamente em SC, SP e PR. Após o sétimo mês os efeitos tornam-se nulos, a exemplo do que ocorreu nas análises anteriores de choques nos preços de SC e SP, mostrando um comportamento dos preços bastante semelhante entre os três estados, confirmando que o mercado de frango possui as mesmas características para os três estados maiores produtores do país, além de haver forte interação entre eles.

O preço do frango no estado do Paraná, como já era esperado, é influenciado tanto pelo preço em São Paulo como em Santa Catarina, conforme Tabela 26 e Figura 2.3 do apêndice 2. Isto pode ser explicado, apesar do Paraná ser o segundo maior produtor, pelo fato de Santa Catarina ser o maior produtor e exportador de carne de frango e por São Paulo ser o maior e mais importante centro consumidor e detentor do maior rebanho de matrizes do país.

Ainda com relação à Tabela 26, verifica-se que após 12 meses o preço do frango em Santa Catarina contribui com cerca de $24 \%$ do erro de previsão do preço no Paraná. O preço em São Paulo contribui com cerca de 44\%, sendo que o próprio preço de frango no Paraná, após estes 12 meses, só explica cerca de $32 \%$ do seu erro de previsão. 
101.

Tabela 25 - Respostas a choque no preço do frango ao produtor no PR (PpPR) no Modelo da Integração*.

\begin{tabular}{|c|c|c|c|}
\hline Meses & $\mathrm{PpSC}$ & PpSP & PpPR \\
\hline 1 & 0,0000 & 0,0000 & 1 \\
\hline 2 & $-0,0309$ & $-0,1060$ & $-0,1245$ \\
\hline 3 & 0,1250 & 0,0247 & $-0,0477$ \\
\hline 4 & 0,0208 & 0,0895 & 0,0761 \\
\hline 5 & $-0,0117$ & $-0,0068$ & 0,0067 \\
\hline 6 & $-0,0144$ & $-0,0344$ & $-0,0277$ \\
\hline 7 & $-0,0010$ & $-0,0063$ & $-0,0067$ \\
\hline 8 & 0,0049 & 0,0105 & 0,0078 \\
\hline 9 & 0,0021 & 0,0053 & 0,0044 \\
\hline 10 & $-0,0012$ & $-0,0021$ & $-0,0014$ \\
\hline 11 & $-0,0011$ & $-0,0025$ & $-0,0020$ \\
\hline 12 & 0,0001 & $-0,0000$ & $-0,0001$ \\
\hline 13 & 0,0004 & 0,0009 & 0,0007 \\
\hline 14 & 0,0001 & 0,0003 & 0,0003 \\
\hline 15 & $-0,0001$ & $-0,0002$ & $-0,0002$ \\
\hline 16 & $-7,8 \mathrm{E}-05$ & $-0,0002$ & $-0,0001$ \\
\hline 17 & $1,9 \mathrm{E}-05$ & $2,6 \mathrm{E}-05$ & $1,3 \mathrm{E}-05$ \\
\hline 18 & $3,4 \mathrm{E}-05$ & $7,3 \mathrm{E}-05$ & $5,5 \mathrm{E}-05$ \\
\hline 19 & $3,8 \mathrm{E}-06$ & $1,3 \mathrm{E}-05$ & $1,3 E-05$ \\
\hline 20 & $-1,1 \mathrm{E}-05$ & $-2,2 E-05$ & $-1,6 \mathrm{E}-05$ \\
\hline 21 & $-4,9 \mathrm{E}-06$ & $-1,2 \mathrm{E}-05$ & $-9,6 E-06$ \\
\hline 22 & 2,5E-06 & $4,3 \mathrm{E}-06$ & $2,7 \mathrm{E}-06$ \\
\hline 23 & $2,5 \mathrm{E}-06$ & $5,6 \mathrm{E}-06$ & $4,3 E-06$ \\
\hline 24 & $-1,0 \mathrm{E}-07$ & $2,1 E-07$ & 3,7E-07 \\
\hline
\end{tabular}

Fonte: Dados da pesquisa.

* Foram utilizados no ajustamento, dados do período 1985-93. 
Tabela 26 - Decomposição da variância dos erros de previsão do preço do frango ao produtor no Paraná (PpPR) no Modelo da Integração, em porcentagem*.

\begin{tabular}{cccc}
\hline Meses & PpSC & PpSP & PpPR \\
\hline 1 & 17,03 & 45,71 & 37,25 \\
2 & 22,84 & 42,93 & 34,23 \\
3 & 22,55 & 44,17 & 33,28 \\
4 & 23,38 & 43,99 & 32,63 \\
5 & 23,37 & 44,01 & 32,62 \\
6 & 23,45 & 44,02 & 32,53 \\
7 & 23,47 & 44,01 & 32,52 \\
8 & 23,47 & 44,02 & 32,51 \\
9 & 23,47 & 44,02 & 32,51 \\
10 & 23,47 & 44,02 & 32,51 \\
11 & 23,47 & 44,02 & 32,51 \\
12 & 23,47 & 44,02 & 32,51 \\
\hline
\end{tabular}

Fonte: Dados da pesquisa.

* Foram utilizados no ajustamento, dados do período 1985-93.

Os resultados mostrados sugerem que existe, entre os três principais produtores de carne de frango do país, um grau de interação muito forte, mesmo estando espacialmente separados. O Estado de Santa Catarina exerce um importante papel na formação de preços devido principalmente à condição de maior produtor, exportador, apresentar o mais alto nível de integração da avicultura brasileira, além de liderar a geração de tecnologia no setor. Já o Estado do Paraná recebe a influência de Santa Catarina e São Paulo, sendo que deste último a influência é justificada pelo fato de São Paulo apresentar o maior centro de consumo e o maior plantel de matrizes. São Paulo, que já foi o maior produtor nacional de carne de frango, vem recuperando o seu espaço no cenário avícola, constituindo-se em importante centro produtivo e de consumo, além de apresentar um bom nível de integração no processo produtivo. 
103.

\section{2 - Modelo de Monopsônio}

\subsection{1 - Testes de raiz unitária}

De acordo com o modelo monopsonista exposto no capítulo 3, tem-se oito variáveis, sendo que os preços dos insumos de comercialização no atacado e no varejo se equivalem. Isto torna a utilização simultânea destas duas variáveis dispensável. A taxa de juros seria uma variável proxy dos insumos de comercialização tanto no atacado quanto no varejo.

Com o modelo sendo representado por sete variáveis, deve-se proceder primeiramente, ao teste de raiz unitária para as séries individuais. Mais uma vez utilizamse as estatísticas $\tau, \tau_{\mu}$ e $\tau_{\tau}$, conforme as Tabelas a seguir.

De acordo com a estatística $(\tau)$, as sete variáveis do modelo apresentam uma raiz unitária ao nível de $1 \%$ de probabilidade, o que significa que segundo estes testes as mesmas são I (1). 
Tabela 27 - Testes de raiz unitária, modelo sem constante e sem tendência ( $\tau$ )

\begin{tabular}{|c|c|c|c|c|}
\hline Modelo: & \multicolumn{2}{|c|}{$\Delta x_{t}=\gamma_{1} x_{t-1}+\sum_{j=2}^{n} \gamma_{j} \Delta x_{t-j-1}+e_{t}$} & \multicolumn{2}{|c|}{ Ho : $\gamma_{1}=0$} \\
\hline Variáveis & Defasagens & Valor da Estatística $t$ & $\mathbf{Q}$ & (G.L.) \\
\hline PpSP & 12 & $-1,327$ & 20,79 & (27) \\
\hline PaSP & 12 & $-1,948$ & 12,07 & (27) \\
\hline PvSP & 4 & $-1,444$ & 16,43 & (27) \\
\hline \multirow[t]{2}{*}{$\mathbf{X}$} & 7 & 0,226 & 28,43 & (30) \\
\hline & 12 & 0,195 & 18,81 & (27) \\
\hline \multirow[t]{2}{*}{ IProd } & 10 & $-1,153$ & 27,81 & (27) \\
\hline & 12 & $-0,952$ & 23,29 & (27) \\
\hline $\mathbf{T j}$ & 12 & $-2,530$ & 13,80 & (27) \\
\hline \multirow[t]{2}{*}{ Pcbov } & 3 & $-0,095$ & 24,80 & (30) \\
\hline & 12 & $-0,877$ & 18,87 & (27) \\
\hline
\end{tabular}

Fonte: Dados da pesquisa. 
Tabela 28 - Testes de raíz unitária, modelo sem constante e sem tendência $(\tau)$

$$
\Delta \Delta x_{t}=\sigma_{1} x_{t-1}+\sum_{j=2}^{n} \sigma_{j} \Delta \Delta x_{t-j-1}+e_{t} \quad \text { Ho : } \sigma_{1}=0
$$

Modelo :

\begin{tabular}{lcccc} 
Variáveis & Defasagens & Valor da Estatistica $\mathrm{t}$ & $\mathrm{Q}$ & (G.L.) \\
\hline PpSP & 12 & $-3,137^{*}$ & 15,67 & $(27)$ \\
PaSP & 12 & $-3,600^{*}$ & 10,09 & $(27)$ \\
PvSP & 12 & $-3,941^{*}$ & 14,57 (27) \\
$\mathrm{X}$ & 7 & $-7,423^{*}$ & 24,45 (27) \\
& 12 & $-3,609^{*}$ & 19,99 (27) \\
IProd & 10 & $-2,790^{*}$ & 20,15 (27) \\
& 12 & $-2,419 * *$ & 21,17 (27) \\
Tj & 12 & $-4,442^{*}$ & 15,41 (27) \\
Pcbov & 3 & $-6,234^{*}$ & 21,00 & $(30)$ \\
& 12 & $-3,360^{*}$ & 14,67 & $(27)$ \\
\hline
\end{tabular}

* significativo a $1 \%$ de probabilidade

** significativo a $2,5 \%$ de probabilidade

*** significativo a $5 \%$ de probabilidade

Fonte: Dados da pesquisa. 
A estatística $\left(\tau_{\mu}\right)$ nas Tabelas 29 e 30 abaixo, mostra o mesmo resultado encontrado no teste $(\tau)$.

Tabela 29 - Testes de raiz unitária, modelo com constante e sem tendência $\left(\tau_{\mu}\right)$

$$
\Delta x_{t}=\alpha+\gamma_{1} x_{t-1}+\sum_{j=2}^{n} \gamma_{j} \Delta x_{t-j-1}+e_{t} \quad \text { Ho : } \gamma_{1}=0
$$

Modelo :

\begin{tabular}{lcccc} 
Variáveis & Defasagens & Valor da Estatística $\mathrm{t}$ & $\mathrm{Q}$ & (G.L.) \\
\hline PpSP & 9 & $-1,284$ & 21,80 (27) \\
& 12 & $-1,118$ & 19,78 (27) \\
PaSP & 4 & $-1,338$ & 19,76 (30) \\
& 12 & $-0,921$ & 11,13 & $(27)$ \\
PvSP & 12 & $-0,977$ & 14,70 (27) \\
X & 7 & $-2,558$ & 25,06 (30) \\
IProd & 9 & $-1,589$ & 27,21 (27) \\
& 12 & $-2,478$ & 18,55 (27) \\
Tj & 12 & $-2,724$ & 14,15 (27) \\
Pcbov & 4 & $-2,836$ & 16,77 (30) \\
& 12 & $-1,256$ & 16,59 (27) \\
\hline
\end{tabular}

Fonte: Dados da pesquisa. 
Tabela 30 - Testes de raiz unitária, modelo com constante e sem tendência $\left(\tau_{\mu}\right)$

$$
\Delta \Delta x_{t}=\alpha+\sigma_{1} x_{t-1}+\sum_{j=2}^{n} \sigma_{j} \Delta \Delta x_{t-j-1}+e_{t} \quad \text { Ho : } \sigma_{1}=0
$$

Modelo :

\begin{tabular}{lccc} 
Variáveis & Defasagens & Valor da Estatística t & Q \\
\hline PpSP & 9 & $-4,447^{*}$ & 22,23 (27) \\
\hline PaSP & 12 & $-3,317 * *$ & 18,20 (27) \\
& 4 & $-7,370^{*}$ & 16,19 (30) \\
PvSP & 12 & $-3,920^{*}$ & 12,70 (27) \\
X & 12 & $-4,119 *$ & 17,64 (27) \\
IProd & 7 & $-7,389^{*}$ & 24,53 (27) \\
& 9 & $-4,446^{*}$ & 27,79 (27) \\
Tj & 12 & $-2,513$ & $22,16(27)$ \\
Pcbov & 12 & $-4,442 *$ & 15,74 (27) \\
& 4 & $-6,381^{*}$ & 20,08 (30) \\
\hline
\end{tabular}

* significativo a $1 \%$ de probabilidade

** significativo a $2,5 \%$ de probabilidade

*** significativo a $5 \%$ de probabilidade

Fonte: Dados da pesquisa. 
As variáveis do modelo mostraram-se não-estacionárias segundo as estatísticas $(\tau),\left(\tau_{\mu}\right)$ e $\left(\tau_{\tau}\right)$. Esta última pode ser constatada nas Tabelas 31 e 32 .

Tabela 31 - Testes de raiz unitária, modelo com constante e com tendência $\left(\tau_{\tau}\right)$

\begin{tabular}{lcccc}
\hline & $\Delta x_{t}=\alpha+\beta_{1} T+\gamma_{1} x_{t-1}+\sum_{j=2}^{n} \gamma_{j} \Delta x_{t-j-1}+e_{t}$ & Ho : $\gamma_{1}=0$ \\
Modelo : & Defasagens & Valor da Estatística $t$ & $\mathrm{Q}$ & (G.L.) \\
Variáveis & 9 & $-3,178$ & 20,29 & (27) \\
\hline PpSP & 12 & $-2,375$ & 20,52 & (27) \\
& 12 & $-2,129$ & 10,54 & (27) \\
PaSP & 12 & $-2,145$ & 14,57 & $(27)$ \\
PvSP & 7 & $-1,925$ & 25,63 & (30) \\
X & 9 & $-1,685$ & 27,59 & (27) \\
IProd & 12 & $-3,273$ & 21,03 & (27) \\
& 12 & $-3,275$ & 17,11 & (27) \\
Tj & 6 & $-3,361$ & 22,97 & (30) \\
Pcbov & 12 & $-2,539$ & 17,58 & (27) \\
\hline
\end{tabular}

\footnotetext{
* significativo a $1 \%$ de probabilidade

** significativo a $2,5 \%$ de probabilidade

*** significativo a $5 \%$ de probabilidade

Fonte: Dados da pesquisa.
} 
Tabela 32 - Testes de raiz unitária, modelo com constante e com tendência $\left(\tau_{\tau}\right)$

$$
\Delta \Delta x_{t}=\alpha+\beta_{1} T+\sigma_{1} x_{t-1}+\sum_{j=2}^{n} \sigma_{j} \Delta \Delta x_{t-j-1}+e_{t} \quad \text { Ho : } \sigma_{1}=0
$$

Modelo :

\begin{tabular}{lcccc} 
Variáveis & Defasagens & Valor da Estatística t & Q & (G.L.) \\
\hline PpSP & 9 & $-4,372 *$ & 22,27 & $(27)$ \\
& 12 & $-3,276$ & 18,46 & $(27)$ \\
PaSP & 12 & $-3,854^{* *}$ & 12,69 & $(27)$ \\
PvSP & 12 & $-4,076^{*}$ & 17,75 & $(27)$ \\
X & 7 & $-7,363^{*}$ & 24,84 & $(27)$ \\
Prod & 9 & $-4,536^{*}$ & 27,86 & $(27)$ \\
& 12 & $-2,585$ & 22,90 & $(27)$ \\
Tj & 12 & $-4,423^{*}$ & 16,05 & $(27)$ \\
Pcbov & 6 & $-5,586 *$ & 20,22 & $(30)$ \\
& 12 & $-3,381$ & 16,41 & $(27)$ \\
\hline
\end{tabular}

* significativo a $1 \%$ de probabilidade

** significativo a $2,5 \%$ de probabilidade

*** significativo a $5 \%$ de probabilidade

Fonte: Dados da pesquisa.

Nas variáveis PpSP, IProd e Pcbov, todas com 12 defasagens, não se rejeita a hipótese de haver mais de uma raiz unitária. Ou seja , com este número de defasagem estas variáveis podem ser consideradas integradas de ordem 2, I (2), mas com um número de defasagem menor que 12, a hipótese de haver apenas uma raiz unitária não é rejeitada, indicando que estas séries são $\mathrm{I}(1)$ ao nível de significância de $2,5 \%$, confirmando os resultados obtidos dos testes anteriores $(\tau)$ e $\left(\tau_{\mu}\right)$. 


\subsection{2 - Testes de cointegração}

Os resultados dos testes do Traço e do Máximo Autovalor para o Modelo de Monopsônio encontram-se na Tabela 33, sugerindo que existem 5 relações de cointegração.

Tabela 33 - Resultados dos testes para determinação do número de relações de cointegração ${ }^{\mathbf{a}}$.

\begin{tabular}{ccccc}
\hline Hipótese Nula & Traço & Traço (95\%) & $\lambda_{\text {máx }}$ & $\lambda_{\text {máx }}(95 \%)$ \\
\hline$r \leq 6$ & 5,48 & 8,08 & 5,48 & 8,08 \\
$r \leq 5$ & 19,90 & 17,84 & 14,42 & 14,60 \\
$r \leq 4$ & 45,42 & 31,26 & 25,52 & 21,28 \\
$r \leq 3$ & 79,46 & 48,42 & 34,04 & 27,34 \\
$r \leq 2$ & 117,55 & 69,97 & 38,08 & 33,26 \\
$r \leq 1$ & 169,98 & - & 52,43 & - \\
$r=0$ & 253,00 & - & 83,02 & - \\
\hline
\end{tabular}

\footnotetext{
a Foi utilizado para estes testes um modelo VAR apenas com as 7 variáveis e uma constante. O número de defasagens utilizada foi de 2, de acordo com os critérios de Akaike e Schwarz. Fonte: Dados da pesquisa.
}

Conforme os resultados dos testes da Tabela 33, tem-se cinco e seis relações de cointegração, respectivamente, para os testes do Máximo Autovalor e do Traço. No primeiro caso não se rejeita a hipótese de $r \leq 5$, mas rejeita-se $r \leq 4$, o que significa que devem existir cinco relações de cointegração. Já no teste do Traço, não se rejeita a hipótese de $\mathbf{r} \leq 6$, mas sim $r \leq 5$, podendo-se considerar, neste caso, seis relações de cointegração.

Para utilização das relações no modelo VAR estruturado como correção do erro, optou-se pela utilização de cinco relações ou equações de cointegração, uma vez 
que os dois testes satisfazem a não rejeição da hipótese de $\mathbf{r} \leq \mathbf{5}$. Estas relações são provenientes da Tabela 34 .

Tabela 34 - Estimativas dos autovalores $(\lambda)$, auvetores da matriz de cointegração $(\beta)$.

Autovalores $(\lambda)$

\begin{tabular}{lllllll}
0,543 & 0,390 & 0,302 & 0,275 & 0,214 & 0,127 & 0,050 \\
\hline
\end{tabular}

\begin{tabular}{lccccccc}
\hline Autovetores $(\beta$ 's) & \multicolumn{7}{c}{ ' } \\
X & $-2,709$ & $-2,812$ & 8,269 & 8,591 & $-1,570$ & 0,027 & $-1,766$ \\
IProd & $-3,691$ & $-2,835$ & $-1,015$ & 2,027 & 0,459 & 4,519 & $-2,691$ \\
Tj & 26,630 & $-20,137$ & $-0,917$ & $-7,999$ & 7,451 & $-6,360$ & 5,939 \\
PpSP & 3,629 & 5,143 & 8,067 & $-8,518$ & $-6,739$ & 1,715 & 0,847 \\
PaSP & 13,927 & 4,165 & $-10,713$ & 8,068 & 2,734 & $-7,139$ & $-3,635$ \\
Pcbov & $-1,506$ & $-3,902$ & $-4,283$ & $-1,646$ & $-6,173$ & $-2,188$ & 0,022 \\
PvSP & $-15,453$ & $-5,892$ & 6,549 & $-2,186$ & 10,077 & 2,712 & 1,939 \\
\hline
\end{tabular}

Fonte: Dados da pesquisa.

$\mathrm{Na}$ Tabela 34 tem-se as cinco relações de cointegração relevantes que serão incorporadas como variáveis pré-determinadas, no modelo VAR com correção de erro. Estas relações, que são representadas pelas cinco primeiras colunas de autovetores $(\boldsymbol{\beta})$, são utilizadas no modelo com uma defasagem, isto é, considera-se no modelo $Z_{1 \text { t-1 }}, Z_{2 t-1}$ , ... $Z_{\mathrm{n} t-1}$. As cinco relações são:

$$
\begin{aligned}
Z_{1 t}= & -2,709 X-3,691 \mathrm{IProd}+26,630 \mathrm{Tj}+3,629 \mathrm{PpSP}+13,927 \text { PaSP } \\
& -1,506 \text { Pcbov }-15,453 \text { PvSP }
\end{aligned}
$$


112.

$$
\begin{aligned}
Z_{2 t}= & -2,812 X-2,835 \mathrm{IProd}-20,137 \mathrm{Tj}+5,143 \mathrm{PpSP}+4,165 \mathrm{PaSP} \\
& -3,902 \text { Pcbov }-5,892 \mathrm{PvSP} \\
Z_{3 t}= & 6,269 \mathrm{X}-1,015 \mathrm{IProd}-0,917 \mathrm{Tj}+8,067 \mathrm{PpSP}-10,713 \mathrm{PaSP} \\
& -4,283 \text { Pcbov }+6,549 \mathrm{PvSP} \\
Z_{4 t}= & 8,591 \mathrm{X}+2,027 \mathrm{IProd}-7,999 \mathrm{Tj}-8,518 \mathrm{PpSP}+8,068 \mathrm{PaSP} \\
& -1,646 \mathrm{pcbov}-2,186 \mathrm{PvSP} \\
Z_{5 t}= & -1,570 \mathrm{X}+0,459 \mathrm{IProd}+7,451 \mathrm{Tj}-6,739 \mathrm{PpSP}+2,734 \mathrm{PaSP} \\
& -6,173 \mathrm{Pcbov}+10,077 \mathrm{PvSP}
\end{aligned}
$$

\subsection{3 - Modelo VAR estruturado (Bernanke) com correção de erro}

Neste item apresenta-se os resultados do modelo VAR estruturado com a fatoração de Bernanke. Mediante esta fatoração pode-se especificar relações contemporâneas entre as variáveis através da matriz de interações contemporâneas Estas relações são determinadas por intermédio de um arcabouço teórico, que nesta pesquisa é representado pelo modelo monopsonista já exposto anteriormente.

A Tabela 35 apresenta as estimativas dos coeficientes da matriz $(\Gamma)$, que mostram até que ponto as restrições de identificação adotadas para o modelo são adequadas.

Conforme a Tabela 35, que deve ser interpretada com os sinais dos coeficientes trocados para se verificar o impacto de cada variável sobre as demais, os sinais obtidos das estimativas dos coeficientes foram todos coerentes com os que foram definidos no 
modelo monopsonista, com exceção dos coeficientes dos insumos de comercialização (Tj) na equação do preço ao produtor (PpSP) e da renda (X) na equação do preço de varejo (PpSP). Este último foi definido como positivo, ou seja, um aumento na renda da população elevaria os preços ao nível de varejo, mas a estimativa deste coeficiente mostrou sinal contrário ao esperado. Isto provavelmente se deve ao fato de a variável utilizada como proxy da renda da população, o índice de produção industrial, não ter sido apropriado, já que não se tem bons indicadores de renda no Brasil ${ }^{22}$.

Quanto ao coeficiente dos insumos de comercialização (Tj), na equação do preço da carne de frango ao produtor (PpSP), o sinal estimado foi positivo, contrariando o modelo teórico, o qual previa um sinal negativo. Este resultado esperado é justificado, assim como em outros estudos (AGUIAR, 1994), pelo fato de que o efeito de um aumento da taxa de juros parecer desdobrar-se em dois. Por um lado o produto passa a ter um maior custo de armazenamento e os preços devem aumentar. Por outro, o maior custo de armazenamento leva à desova do produto, visando aplicações mais rentáveis indicadas pelas taxas de juros, e os preços tendem a cair. Na equação do preço da carne de frango ao atacado (PaSP), os coeficientes estimados tiveram sinais negativo e positivo, respectivamente para as variáveis insumos de comercialização (Tj) e preço de frango ao varejo (PvSP), estando, assim, de acordo com o modelo teórico. A última equação estimada, a do preço do frango ao varejo (PvSP), também apresentou estimativas dos coeficientes coerentes com a teoria, sendo positivos os sinais da estimativa do coeficiente do preço da carne bovina no varejo (Pcbov) e dos insumos de comercialização $(\mathbf{T j})$, sendo que a única exceção foi a estimativa da renda $(\mathbf{X})$, com sinal negativo, já comentada anteriormente.

22 No modelo VAR também foram utilizadas as variáveis PIB/per capita e Salário Mínimo como indicadores de renda com resultados inconsistentes em comparação com a utilização do Índice de Produção Industrial. 
Pelo fato de apenas dois dos coeficientes estimados terem sido contrários ao esperado consideram-se adequadas as restrições impostas pelo modelo.

Tabela 35 - Matriz de interações contemporâneas $(\Gamma$ ) para modelo VAR estruturado.*

\begin{tabular}{|c|c|c|c|c|c|c|c|}
\hline \multirow[b]{2}{*}{ Equações } & \multicolumn{7}{|c|}{ Variáveis Explicativas } \\
\hline & IProd & $X$ & $\mathrm{Tj}$ & Pcbov & $\mathrm{PpSP}$ & PaSP & PvSP \\
\hline IProd & 1 & & & & & & \\
\hline$X$ & & 1 & & & & & \\
\hline $\mathrm{T} \mathbf{j}$ & & & 1 & & & & \\
\hline Pcbov & & & & 1 & & & \\
\hline \multirow[t]{2}{*}{ PpSP } & & & $-0,087$ & & 1 & & \\
\hline & & & $(0,257)$ & & & & \\
\hline \multirow[t]{2}{*}{ PaSP } & & & 0,172 & & & 1 & $-0,966$ \\
\hline & & & $(0,117)$ & & & & $(0,047)$ \\
\hline \multirow[t]{2}{*}{ PvSP } & & 0,031 & $-0,242$ & $-0,585$ & & & 1 \\
\hline & & $(0,148)$ & $(0,201)$ & $(0,077)$ & & & \\
\hline
\end{tabular}

Fonte: Dados da pesquisa.

* Entre parêntesis estão as estimativas do desvio-padrão de cada coeficiente.

A função logarítmica de verossimilhança (99) convergiu após 5 iterações.

Analisando-se cada uma das variáveis individualmente, tem-se, através da decomposição da variância dos erros de previsão, quais as variáveis importantes na explicação da variável em estudo.

Deste modo, iniciamos com o índice de custo de produção (IProd), onde, na Tabela 36, podemos verificar a decomposição da variância. Observa-se que o índice de custo de produção (IProd) é afetado moderadamente somente pela taxa de juros (Tj), pois após 12 meses esta explica cerca de $17 \%$ da variação daquela, o que implica que 
(IProd) é uma variável exógena, ou seja, é determinada através de componentes que não estão especificados no modelo teórico implícito neste trabalho.

Tabela 36 - Decomposição da variância dos erros de previsão do índice de custo de produção do frango em São Paulo (IProd) no Modelo de Monopsônio, em porcentagem*.

\begin{tabular}{cccccccc}
\hline Meses & IProd & $\mathrm{X}$ & $\mathrm{Tj}$ & Pcbov & PpSP & PaSP & PvSP \\
\hline 1 & 100 & 0,00 & 0,00 & 0,00 & 0,00 & 0,00 & 0,00 \\
2 & 68,63 & 2,80 & 18,40 & 1,24 & 3,38 & 5,49 & 0,07 \\
3 & 66,30 & 3,44 & 18,31 & 2,11 & 3,23 & 6,37 & 0,24 \\
4 & 61,93 & 3,53 & 17,24 & 2,01 & 4,66 & 8,20 & 2,43 \\
5 & 61,35 & 3,52 & 17,21 & 2,31 & 4,97 & 8,21 & 2,44 \\
6 & 61,05 & 3,51 & 17,10 & 2,43 & 4,98 & 8,44 & 2,48 \\
7 & 60,95 & 3,51 & 17,09 & 2,43 & 5,11 & 8,43 & 2,48 \\
8 & 60,94 & 3,51 & 17,08 & 2,42 & 5,13 & 8,44 & 2,48 \\
9 & 60,93 & 3,51 & 17,08 & 2,42 & 5,15 & 8,44 & 2,48 \\
10 & 60,92 & 3,51 & 17,07 & 2,42 & 5,16 & 8,44 & 2,48 \\
11 & 60,92 & 3,51 & 17,07 & 2,42 & 5,16 & 8,44 & 2,48 \\
12 & 60,91 & 3,51 & 17,07 & 2,42 & 5,17 & 8,44 & 2,48 \\
\hline
\end{tabular}

Fonte: Dados da pesquisa.

* Foram utilizados no ajustamento dados do período 1985-93.

Na Tabela 37, verifica-se que na explicação da variável índice de produção industrial (X), nenhuma das variáveis, além dela mesma, é relevante, pois decorridos 12 meses, tem-se que ela é auto-explicativa em cerca de $75 \%$ da variância do erro de previsão. Isto significa dizer que a variável $(\mathbf{X})$ é exógena. 
Tabela 37 - Decomposição da variância dos erros de previsão do índice produção industrial $(\mathrm{X})$ no Modelo de Monopsônio, em porcentagem*.

\begin{tabular}{cccccccc}
\hline Meses & IProd & $\mathrm{X}$ & $\mathrm{Tj}$ & Pcbov & PpSP & PaSP & PvSP \\
\hline 1 & 0,00 & 100 & 0,00 & 0,00 & 0,00 & 0,00 & 0,00 \\
2 & 2,95 & 92,36 & 1,10 & 0,05 & 0,77 & 2,65 & 0,13 \\
3 & 2,50 & 78,09 & 2,67 & 6,41 & 7,17 & 2,64 & 0,52 \\
4 & 3,20 & 77,60 & 2,67 & 6,34 & 7,06 & 2,60 & 0,52 \\
5 & 3,32 & 75,84 & 4,20 & 6,58 & 7,01 & 2,53 & 0,52 \\
6 & 3,33 & 75,60 & 4,30 & 6,60 & 7,13 & 2,52 & 0,53 \\
7 & 3,32 & 75,41 & 4,36 & 6,67 & 7,11 & 2,54 & 0,59 \\
8 & 3,32 & 75,36 & 4,39 & 6,70 & 7,10 & 2,54 & 0,59 \\
9 & 3,32 & 75,33 & 4,40 & 6,71 & 7,10 & 2,54 & 0,59 \\
10 & 3,32 & 75,33 & 4,40 & 6,71 & 7,10 & 2,54 & 0,59 \\
11 & 3,32 & 75,33 & 4,40 & 6,71 & 7,10 & 2,54 & 0,59 \\
12 & 3,32 & 75,33 & 4,40 & 6,71 & 7,10 & 2,54 & 0,59 \\
\hline
\end{tabular}

Fonte: Dados da pesquisa.

* Foram utilizados no ajustamento dados do período 1985-93.

A taxa de juros (Tj) também se apresentou exógena, conforme a Tabela 38, sendo que após 12 meses a variável é responsável por aproximadamente $84 \%$ da sua variância de previsão. 
Tabela 38 - Decomposição da variância dos erros de previsão da taxa de juros real $(\mathrm{Tj})$ no Modelo de Monopsônio, em porcentagem*.

\begin{tabular}{cccccccc}
\hline Meses & IProd & $\mathrm{X}$ & $\mathrm{Tj}$ & Pcbov & PpSP & PaSP & PvSP \\
\hline 1 & 0,00 & 0,00 & 100 & 0,00 & 0,00 & 0,00 & 0,00 \\
2 & 1,58 & 0,47 & 91,94 & 1,21 & 2,12 & 1,06 & 1,62 \\
3 & 1,86 & 0,62 & 86,45 & 1,41 & 2,04 & 1,89 & 5,73 \\
4 & 1,93 & 1,04 & 85,41 & 1,67 & 2,06 & 2,07 & 5,83 \\
5 & 1,94 & 1,10 & 84,52 & 1,69 & 2,79 & 2,05 & 5,90 \\
6 & 2,05 & 1,15 & 84,36 & 1,69 & 2,78 & 2,07 & 5,89 \\
7 & 2,07 & 1,18 & 84,29 & 1,69 & 2,82 & 2,07 & 5,89 \\
8 & 2,08 & 1,20 & 84,25 & 1,69 & 2,84 & 2,07 & 5,89 \\
9 & 2,08 & 1,20 & 84,24 & 1,69 & 2,84 & 2,07 & 5,89 \\
10 & 2,08 & 1,20 & 84,23 & 1,69 & 2,85 & 2,07 & 5,89 \\
11 & 2,08 & 1,20 & 84,23 & 1,69 & 2,85 & 2,07 & 5,89 \\
12 & 2,08 & 1,20 & 84,23 & 1,69 & 2,85 & 2,07 & 5,89 \\
\hline
\end{tabular}

Fonte: Dados da pesquisa..

* Foram utilizados no ajustamento dados do período 1985-93.

O preço da carne bovina (Pcbov) se mostrou exógeno pois, após um horizonte de 12 meses de previsão, a variância do erro da mesma foi de $84,8 \%$, ou seja, a variável é auto-explicativa, com as demais variáveis do modelo tendo pouca influência no nível de preço da carne bovina (Tabela 39). 
Tabela 39 - Decomposição da variância dos erros de previsão do preço da carne bovina (Pcbov) no Modelo de Monopsônio, em porcentagem*.

\begin{tabular}{cccccccc}
\hline Meses & IProd & $\mathrm{X}$ & $\mathrm{Tj}$ & Pcbov & PpSP & PaSP & PvSP \\
\hline 1 & 0,00 & 0,00 & 0,00 & 100 & 0,00 & 0,00 & 0,00 \\
2 & 1,25 & 0,70 & 1,09 & 94,04 & 2,34 & 0,58 & 0,01 \\
3 & 2,27 & 0,67 & 1,01 & 87,73 & 6,84 & 0,75 & 0,73 \\
4 & 2,51 & 0,78 & 1,47 & 85,60 & 8,08 & 0,80 & 0,76 \\
5 & 2,50 & 0,79 & 1,55 & 85,33 & 8,19 & 0,88 & 0,76 \\
6 & 2,55 & 0,81 & 1,54 & 84,90 & 8,47 & 0,92 & 0,82 \\
7 & 2,55 & 0,81 & 1,57 & 84,87 & 8,47 & 0,92 & 0,82 \\
8 & 2,55 & 0,81 & 1,57 & 84,80 & 8,52 & 0,93 & 0,82 \\
9 & 2,55 & 0,81 & 1,57 & 84,79 & 8,53 & 0,93 & 0,82 \\
10 & 2,55 & 0,81 & 1,57 & 84,78 & 8,53 & 0,93 & 0,82 \\
11 & 2,55 & 0,81 & 1,57 & 84,78 & 8,53 & 0,93 & 0,82 \\
12 & 2,55 & 0,81 & 1,57 & 84,78 & 8,53 & 0,93 & 0,82 \\
\hline
\end{tabular}

Fonte: Dados da pesquisa..

* Foram utilizados no ajustamento dados do periodo 1985-93.

A participação do preço de frango ao produtor (PpSP) na explicação da variância dos erros de sua previsão permanece alta após 12 meses, com cerca de $82,4 \%$, o que significa dizer que esta variável também é exógena, não sofrendo influência significativa das demais (Tabela 40). Este resultado confirma a hipótese de que o preço ao produtor é fixado antecipadamente aos preços dos demais níveis. Ou seja, o frigorífico estabelece com a necessária antecedência o nível de preços ao produtor que atenderá a demanda futura por carne de frango. 
Tabela 40 - Decomposição da variância dos erros de previsão do preço do frango ao produtor (PpSP) no Modelo de Monopsônio, em porcentagem*.

\begin{tabular}{cccccccc}
\hline Meses & IProd & $X$ & $T j$ & Pcbov & PpSP & PaSP & PvSP \\
\hline 1 & 0,00 & 0,00 & 0,10 & 0,00 & 99,90 & 0,00 & 0,00 \\
2 & 4,13 & 0,03 & 0,47 & 1,04 & 86,88 & 7,43 & 0,01 \\
3 & 4,76 & 0,58 & 0,43 & 1,09 & 86,82 & 6,17 & 0,16 \\
4 & 6,55 & 0,80 & 1,75 & 1,04 & 83,10 & 6,61 & 0,16 \\
5 & 6,63 & 0,77 & 1,70 & 1,03 & 83,30 & 6,40 & 0,17 \\
6 & 7,17 & 0,76 & 1,83 & 1,06 & 82,64 & 6,31 & 0,22 \\
7 & 7,17 & 0,76 & 1,90 & 1,11 & 82,54 & 6,28 & 0,22 \\
8 & 7,28 & 0,76 & 1,94 & 1,11 & 82,41 & 6,26 & 0,24 \\
9 & 7,28 & 0,76 & 1,95 & 1,12 & 82,38 & 6,26 & 0,25 \\
10 & 7,29 & 0,76 & 1,95 & 1,12 & 82,36 & 6,26 & 0,25 \\
11 & 7,29 & 0,76 & 1,95 & 1,12 & 82,35 & 6,26 & 0,26 \\
12 & 7,29 & 0,76 & 1,95 & 1,12 & 82,35 & 6,26 & 0,26 \\
\hline
\end{tabular}

Fonte: Dados da pesquisa.

* Foram utilizados no ajustamento dados do período 1985-93.

Na Tabela 41 verifica-se que o preço de atacado (PaSP) é influenciado pelos preços da carne bovina, do frango ao produtor e do frango no varejo, além do próprio preço ao atacado. A decomposição da variância dos erros de previsão do preço de atacado mostra que esta variância é atribuída, em cerca de $19,8 \%$, ao próprio preço de atacado, $31 \%$ ao preço de varejo, $18 \%$ ao preço ao produtor e $18 \%$ ao preço da carne bovina. $\mathrm{O}$ preço ao produtor de frango só passou a ter importância significativa a partir do terceiro mês, sendo que já era de se esperar uma influência relativamente forte desta variável devido à política de "markup" e à condição dos produtores possuírem contratos de venda para os atacadistas (frigoríficos ou integradoras). A influência das outras variáveis, preço de frango no varejo e preço da carne bovina, também já eram esperadas conforme modelo teórico do capítulo 3, sendo uma influência direta por parte do preço 
de frango no varejo, e indireta, por parte do preço da carne bovina. Mas esperava-se uma maior importância da variável insumos de comercialização $(\mathbf{T j})$ na explicação do preço de frango no atacado.

Tabela 41 - Decomposição da variância dos erros de previsão do prę̧o do frango no atacado (PaSP) no Modelo de Monopsônio, em porcentagem*.

\begin{tabular}{cccccccc}
\hline Meses & Prod & $X$ & Tj & Pcbov & PpSP & PaSP & PvSP \\
\hline 1 & 0,00 & 0,02 & 0,04 & 29,49 & 0,00 & 19,50 & 50,95 \\
2 & 1,71 & 1,03 & 1,54 & 24,84 & 2,68 & 25,01 & 43,20 \\
3 & 4,65 & 0,87 & 2,53 & 20,25 & 15,19 & 21,41 & 35,10 \\
4 & 6,61 & 1,16 & 3,03 & 19,55 & 14,58 & 21,41 & 33,67 \\
5 & 7,00 & 1,10 & 2,96 & 18,77 & 17,68 & 20,37 & 32,12 \\
6 & 7,65 & 1,09 & 3,29 & 18,49 & 17,79 & 20,05 & 31,64 \\
7 & 7,69 & 1,09 & 3,32 & 18,43 & 18,07 & 19,94 & 31,46 \\
8 & 7,80 & 1,09 & 3,36 & 18,34 & 18,22 & 19,85 & 31,34 \\
9 & 7,80 & 1,09 & 3,37 & 18,35 & 18,23 & 19,84 & 31,32 \\
10 & 7,82 & 1,09 & 3,37 & 18,33 & 18,25 & 19,83 & 31,31 \\
11 & 7,82 & 1,09 & 3,37 & 18,33 & 18,25 & 19,83 & 31,30 \\
12 & 7,82 & 1,09 & 3,37 & 18,33 & 18,25 & 19,83 & 31,30 \\
\hline
\end{tabular}

Fonte: Dados da pesquisa.

* Foram utilizados no ajustamento dados do período 1985-93.

Convém agora, após se determinar quais as variáveis que influenciam o preço de frango no atacado (PaSP), analisar os impactos causados por choques dinâmicos nestas variáveis em relação ao preço recebido pelas integradoras, ou seja, o preço de frango no atacado.

Após um choque de $1 \%$ nas variáveis relevantes na explicação do preço de frango no atacado tem-se um impacto positivo no preço de frango no atacado no periodo 
imediatamente após este choque, havendo alternância de sinal nestes impactos nos meses seguintes, segundo a Tabela 42 e Figuras $3.1,3.2,3.3$ e 3.4 do apêndice 3 . Mas o impacto dura pouco, pois, a partir do sétimo mês, praticamente desaparece. Os resultados obtidos estão de acordo com o modelo teórico, com efeitos positivos destas variáveis no preço de frango no atacado. 
Tabela 42 - Respostas do preço do frango no atacado em São Paulo (PaSP) no Modelo de Monopsônio, a choques no preço do frango ao produtor (PpSP), no próprio preço de frango no atacado (PaSP), no preço de frango no varejo (PvSP) e no preço da carne bovina (PcBov)*.

\begin{tabular}{|c|c|c|c|c|}
\hline Meses & Pcbov & PpSP & $\mathrm{PaSP}$ & PvSP \\
\hline 1 & 0,5647 & 0,0000 & 1 & 0,9657 \\
\hline 2 & $-0,0096$ & 0,1845 & $-0,7235$ & $-0,0805$ \\
\hline 3 & $-0,0396$ & $-0,4514$ & $-0,2905$ & $-0,0395$ \\
\hline 4 & 0,0463 & 0,0129 & 0,2607 & $-0,0028$ \\
\hline 5 & 0,0555 & 0,2555 & $-0,0144$ & $-0,0530$ \\
\hline 6 & $-0,0131$ & $-0,0826$ & $-0,0258$ & 0,0283 \\
\hline 7 & $-0,0291$ & $-0,0821$ & 0,0081 & $-0,0005$ \\
\hline 8 & 0,0092 & 0,0644 & $-0,0356$ & $-0,0330$ \\
\hline 9 & 0,0163 & 0,0202 & 0,0068 & 0,0094 \\
\hline 10 & $-0,0068$ & $-0,0271$ & 0,0260 & 0,0175 \\
\hline 11 & $-0,0091$ & $-0,0015$ & $-0,0091$ & $-0,0061$ \\
\hline 12 & 0,0020 & 0,0096 & $-0,0117$ & $-0,0059$ \\
\hline 13 & 0,0029 & $-0,0003$ & 0,0062 & 0,0037 \\
\hline 14 & $-0,0014$ & $-0,0026$ & 0,0049 & 0,0024 \\
\hline 15 & $-0,0015$ & 0,0001 & $-0,0026$ & $-0,0013$ \\
\hline 16 & 0,0003 & 0,0006 & $-0,0017$ & $-0,0008$ \\
\hline 17 & 0,0005 & 0,0001 & 0,0010 & 0,0004 \\
\hline 18 & $-9,2 E-05$ & $-0,0001$ & 0,0007 & 0,0003 \\
\hline 19 & $-0,0002$ & $-0,0002$ & $-0,0003$ & $-0,0001$ \\
\hline 20 & $9,8 \mathrm{E}-06$ & $1,8 \mathrm{E}-05$ & $-0,0003$ & $-0,0001$ \\
\hline 21 & 0,0001 & $9,2 \mathrm{E}-05$ & $8,4 E-05$ & $1,5 \mathrm{E}-05$ \\
\hline 22 & $1,5 \mathrm{E}-05$ & $-7,1 \mathrm{E}-06$ & $1,3 E-04$ & $6,4 \mathrm{E}-05$ \\
\hline .23 & $-3,9 \mathrm{E}-05$ & $-5,0 \mathrm{E}-05$ & $-1,6 \mathrm{E}-05$ & $1,2 \mathrm{E}-06$ \\
\hline 24 & $-8,2 E-06$ & $1,5 E-06$ & $-6,1 \mathrm{E}-05$ & $-3,1 E-05$ \\
\hline
\end{tabular}

Fonte: Dados da pesquisa.

* Foram utilizados no ajustamento dados do periodo 1985-93. 
A decomposição da variância na Tabela 43 , mostra que o preço do frango no varejo (PvSP) é explicado, além dele mesmo, pelo preço da carne bovina e, em menor grau, pelo preço de frango ao produtor. Após 12 meses, a parcela destas variáveis na determinação do preço de frango no varejo são respectivamente de $27,1 \%$ e $12,2 \%$. Esperava-se que a variável índice de produção industrial $(\mathbf{X})$ também explicasse uma boa parcela da variância dos preços de frango no varejo.

Tabela 43 - Decomposição da variância dos erros de previsão do preço do frango no varejo (PvSP) no Modelo de Monopsônio, em porcentagem*.

\begin{tabular}{cccccccc}
\hline Meses & IProd & $\mathrm{X}$ & $\mathrm{Tj}$ & Pcbov & PpSP & PaSP & PvSP \\
\hline 1 & 0,00 & 0,02 & 0,89 & 36,32 & 0,00 & 0,00 & 62,76 \\
2 & 1,51 & 0,04 & 8,44 & 32,76 & 0,01 & 4,16 & 53,08 \\
3 & 2,21 & 0,30 & 8,79 & 28,86 & 9,42 & 3,75 & 46,67 \\
4 & 3,20 & 0,60 & 8,66 & 28,19 & 9,66 & 3,88 & 45,81 \\
5 & 3,36 & 0,61 & 8,47 & 27,44 & 11,81 & 3,77 & 44,53 \\
6 & 3,73 & 0,62 & 8,54 & 27,24 & 11,92 & 3,75 & 44,20 \\
7 & 3,77 & 0,64 & 8,57 & 27,19 & 12,04 & 3,74 & 44,06 \\
8 & 3,83 & 0,64 & 8,60 & 27,10 & 12,15 & 3,73 & 43,94 \\
9 & 3,83 & 0,65 & 8,60 & 27,10 & 12,16 & 3,73 & 43,93 \\
10 & 3,84 & 0,65 & 8,59 & 27,09 & 12,17 & 3,74 & 43,92 \\
11 & 3,84 & 0,65 & 8,60 & 27,09 & 12,17 & 3,74 & 43,92 \\
12 & 3,84 & 0,65 & 8,60 & 27,09 & 12,18 & 3,74 & 43,91 \\
\hline
\end{tabular}

Fonte: Dados da pesquisa.

* Foram utilizados no ajustamento dados do período 1985-93.

As respostas do preço do frango no varejo (PvSP) devidas a um choque de $1 \%$ no preço da carne bovina (PcBov), no preço de frango ao produtor (PpSP), e no próprio preço de frango ao varejo (PvSP), estão na Tabela 44 e Figuras 3.5, 3.6 e 3.7 do 
apêndice 3. O preço do frango no varejo reage positivamente a um choque no preço da carne bovina, pois são dois produtos concorrentes e que, portanto, se o preço de um deles aumenta, a população o substitui pelo outro, elevando a demanda que, por consequência, ocasiona uma alta no preço deste. Os impactos do choque nas variáveis persistem até o sexto mês, a partir do qual estes impactos tornam-se muito pequenos. Os efeitos de um choque no preço de frango ao produtor em relação ao preço de frango no varejo são variados, com alternância de sinal. Notar, porém, que o preço da carne bovina é exógena no contexto deste modelo. 
Tabela 44 - Respostas do preço do frango no varejo em São Paulo (PvSP) no Modelo de Monopsônio, a choques no preço da carne bovina (PcBov), no preço de frango ao produtor (PpSP) e no próprio preço de frango ao varejo*.

\begin{tabular}{|c|c|c|c|}
\hline Meses & Pcbov & PpSP & PvSP \\
\hline 1 & 0,5847 & 0,0000 & 1 \\
\hline 2 & 0,1508 & $-0,0096$ & 0,0159 \\
\hline 3 & $-0,0310$ & $-0,3434$ & $-0,0197$ \\
\hline 4 & 0,0121 & 0,0766 & $-0,0736$ \\
\hline 5 & 0,0410 & 0,1801 & $-0,0565$ \\
\hline 6 & $-0,0061$ & $-0,0513$ & 0,0151 \\
\hline 7 & $-0,0215$ & $-0,0462$ & 0,0002 \\
\hline 8 & 0,0026 & 0,0442 & $-0,0177$ \\
\hline 9 & 0,0069 & 0,0137 & 0,0082 \\
\hline 10 & $-0,0068$ & $-0,0171$ & 0,0123 \\
\hline 11 & $-0,0071$ & $-0,0004$ & $-0,0029$ \\
\hline 12 & 0,0004 & 0,0065 & $-0,0031$ \\
\hline 13 & 0,0012 & $-0,0004$ & 0,0027 \\
\hline 14 & $-0,0012$ & $-0,0017$ & 0,0016 \\
\hline 15 & $-0,0010$ & 0,0002 & $-0,0008$ \\
\hline 16 & 0,0002 & 0,0004 & $-0,0004$ \\
\hline 17 & 0,0003 & $5,3 \mathrm{E}-06$ & 0,0003 \\
\hline 18 & $-6,2 E-05$ & $-9,7 \mathrm{E}-05$ & 0,0002 \\
\hline 19 & $-0,0001$ & $-8,6 \mathrm{E}-05$ & $-9,1 \mathrm{E}-05$ \\
\hline 20 & $2,6 E-05$ & $7,6 \mathrm{E}-06$ & $-9,0 \mathrm{E}-05$ \\
\hline 21 & $7,0 \mathrm{E}-05$ & $4,9 \mathrm{E}-05$ & $9,6 \mathrm{E}-06$ \\
\hline 22 & $1,2 \mathrm{E}-05$ & $-6,6 \mathrm{E}-06$ & $3,5 \mathrm{E}-05$ \\
\hline 23 & $-2,1 \mathrm{E}-05$ & $-3,0 \mathrm{E}-05$ & $-3,0 \mathrm{E}-06$ \\
\hline 24 & $-1,9 \mathrm{E}-06$ & $1,4 \mathrm{E}-06$ & $-2,0 E-05$ \\
\hline
\end{tabular}

Fonte: Dados da pesquisa.

* Foram utilizados no ajustamento dados do período 1985-93. 
126.

\section{6 - CONCLUSÕES}

No período em estudo, 1985 a 1993, ocorreram muitas mudanças na cadeia produtiva do frango, principalmente pelo aparecimento, fortalecimento e alastramento da integração vertical nas principais regiões produtoras de frango do Brasil, que se refletiram nos preços de mercado de modo a proporcionar aumentos gradativos na produtividade e, consequentemente, nas quantidades produzida e consumida, com queda de preços a níveis bem baixos, como os encontrados hoje. Quanto ao consumidor, este tem sido beneficiado, pois tem à sua disposição um alimento de qualidade a baixo preço e que é uma alternativa saudável e rentável quando comparada aos outros alimentos similares. As repercussões que estes avanços do' setor com a integração vertical tiveram nos demais segmentos relacionados à avicultura foram os melhores possíveis para os segmentos de suporte, como os de remédios, milho, soja, rações, equipamentos e instalações, entre outros, pois houve um aumento significativo na demanda destes itens, proporcionando aumento no crescimento destes segmentos. Pelo lado dos outros tipos de carne, como a suína e a bovina, as repercussões não foram das melhores, pois estas tiveram perda muito grande de consumo relativo, já que o consumo "per capita" de frango cresce a cada ano, enquanto o dos outros tipos de carne não acompanha na mesma magnitude.

Este trabalho, por um lado, teve como objetivos analisar a evolução do mercado de frango no Brasil e, por outro, estudar o processo de formação de preços neste mercado. Apresentou também, duas análises relacionadas ao mecanismo de formação de preços no mercado de frango para o período de 1985 a 1993. Procurou-se verificar : a) A 
existência de integração entre os mercados dos estados de São Paulo, Paraná e Santa Catarina, através das relações existentes entre estes no que se refere ao processo de formação de preços. Nesta análise utilizou-se o Modelo da Integração (modelo VAR convencional), sem uma estrutura econômica pré-definida, mas com a ordenação das variáveis no vetor obedecendo uma estrutura empirica baseada na teoria da integração vertical na região centro-sul do Brasil. b) De acordo com o modelo monopsonista elaborado no capítulo 3, as relações de preços entre os três níveis do mercado de frango e o nível de interação destes com os demais mercados, como carne bovina, milho e soja (insumos de produção). Para tanto, foi utilizado o modelo VAR com procedimento de Bernanke no Modelo de Monopsônio.

- $O$ Os resultados da estimação do Modelo da Integração (modelo VAR convencional com correção de erro), mostraram coerência em toda a análise, pois, como era esperado, o preço do frango em Santa Catarina mostrou-se exógeno e importante na determinação do preço do frango em São Paulo e Paraná. O preço do frango em São Paulo, conjuntamente com o de Santa Catarina, mostrou-se importante na formação do preço de frango no Paraná. Estes resultados refletem a influência da integração vertical do mercado catarinense, notadamente pela importância deste mercado sobre os demais. A influência de São Paulo sobre o preço no Paraná reflete possivelmente a maior importância e tamanho do mercado consumidor paulista em relação a este. Nas respostas dos preços a choques fica evidente o alto grau de integração da avicultura nesta região do país, pois os impactos duravam no máximo oito meses com um rápido ajuste do mercado destes estados a choques nos preços.

A estimação do Modelo de Monopsônio para o Estado de São Paulo, mostrou que o modelo teórico proposto foi bem definido, apesar de terem sido estimados alguns coeficientes com sinais contrários aos indicados pelo modelo. De acordo com os 
resultados, verificou-se que o preço de frango a nível de produtor não foi explicado por nenhuma outra variável além dele próprio, justificando a hipótese de que seu valor é fixado pelos frigoríficos com antecedência em relação aos preços nos demais níveis. Já o preço de atacado mostrou sofrer influência dos preços de frango ao produtor e varejo, e dos da carne bovina. O preço do frango ao nível de varejo mostrou ser influenciado pelo preço da carne bovina e pelo preço do frango ao produtor. Estes são os principais resultados obtidos pelo modelo, pois dizem respeito apenas ao mercado de frango. Segundo o modelo teórico, esperava-se que o preço do frango no varejo recebesse a influência da taxa de juros, utilizada como proxy de insumos e comercialização, e do índice de produção industrial, utilizada como proxy da renda da população. Em relação à renda, isto não ocorreu devido, provavelmente, primeiro a esta não ser a melhor variável a ser utilizada como indicadora de renda, apesar de ter fornecido melhores resultados que o salário mínimo e o PIB "per capita", e segundo, principalmente pelo fato do mercado avícola não responder a variações na renda da população, mas sim a variações de preço, pois neste mercado a formação de preço relaciona-se mais a itens de custo de produção/comercialização e à concorrência direta de produtos alternativos. Em relação ao preço de frango ao produtor, a única variável que se esperava ter um efeito mais significativo do que o encontrado, foi o índice de custo de produção, o qual não influenciou o preço de frango ao produtor. O preço do frango no atacado foi explicado pelas variáveis preço da carne bovina, preço do frango ao produtor e preço do frango ao varejo, além do próprio preço. Estes resultados se mostraram coerentes com o modelo teórico, com exceção da variável insumos de comercialização, a qual esperava-se que tivesse uma influência significativa.

Todas as hipóteses testadas nas duas análises foram satisfeitas, com exceção da hipótese da interação do mercado de frango com outros mercados como os de milho e 
soja. Isto porque o índice de custo de produção, que agregou os preços de milho e soja através de um índice de custo de produção, de modo a representar os custos de produção com ração, não se mostrou significativo na formação do.preço do frango, principalmente ao nível de produtor. Já com o mercado de carne bovina, os resultados mostraram-se bem concisos e previsíveis, com forte influência da carne bovina na formação dos preços e no mercado de frango em São Paulo. As outras hipóteses que se referiam à predominância de variações pelo lado da oferta, e existência de um sistema de "markup" na formação de preços, foram plenamente satisfeitos, de acordo com os resultados das análises de choques e decomposição da variância dos preços envolvidos. Quanto à hipótese referente ao Modelo da Integração, de que os mercados de frango no Sul e Sudeste do país deveriam estar bem interagidos, e que Santa Catarina deveria desempenhar um importante papel na formação dos preços nos demais Estados, também foi plenamente satisfeita, conforme mostram os resultados.

No que se refere a aspectos metodológicos, foram utilizados, satisfatoriamente, testes de raiz unitária e cointegração, principalmente através do método de Johansen, o qual resultou nas relações de cointegração utilizadas nas estimações dos modelos de autoregressão vetorial (VAR), propiciando estimativas estáveis e coerentes com a teoria econômica. Além de ter sido proposto um modelo teórico para se analisar o mercado de frango, o modelo monopsonista, que se mostrou adequado à análise dinâmica dos modelos de autoregressão vetorial (VAR).

De modo geral o presente trabalho atingiu os objetivos previamente estabelecidos, que eram os de determinar as relações de preços existentes no mercado de frango entre as principais regiões produtoras do país, e as relações de preços existentes em um mesmo mercado, notadamente o de São Paulo, e suas interações com outros mercados como a de carne bovina e a de insumos de produção. 
130.

\section{7 - REFERÊNCIAS BIBLIOGRÁFICAS}

AGUIAR, D. R. D. Custo, risco e margem de comercialização de arroz e de feijão no estado de São Paulo : análise dinâmica e teste de modelos alternativos. Piracicaba. (Doutorado - Escola Superior de Agricultura Luiz de Queiroz/USP). 1994.

ALEXANDER, C. \& WYETH, J. Cointegration and market integration : an application to the Indonesian rice market. The Journal of Development Studies 30 (2) : 303328. Jan. 1994.

AUBONE, A. Notas sobre vectores autoregressivos (V.A.R.). Revista de Econometria VIII (1) : 99-110. Jan/Jun. 1988.

APA. Revista aves e ovos. Associação Paulista de Avicultura. São Paulo. Vários números.

BABULA, R. A. \& BESSLER, D. A. The Corn-Egg Price Transmission Mechanism. Southern Journal of Agricultural Economics : 79 - 86. December 1990.

BACCHI, M. R. P. Previsão de preços de bovino, suino e frango com modelos de séries temporais. Piracicaba. 1994.166p. (Doutorado - Escola Superior de Agricultura Luiz de Queiroz/ ESALQ - USP).

BAILEY, D. A. \& BRORSEN, B. W. Dynamics of regional fed cattle prices. Western Journal of Agricultural Economics 10 : 126 - 133. 1985. 
BANERJEE, A. ; DOLADO, J. J. ; HENDRY, D. F. \& SMITH, G.W. Exploring Equilibrium Relationships in Econometrics Through Static Models : Some Monte Carlo Evidence . Oxford Bulletin of Economists and Statistics 48 (3) : 253 - 277. 1986.

BARROS, G. C. Economia da comercialização agrícola. Piracicaba. FEALQ. 1987. $306 \mathrm{p}$.

BARROS, G. C. Transmissão de preços pela central de abastecimento de São Paulo, Brasil. Revista Brasileira de Economia , 44 (1) : 5 - 20. Jan./mar. 1990.

BARROS, G. C. Impacts of monetary and real factors on the US dollar in identifiable VAR models. Revista Brasileira de Economia 45 (4) : 519 - 541. Out./ Dez. 1991.

BESSLER, D. A. An Analysis of Dynamic Economic Relationships : an Application to the U.S. Hog Market. Canadian Journal of Agricultural Economics 32 : 109 124. March 1984.

BESSLER, D. A. \& COVEY, T. On the search for econometric structure in agriculture. American Journal of Agricultural Economics 75: 41 - 47. Oct. 1993.

BLAIR, R. D. \& KASERMAN, D. L. Law and economics of vertical integration and control. N. York. Academic Press. 1983. 211 p.

BOX, G. \& JENKINS, G. Time series analysis, forecasting and control. San Francisco : Holden-Day. 1970.

BRANDÃO, A. S. P. Moeda e preços relativos : evidência empírica. Revista de Econometria 5 (2): 33 - 80. 1985. 
BRAUN, P. A. \& MITTNIK, S. Misspecifications in VAR and their Effects on Impulse Responses and Variance Decompositions. Journal of Econometrics 59: 319-341. 1993.

BRORSEN, B. W. ; CHAVAS, J. P. ; GRANT, W. R. ; SCHNAKE, L. D. Marketing margins and price uncertainty : the case of the U.S. wheat market. American Journal of Agricultural Economics, 67 : 521 - 528. 1985.

BURNQUIST, H. L. Identifying effects of the macroeconomy on brazilian agricultural prices. PhD dissertation. Cornell University. May, 1992.

CAMPBELL, J. Y. \& PERRON, P. Pitfalls and opportunities : what macroeconomists should know about unit roots. NBER Macroeconomics Annual 1991 : 141-201. 1991.

CHAVAS, J. P. Structural change in the demand for meat. American Journal of Agricultural Economics 65 : 148 - 153. Feb. 1983.

CHOI, I. Durbin-Hausman tests for cointegration. Journal of Economic Dynamics and Control 18 (2) : 467-480. March 1994.

COCHRANE, J. H. A critique of the application of unit root tests. Journal of Economic Dynamics and Control 15 : 275-284. 1991.

COOLEY, T. F. \& LE ROY, S. F. Atheoretical macroeconometrics, a critique. Journal of Monetary Economics 16 : 283 - 308. 1985.

DICKEY, D. A. \& FULLER, W. A. Distributions of the estimators for autoregressive time series with a unit root. Journal of the American Statistical Association 74 : 427 - 431. 1979.

DICKEY, D. A. \& FULLER, W. A. The likelihood ratio statistics for autoregressive time series with a unit root. Econometrica 49: 1057 - 1072. 1981. 
DICKEY, D. A. \& PANTULA, S. G. Determining the order of differencing in autoregressive processes. Journal of Business and Economic Statistics 5 : 455 462. 1987.

DOAN, T. A. \& LITTERMAN, R. B. Rats - User's manual version 3.1. 1990.

DOAN, T. A. \& LITTERMAN, R. B. Rats - User's manual version 4.0. 1992.

DOLADO, J.J. ; JENKINSON, T. \& SOSVILLA-RIVERO, S. Cointegration and unit roots. Journal of Economic Surveys 4 (3) : 249-273. 1990.

ENGLE, R .F. \& GRANGER, C. W. J. Cointegration and Error Correction: Representation, Estimation and Testing. Econometrica 55 : 251 - 276. 1987.

ENGLE, R. F. \& ISSLER, J. V. Estimating sectoral cycles using cointegration and common features. Ensaios econômicos EPGE - FGV n0 232. Março/1994.

ENGLE, R. F. \& YOO, S. Forecasting and testing in cointegrated systems. Journal of Econometrics 35 : $143-159.1987$.

FAMINOW, M. D. \& LAUBSCHER, J. M. Empirical testing of alternative price spread models in the South African maize market. Agricultural Economics, $6: 49$ $-66.1991$.

FERREIRA, P. C. \& ISSLER, J. V. Testing the externalities hypothesis of endogenous growth using cointegration. Ensaios econômicos EPGE - FGV no 236. Abril/1994.

FGV. Acompanhamento conjuntural da agropecuária. Fundação Getúlio Vargas. Rio de Janeiro. Vários números.

FGV. Conjuntura econômica. Fundação Getúlio Vargas. Rio de Janeiro, diversos. 
FIBGE. Anuário estatístico do Brasil. Fundação Instituto Brasileiro de Geografia e Estatística. Rio de Janeiro, vários.

FULLER, W. A. Introduction to Statistical Time Series. New York. John Wiley and Sons, Inc. 1976.

GARDNER, B. L. The farm-retail price spread in a competitive food industry. American Journal of Agricultural Economics, 57 : 399 - 409. 1975.

GIANNINI, C. \& MOSCONI, R. Predictions from unrestricted and restricted VAR models. Giornale Degli Economisti e Annali di Economia 5 - 6 : 291 - 316. Ano XIVI. Universitá Comerciale Luigi Bocconi. Maggio- Giugno 1987.

GIULIETTI, N. ; CRISCUOLO, P. D. ; LINS, E. R. ; PACKER, I. U. ; NAKANO, M. ; CANCEGLIERO, F. L. B. e TOLEDO, Y. I. M. de . Diagnóstico da avicultura no Brasil, 1970 - 78 : contribuição para um programa de desenvolvimento. São Paulo, Secretaria da Agricultura, Instituto de Economia Agrícola. (Relatório de Pesquisa, 07). 1980. 278 p.

GOODWIN, B. K. \& SCHROEDER, T. C. Cointegration tests and spatial price linkages in regional cattle markets. American Journal of Agricultural Economics 73 (2) : 452 - 464. May 1991.

GRANGER, C. W. J. The typical spectral shape of an economic variable. Econometrica 34 : 150 - 161. 1966.

GRANGER, C. W. J. Some Properties of Time Series Data and Their Use in Econometric Model Specification. Journal of Econometrics 16 : 121-130. 1981.

GRANGER, C. W. J. Developments in the Study of Cointegrated Economic Variables. Oxford Bulletin of Economists and Statistics 48 (3) : 213-228. Aug. 1986.

GRANGER, C. W. J. \& NEWBOLD, P. Spurious regressions in econometrics. Journal of Econometrics 2: 111 - 120. 1974. 
GRANGER, C. W. J. \& NEWBOLD, P. Forecasting economic time series. $2^{\text {a }}$. ed. New York. Academic Press. 1986.

GREENE, W. H. Econometric analysis. $2^{\text {a }}$. ed. Macmillan. 1993. 791 p.

GRIFFITHS, W. E. ; HILL, R. C. \& JUDGE, G. G. Learning and practicing econometrics. New York. John Wiley \& Sons, Inc. 1993. 866 p.

GUIMARÃES, V. D. A. Comercialização e transmissão de preços de carne de frango no estado de São Paulo. Piracicaba. (Mestrado - Escola Superior de Agricultura Luiz de Queiroz/USP). 1990. 119 p.

HAKKIO, C. S. \& MORRIS, C. S. Vector autoregressions : a user's guide. Research Division. Federal Reserve Bank of Kansas City. November 1984. 82 pgs.

HALLAM, D. ; MACHADO, F. \& RAPSOMANIKIS, G. Co-integration analysis and the determinants of land prices. Journal of Agricultural Economics 43 (1) : 28-37. 1992.

HEIEN, D. M. Markup pricing in a dynamic model of food industry. American Journal of Agricultural Economics., $62: 10$ - 18. 1980.

HENDRY, D. F. Econometric modelling with cointegrated variables : an overview. Oxford Bulletin of Economics and Statistics 48 (3) : 201 - 212. Aug. 1986.

IEA. Informações Econômicas. Secretaria de Agricultura e Abastecimento, Instituto de Economia Agrícola. São Paulo, diversos.

INSTITUTO CEPA/SC. Síntese anual da agricultura de Santa Catarina. Florianópolis. Secretaria da Agricultura e do Abastecimento. Vários.

JOHANSEN, S. Statistical analysis of cointegration vectors. Journal of Economic Dynamics and Control 12 : 231-254. 1988. 
JOHANSEN, S. Estimation and hypothesis testing of cointegration vectors in Gaussian vector autoregressive models. Econometrica 59: 1551-1580. 1991.

JOHANSEN, S. \& JUSELIUS, K. Maximum likelihood estimation and inference on cointegration - with applications to the demand for money. Oxford Bulletin of Economics and Statistics 52 (2) : 169-210. 1990.

JUDGE, G. G. ; HILL, R. C. ; GRIFFITHS, W. E. ; LUTKEPOHL, H. \& LEE, T. C. Introduction to theory and practice of econometrics. Second edition. J. Wiley \& Sons. 1988. 1024 pgs.

JUSELIUS, K. Manual to cointegration analysis of time series - Cats in Rats. Institute of Economics. University of Copenhagen. March 1991.38 pgs.

$\mathrm{KOCH}$, J. V. Industrial organization and prices. Prentice-Hall, Inc., Englewood Cliffs, New Jersey, 1980.

LILIEN, D. M. \& HALL, R. E. Micro TSP - user's manual version 6.5. 1989.

LIMA, M. A. A. Mudança tecnológica, organização industrial e expansão da produção de frango de corte no Brasil. S. Paulo. 192 p. (Mestrado - Faculdade de Economia e Administração/USP). 1984.

LIMA, E. C. ; LOPES, H. F. ; MOREIRA, A. R. B. e VALLS PEREIRA, P.L. Tendências estocásticas do produto : efeito de flutuações da produtividade e da taxa de juros real. In : Anais do XV Encontro Brasileiro de Econometria Vol.2. Belo Horizonte. Dez. 1993.

LLOYD, T. A. \& RAYNER, A. J. Co-integration analysis and the determinants of land prices : comment. Journal of Agricultural Economics 44 (1) : 149-156. 1993.

LUCE, F. B. \& KARSTEN, R. Análise competitiva da indústria de frangos do Rio Grande do Sul. Revista de Administração / USP. Vol.27 (1). 1992. 
LUTKEPOHL, H. Introduction to Multiple Time Series Analysis. Springer-Verlag. Berlin, Heidelberg. 1991. 545 pgs.

LYON, C. C. \& THOMPSON, G. D. Temporal and spacial aggregation : alternative marketing margin models. American Journal of Agricultural Economics, 75 : 523-536. 1993.

MADDALA, G. S. Introduction to Econometrics. MacMillan Publishing Company. New York. 1988. 472 pgs.

MARQUES, P. V. Economia da integração vertical na avicultura de corte no estado de São Paulo. Piracicaba. (Livre-Docência - Escola Superior de Agricultura Luiz de Queiroz/USP). 1991.

MARQUES, P.V. \& AGUIAR, D.R. Comercialização de produtos agrícolas. Edusp. São Paulo. 1993. 295 p.

MELLANDER, E. ; VREDIN, A. \& WARNE, A. Stochastic trends and economic fluctuations in a small open economy. Journal of applied econometrics 7 : 369394. 1992.

MOOSA, I. A. The demand for money in India : a cointegration approach. The Indian Economic Journal 40 (1) : 101-115. 1992.

MORETTIN, P. A. \& TOLOI, C. M. Previsão de séries temporais. Atual . São Paulo. 1985. $436 \mathrm{p}$.

MOUNT, T. D. Policy analysis with time-series econometric models : discussion. American Journal of Agricultural Economics 71 : 507-508. 1989.

NELSON, C. R. \& PLOSSER, C. I. Trends and random walks in macroeconomic time series. Journal of Monetary Economics 10 : $139-162.1982$. 
NERLOVE, M. ; GRETHER, D. \& CARVALHO, J. Analysis of economic time series. New York. Academic Press. 1979.

ORDEN, D. \& FACKLER, P. L. Identifying monetary impacts on agricultural prices in VAR models. American Journal of Agricultural Economics 71 : 495 - 502. 1989.

PALASKAS, T. \& VARANGIS, P. Primary commodity prices and macroeconomic variables : a long-run relationship. Policy, Planning and Research Working Papers, International Commodity Markets Division, International Economics Department. World Bank. Washington, D.C. 1989.

PANTULA, S. G. Testing for unit roots in time series data. Econometric Theory 5: 256 - 271. 1989.

PERRY, M. K. Vertical integration: the monopsony case. The American Economic Review 68 (4) : 561 - 570. Sept. / 1978.

PHILLIPS, P. C. B. Understanding spurious regressions in econometrics. Journal of Econometrics 33 : 311 - 340. 1986.

PHILLIPS, P. C. B. Time series regression with a unit root. Econometrica 55 (2) : 277-301. March 1987.

PHILLIPS, P. C. B. Optimal Inference in Cointegrated Systems. Econometrica 59 (2) : 283-306. March, 1991.

PHILLIPS, P.C.B. \& PERRON, P. Testing for a Unit Root in Time Series Regresion. Biometrika 74 : 575-547. 1988.

PINDYCK, R. S. \& RUBINFELD, D. L. Econometric models and economic forecasts. $3^{\mathrm{a}}$. ed. Singapore. McGraw-Hill. 1991. $596 \mathrm{p}$. 
PORTUGAL, M. S. Um Modelo de Correção de Erros para a Demanda por Importações Brasileira. Revista de Pesquisa e Planejamento Econômico 22 (3) : 501-540. Dez. 1992.

RAVALlion, M. Testing market integration. American Journal of Agricultural Economics 68 : 102 - 109. Feb. 1986.

ROBERTSON, J. C. \& ORDEN, D. Monetary impacts on prices in the short and long run : some evidence from New Zeland. American Journal of Agricultural Economics 72 : 160-171. 1990.

ROSSI, J. W. Determinação da taxa de câmbio : testes empíricos para o Brasil. Revista de Pesquisa e Planejamento Econômico 21 (2) : 397-412. Ago. 1991.

SARKER, R. A maximum likelihood cointegration analysis of canadian lumber exports. Canadian Journal of Agricultural Economics 41 : 97-110. 1993.

SCHROEDER, T. C. \& GOODWIN, B. K. Regional Fed Cattle Price Dynamics. Western Journal of Agricultural Economics 15 (1) : 111-122. 1990.

SECRETARIA DA AGRICULTURA E ABASTECIMENTO, DERAL/PR. Acompanhamento da Situação agropecuária do Paraná. Curitiba, vários.

SIMS, C. A. Macroeconomics and reality. Econometrica 48 : 1 - 48. 1980.

SIMS, C. A. Are forecasting models usable for policy analysis ? Quarterly review federal reserve bank of Minneapolis. Winter, 1986.

SIMS, C. A. Models and their uses. American Journal of Agricultural Economics 71 : 489 - 494. 1989.

STOCK, J. H. Asymptotic properties of least squares estimators of cointegration vectors. Econometrica 55 : 1035 - 1056. 1987. 
THOMPSON, G. D. \& LYON, C. C. Marketing order impacts on farm-retail price spreads : the suspension of prorates on California-Arizona navel oranges. American Journal of Agricultural Economics, $71: 647-660.1989$.

VALLS PEREIRA, P. L. Co-integração e suas representações : uma resenha. Revista de Econometria 11 (2) : 185-216. Nov. 1991.

VELASCO, A. M. ; GALAN, V. B. \& BACHA, C. J. C. Proposta de metodologia para o cálculo de custo de rações utilizadas na pecuária brasileira. Informe GEP/DESR - ESALQ/USP 7 (06) : 1 - 14. Jun. 1994.

WILLIAMS, C. H. \& BEWLEY, R. A. The Transmission of Price Information at Queensland Cattle Auctions. Discussion Paper. The University of New South Wales. October, 1991.

WILLIAMS, C. H. \& BEWLEY, R. A. Price arbitrage between Queensland cattle auctions. Australian Journal of Agricultural Economics 37 (1) : 33-55. 1993.

ZAPATA, H. O. \& GARCIA, P. Price Forecasting With Time-Series Methods and Nonstationary Data: an Application to Monthly U.S. Cattle Prices. Western Journal of Agricultural Economics 15 (1) : 123-132. 1990.

ZINI Jr., A. A. Três estudos sobre inflação, taxa de câmbio e reforma monetária no Brasil. São Paulo. 1993. 185 p. ( Livre Docência - Faculdade de Economia e Administração - FEA/USP ).

ZIRLIS et alii. Integração vertical, custos e receitas na avicultura de corte, no estado de São Paulo. Agricultura em São Paulo, SP. 37 (3) : 147-173. 1990. 
141.

\section{A P Ê N D I C E 1}

Estatísticas dos testes de Raiz Unitária e de Cointegração 
142.

Tabela 1.1 - Distribuição de probabilidade de $\tau$ para $\rho=1^{23}$

\begin{tabular}{ccccc}
\hline $\begin{array}{c}\text { Tamanho da } \\
\text { amostra } \\
N\end{array}$ & 1 & 2,5 & 5 & 10 \\
\hline & \multicolumn{4}{c}{$\begin{array}{c}\text { Probabilidade } \\
\%\end{array}$} \\
50 & $-2,62$ & (sem constante e sem tendência) & \\
100 & $-2,60$ & $-2,25$ & $-1,95$ & $-1,61$ \\
$\infty$ & $-2,58$ & $-2,24$ & $-1,95$ & $-1,61$ \\
& $-2,23$ & $-1,95$ & $-1,62$ \\
50 & $-3,58$ & $\tau \mu($ com constante e sem tendência) & $-2,60$ \\
100 & $-3,51$ & $-3,22$ & $-2,93$ & $-2,58$ \\
$\infty$ & $-3,43$ & $-3,17$ & $-2,89$ & $-2,57$ \\
50 & $-4,15$ & $-3,12$ & $-2,86$ & $-3,18$ \\
100 & $-4,04$ & $-3,80$ & $-3,50$ & $-3,15$ \\
$\infty$ & $-3,96$ & $-3,66$ & $-3,45$ & $-3,12$ \\
\hline
\end{tabular}

Fonte : FULLER (1976) e DICKEY \& FULLER (1981).

23 Esta tabela foi construida por David Dickey utilizando o método de Monte Carlo. 
Tabela 1.2 - Distribuição de probabilidade dos testes de Máximo Autovalor $\left(\lambda_{\text {max. }}\right)$ e Traço da matriz estocástica para variável com tendência.

\begin{tabular}{ccccccc}
\hline Dimensão & $50 \%$ & $80 \%$ & $90 \%$ & $95 \%$ & $97,5 \%$ & $99 \%$ \\
\hline \multicolumn{7}{c}{ Máximo } \\
& \multicolumn{7}{c}{ Autovalor } \\
1 & 2,415 & 4,905 & 6,691 & 8,083 & 9,658 & 11,576 \\
2 & 7,474 & 10,666 & 12,783 & 14,595 & 16,403 & 18,782 \\
3 & 12,707 & 16,521 & 18,959 & 21,279 & 23,362 & 26,154 \\
4 & 17,875 & 22,341 & 24,917 & 27,341 & 29,599 & 32,616 \\
5 & 23,132 & 27,953 & 30,818 & 33,262 & 35,700 & 38,858 \\
& & & & & & \\
& & & Traço & & & \\
1 & 2,415 & 4,905 & 6,691 & 8,083 & 9,658 & 11,576 \\
2 & 9,335 & 13,038 & 15,583 & 17,844 & 19,611 & 21,962 \\
3 & 20,188 & 25,445 & 28,436 & 31,256 & 34,062 & 37,291 \\
4 & 34,873 & 41,623 & 45,248 & 48,419 & 51,801 & 55,551 \\
5 & 53,373 & 61,566 & 65,956 & 69,977 & 73,031 & 77,911 \\
\hline
\end{tabular}

Fonte: JOHANSEN \& JUSELIUS (1990). 
144.

\section{A P Ê N D I C E 2}

Figuras da análise de auto-regressão vetorial (VAR) convencional com correção de erro 
145.

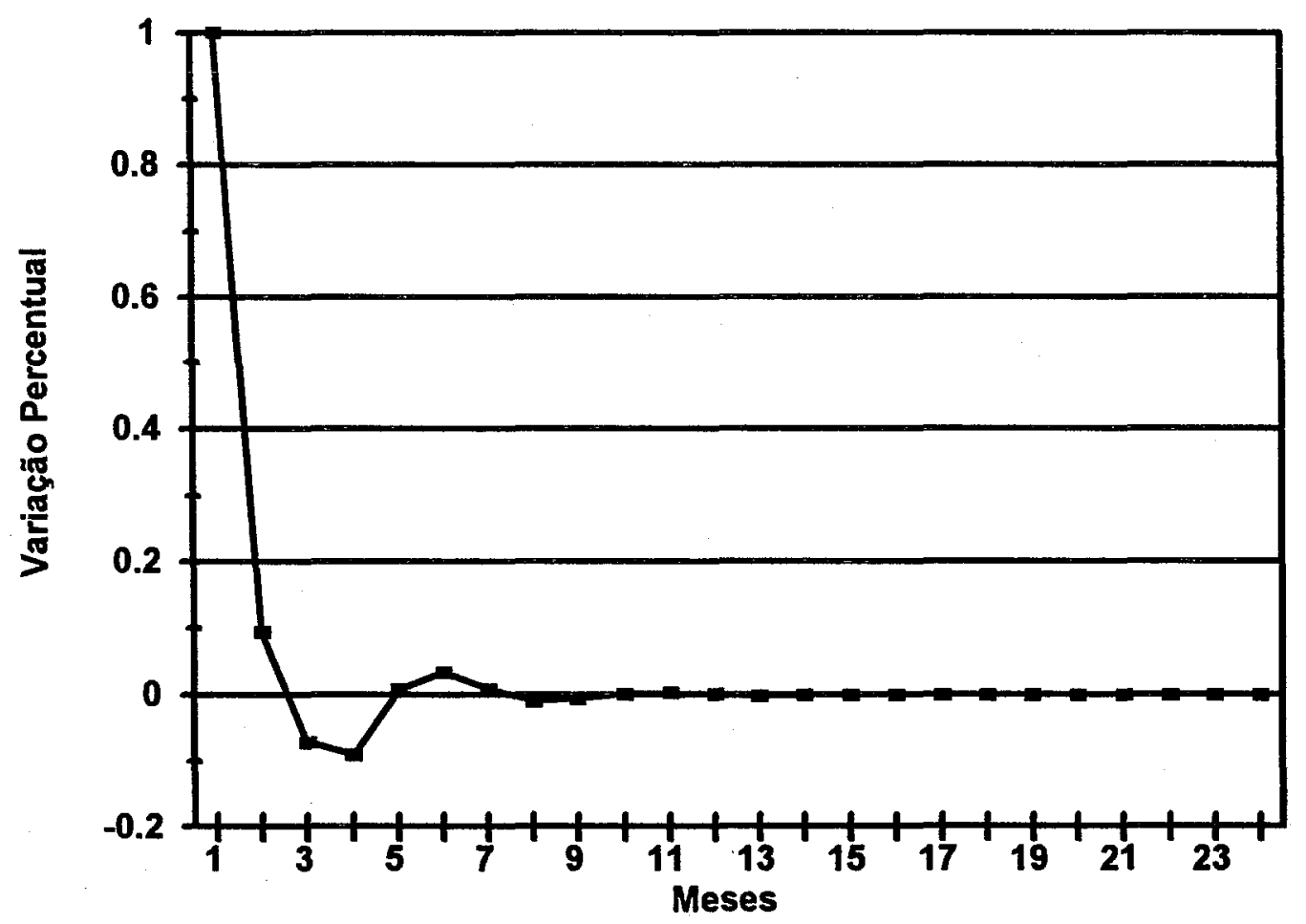

Figura 2.1 - Respostas do preço do frango em SC a um choque de um desvio-padrão nele mesmo - modelo VAR convencional com correção de erro. 
146.

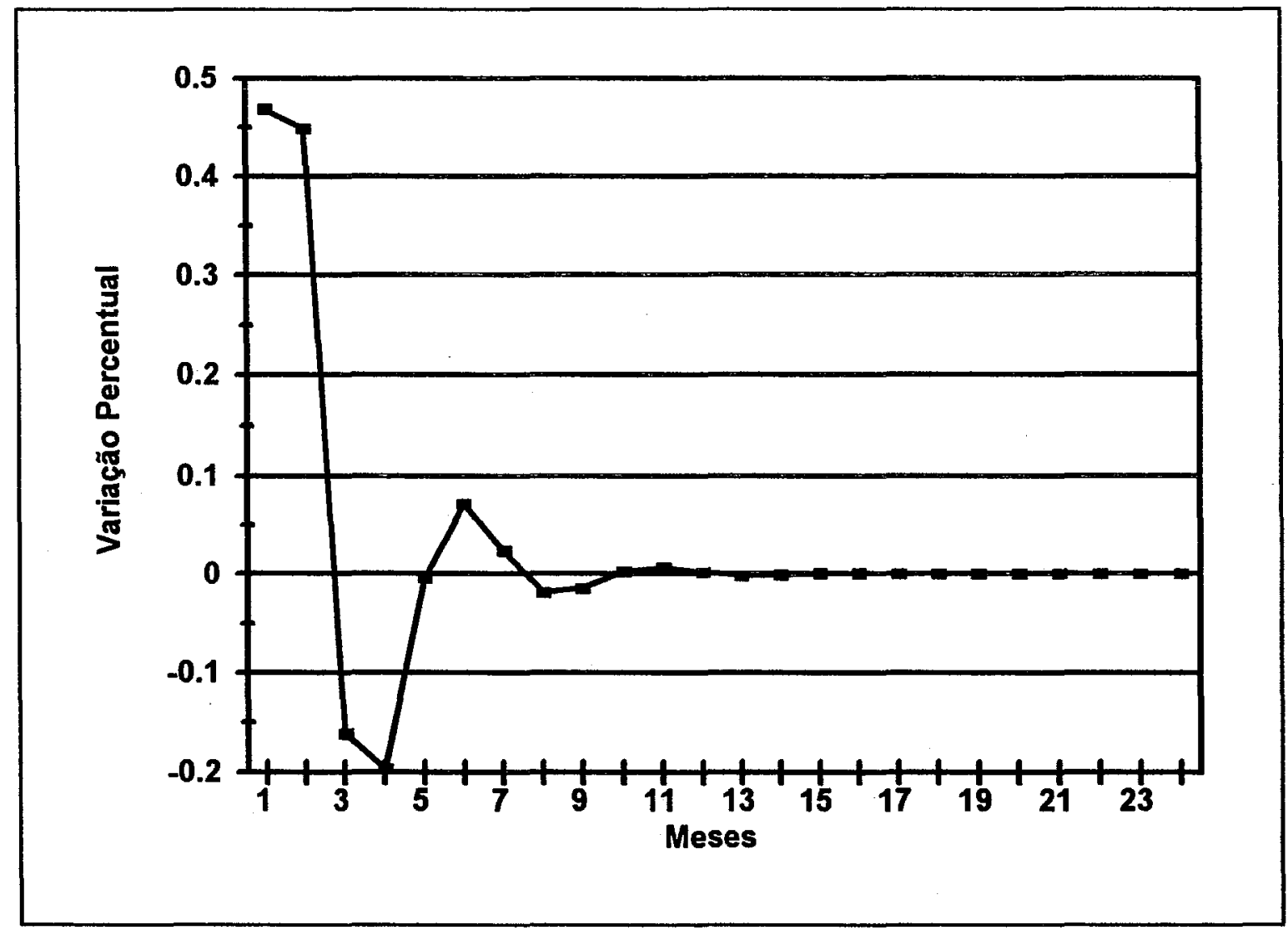

Figura 2.2 - Respostas do preço do frango em SP a um choque de um desviopadrão no preço do frango em SC - modelo VAR convencional com correção de erro. 
147.

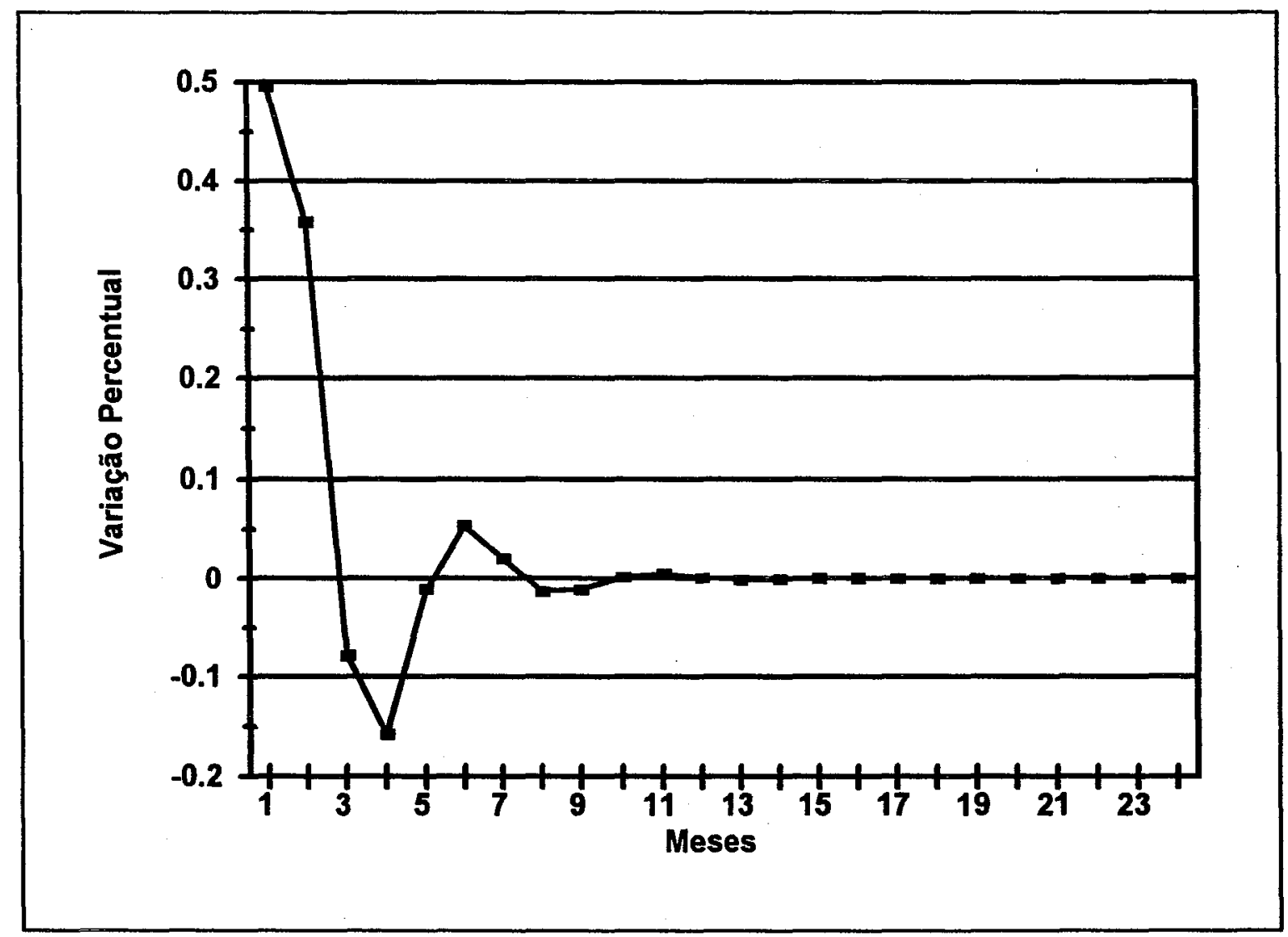

Figura 2.3 - Respostas do preço do frango no PR a um choque de um desviopadrão no preço do frango em SC - modelo VAR convencional com correção de erro. 
148.

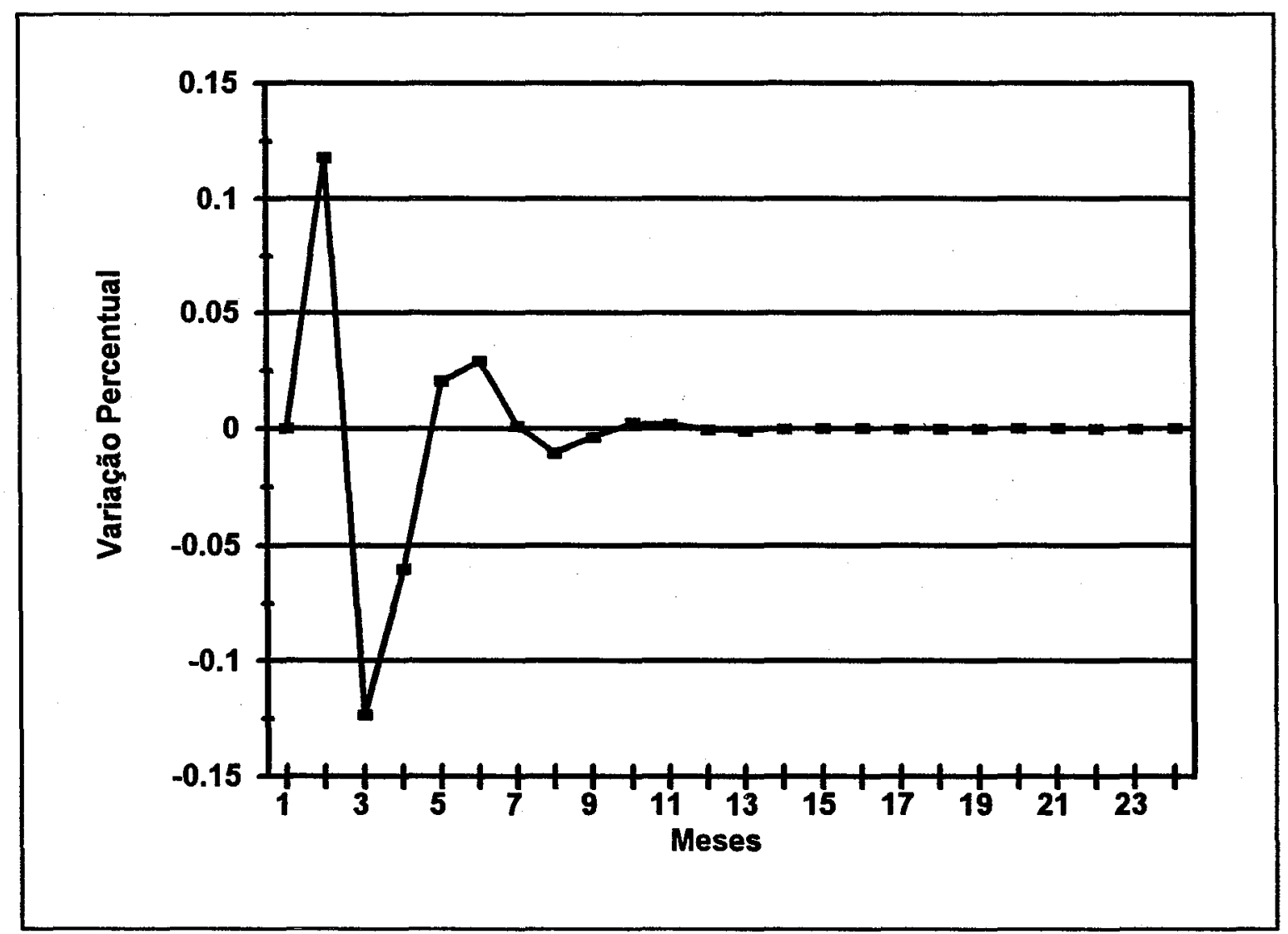

Figura 2.4 - Respostas do preço do frango em SC a um choque de um desviopadrão no preço do frango em SP - modelo VAR convencional com correção de erro. 


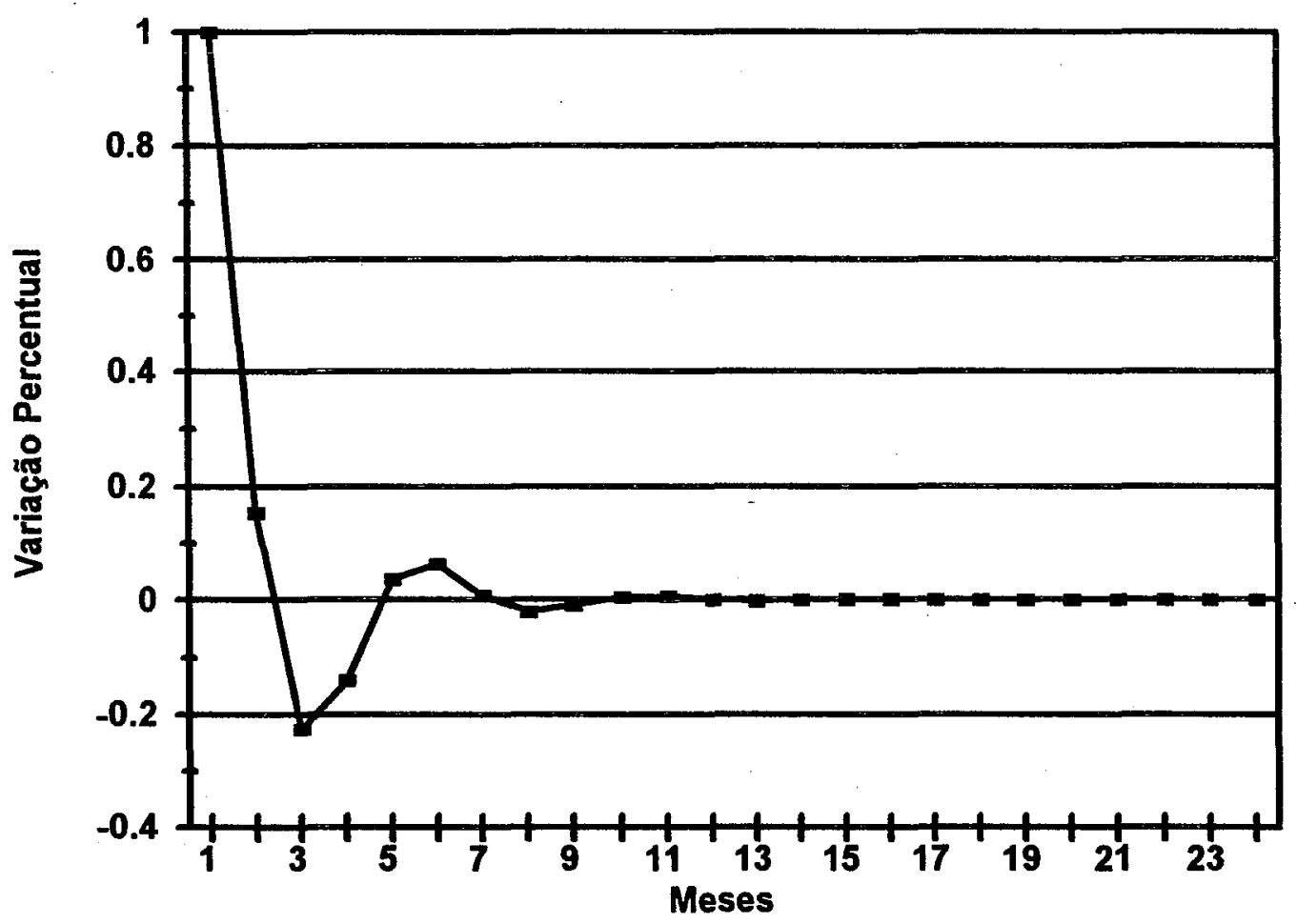

Figura 2.5 - Respostas do preço do frango em SP a um choque de um desviopadrão nele mesmo - modelo VAR convencional com correção de erro. 
150.

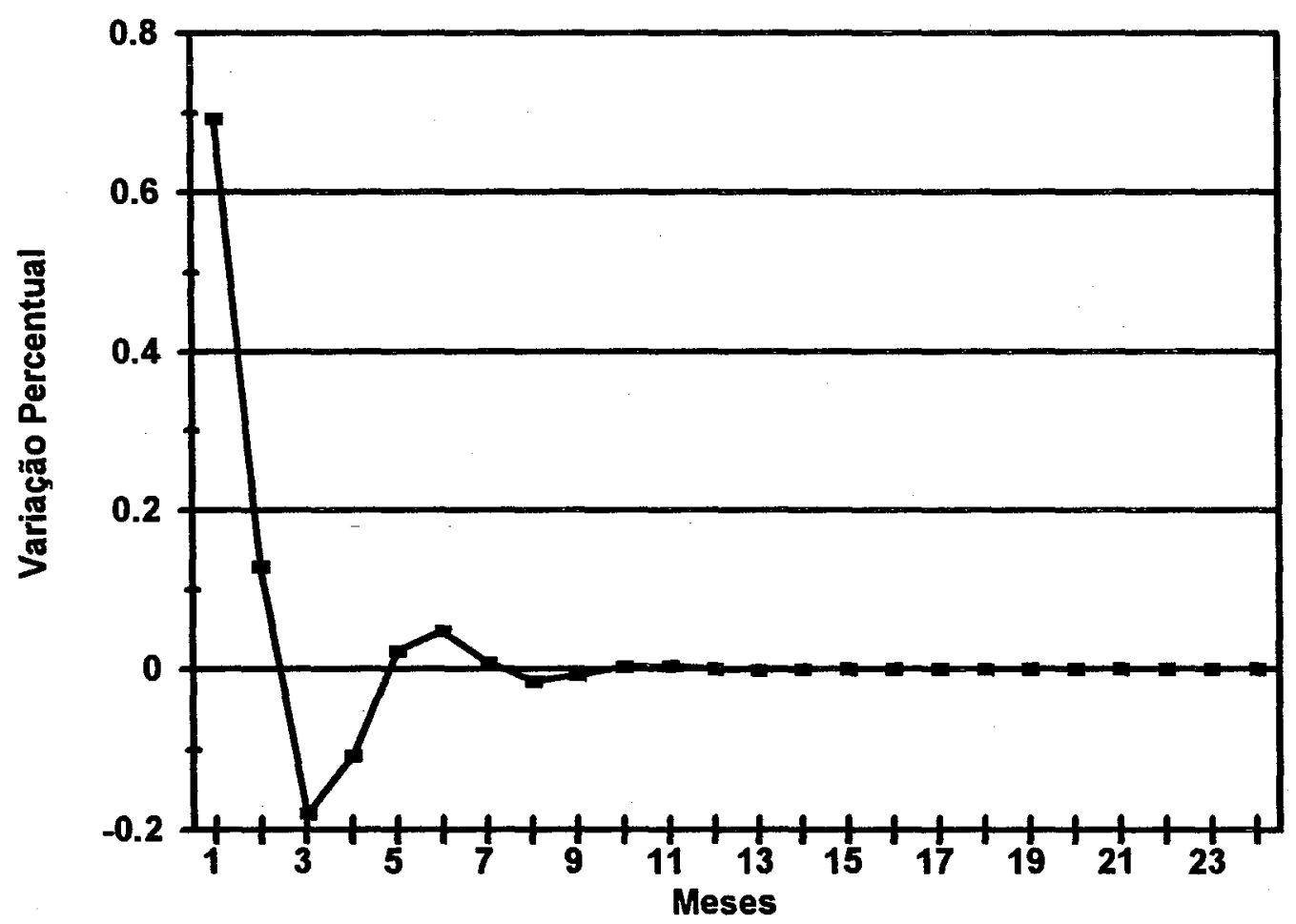

Figura 2.6 - Respostas do preço do frango no PR a um choque de um desviopadrão no preço do frango em SP - modelo VAR convencional com correção de erro. 
151.

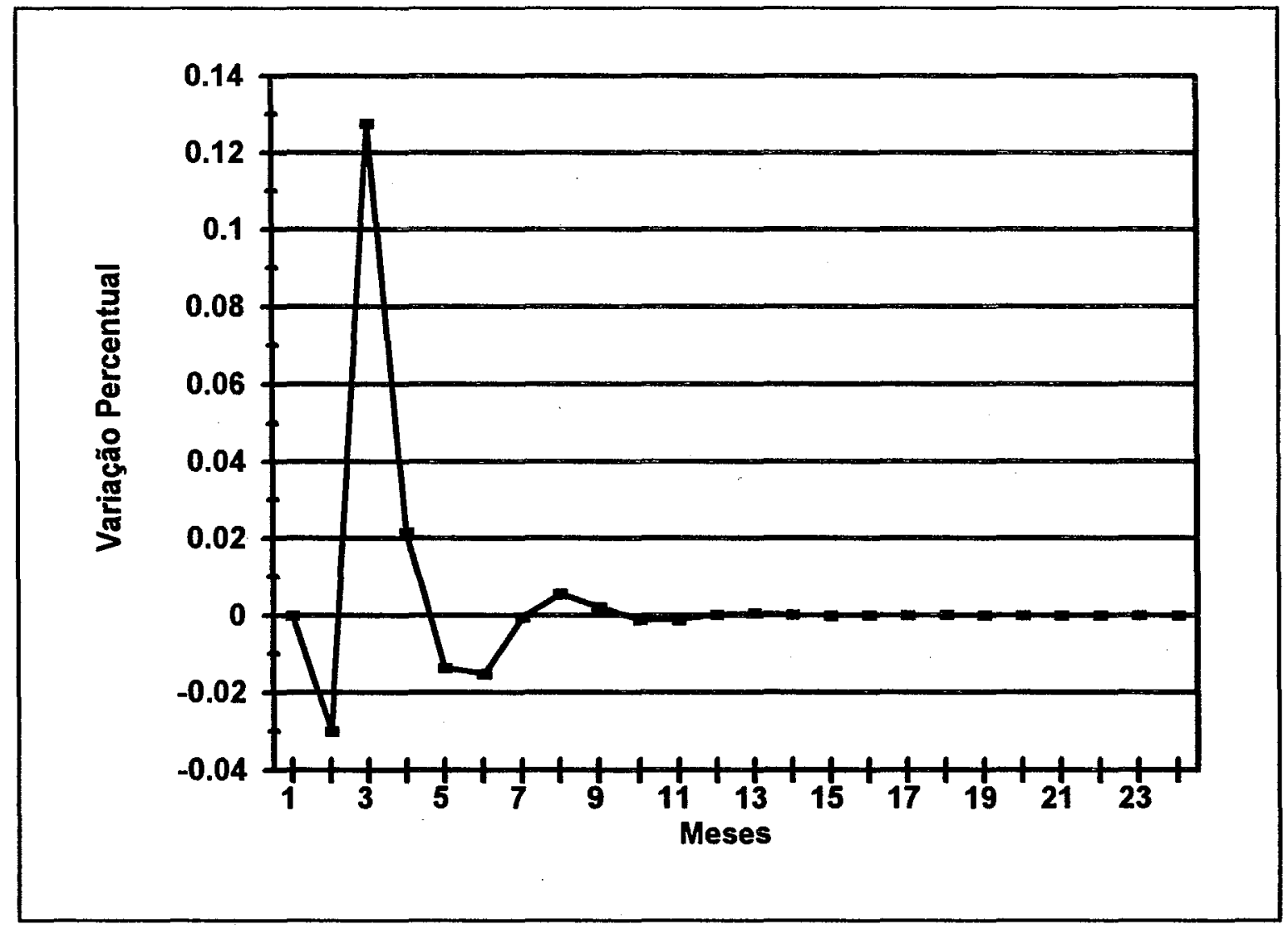

Figura 2.7 - Respostas do preço do frango em SC a um choque de um desviopadrão no preço do frango no PR - modelo VAR convencional com correção de erro. 
152.

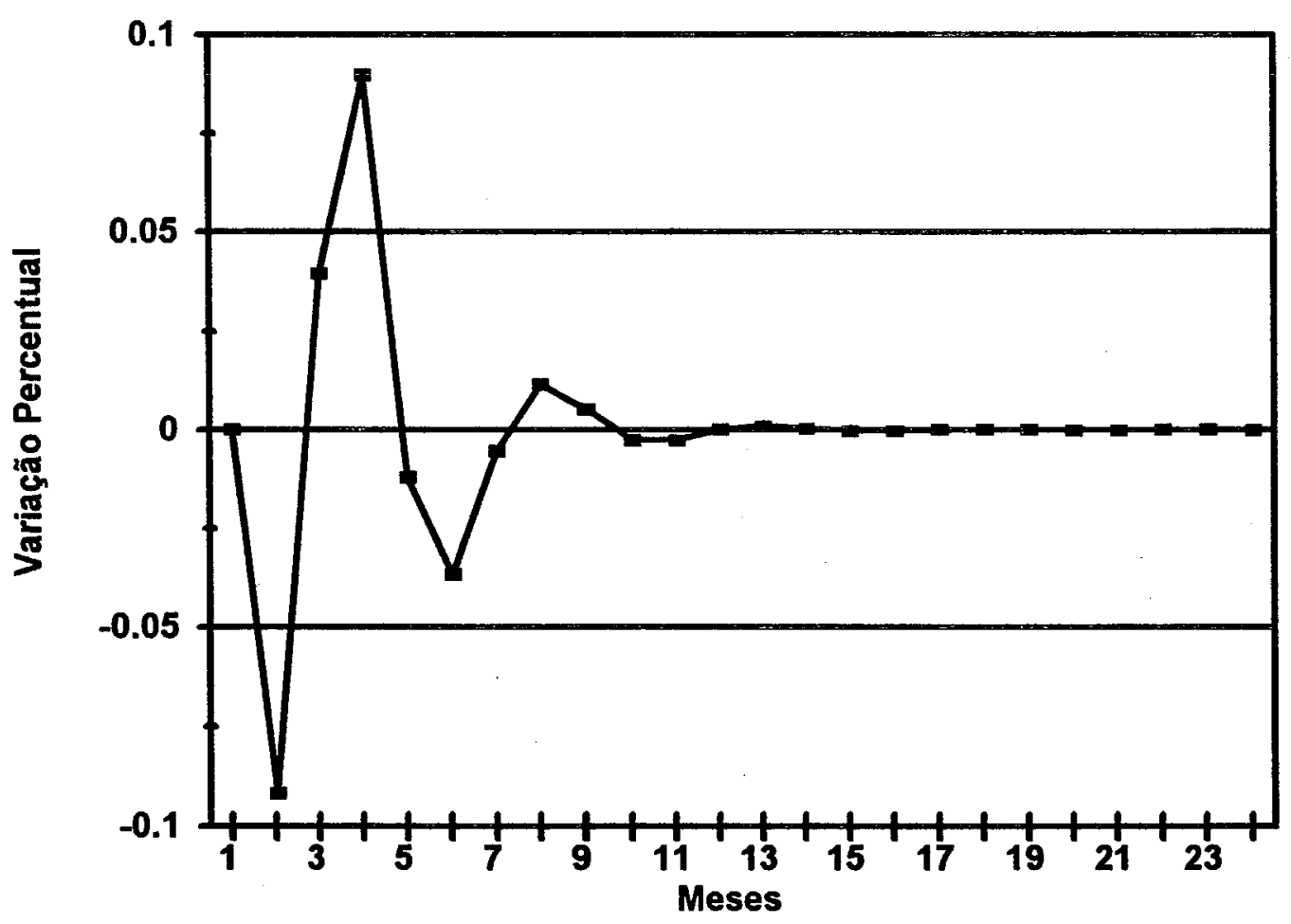

Figura 2.8 - Respostas do preço do frango em SP a um choque de um desviopadrão no preço do frango no PR - modelo VAR convencional com correção de erro. 


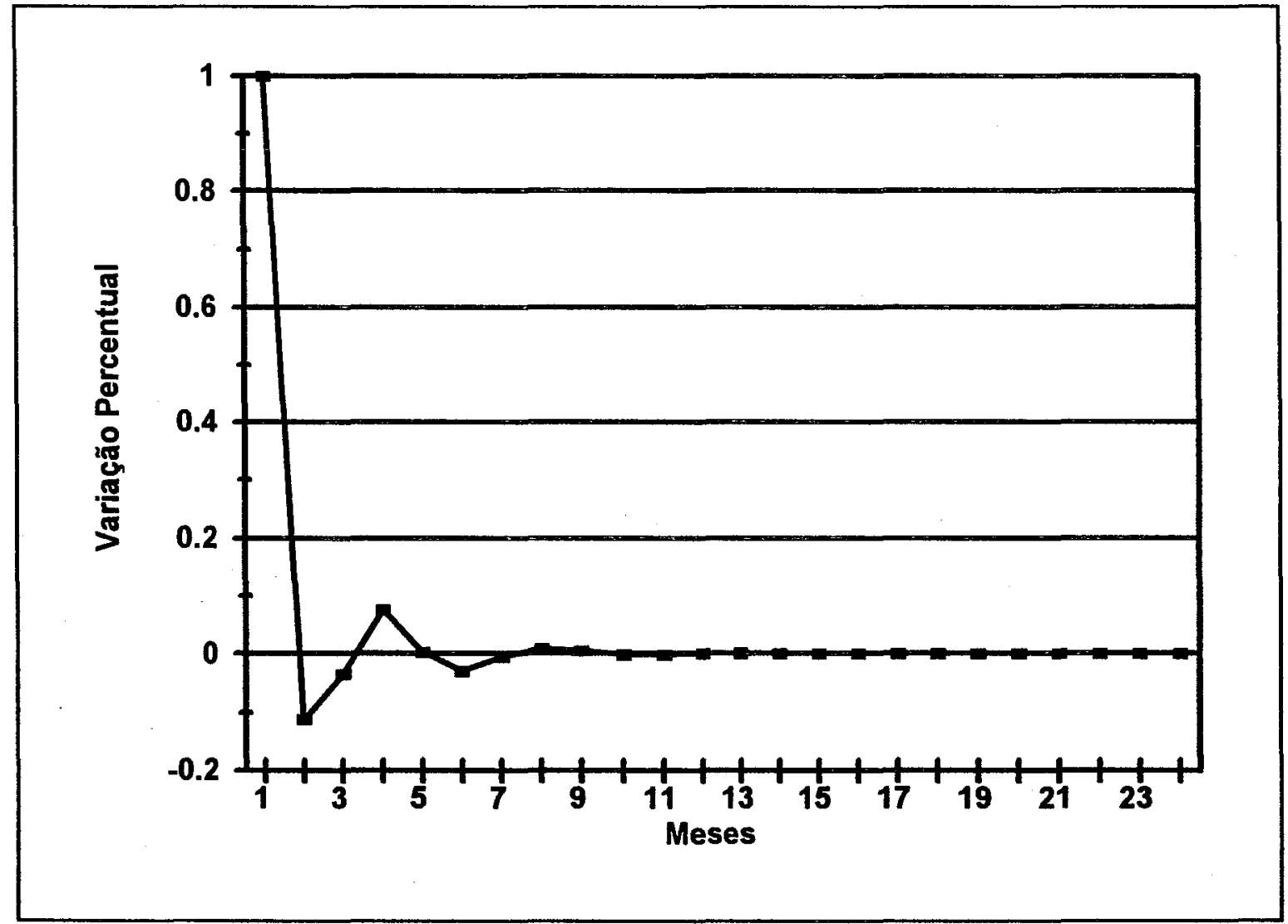

Figura 2.9 - Respostas do preço do frango ao produtor no PR a um choque de um desvio-padrão sobre ele mesmo - modelo VAR convencional com correção de erro. 
154.

\section{A P Ê N D I C E 3}

Figuras da análise de auto-regressão vetorial (VAR) estruturado com correção de erro para o Modelo de Monopsônio em São Paulo. 


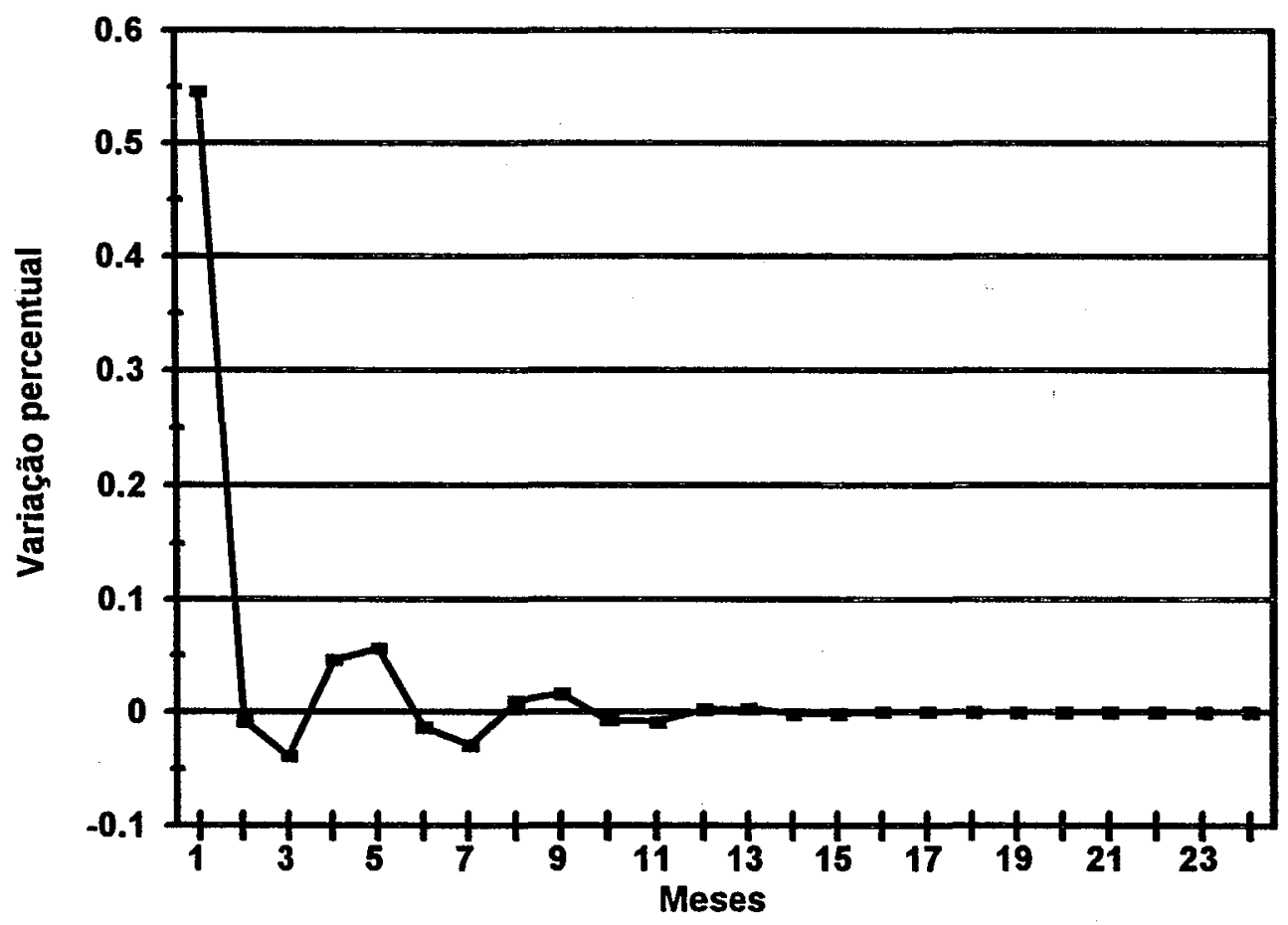

Figura 3.1 - Respostas do preço do frango no atacado a um choque de um desviopadrão no preço da carne bovina - modelo VAR estruturado com correção de erro. 
156.

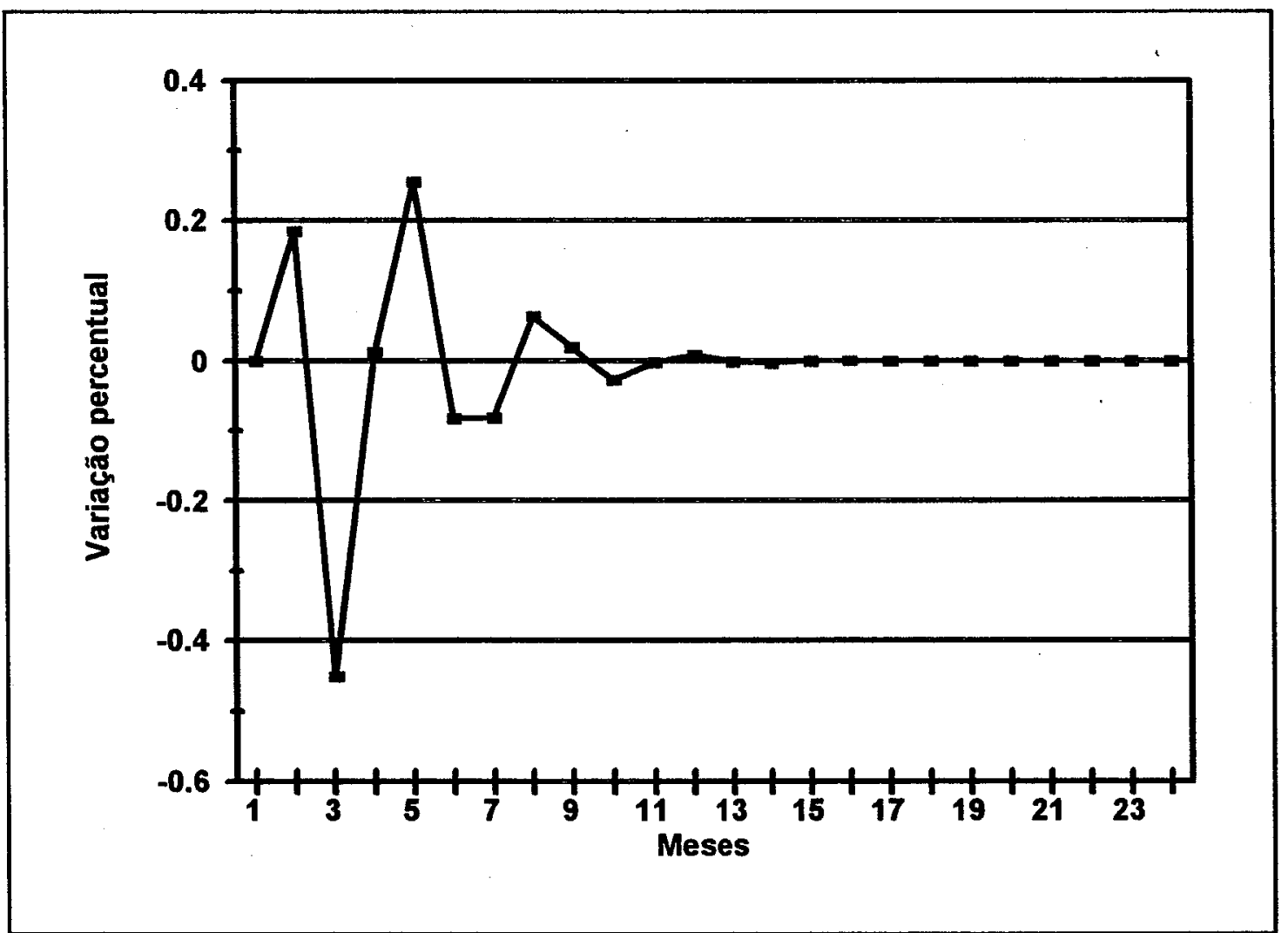

Figura 3.2 -Respostas do preço do frango no atacado a um choque de um desviopadrão no preço do frango ao produtor - modelo VAR estruturado com correção de erro. 
157.

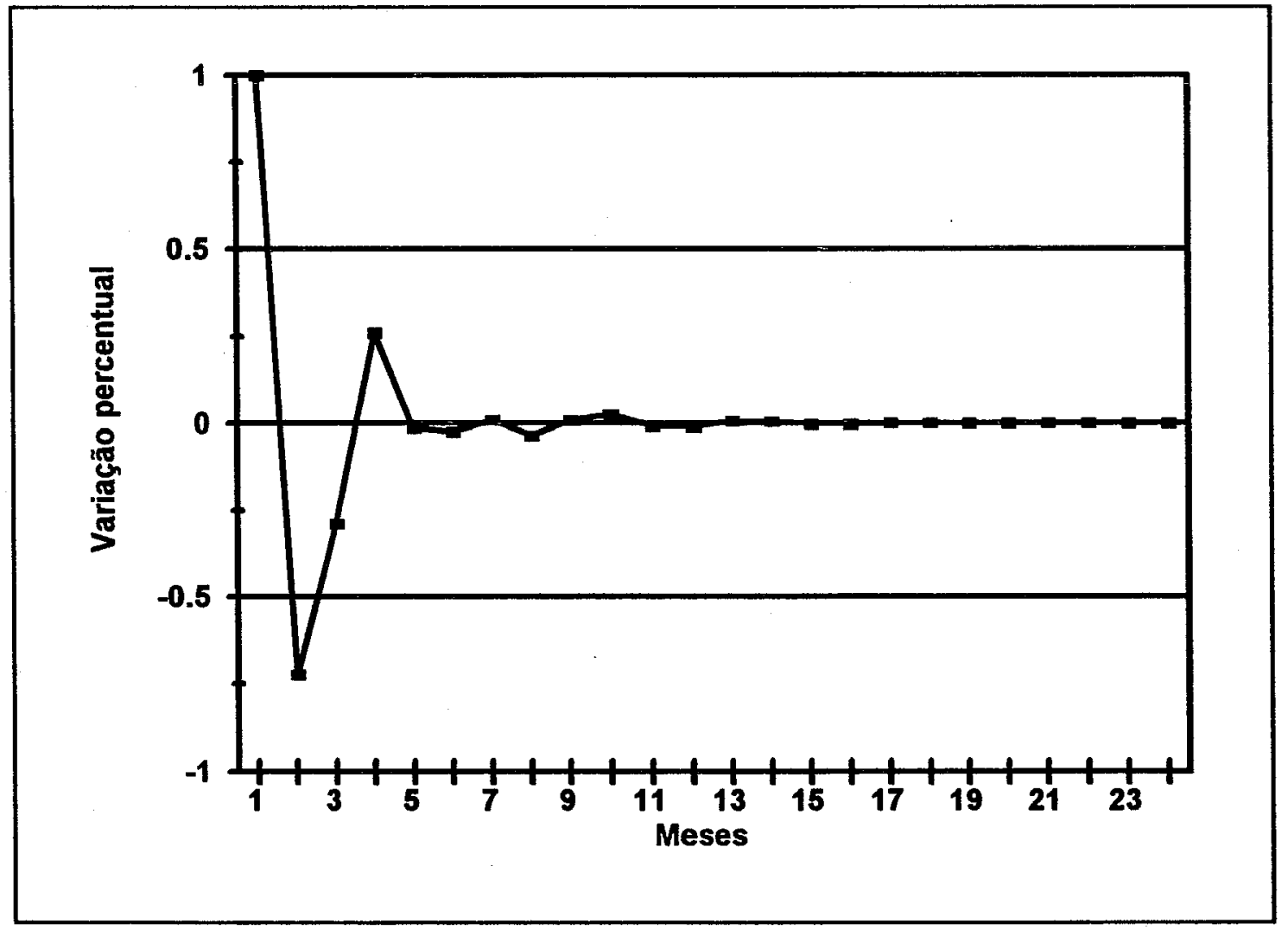

Figura 3.3 -Respostas do preço do frango no atacado a um choque de um desviopadrão no próprio preço - modelo VAR estruturado com correção de erro. 
158.

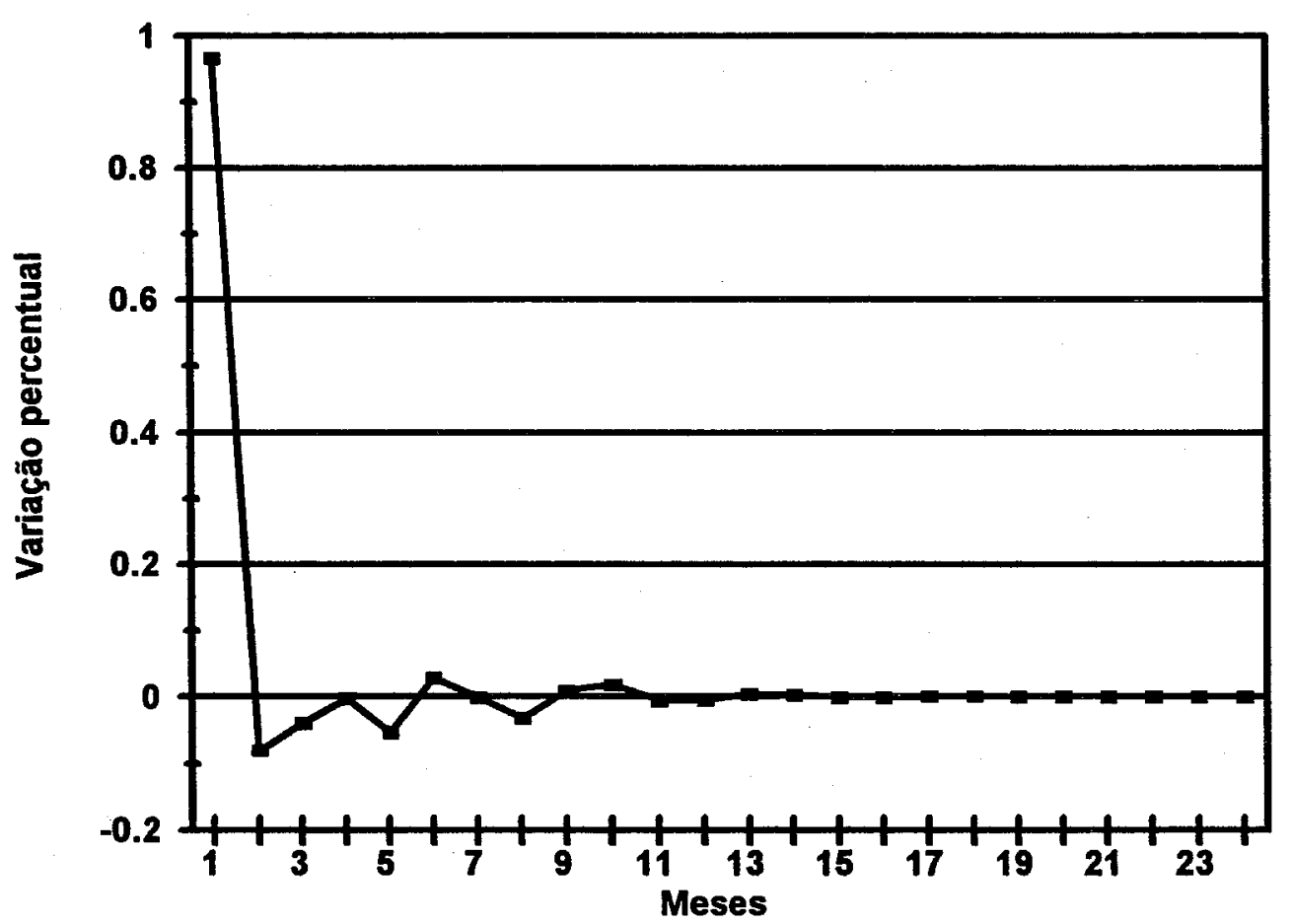

Figura 3.4 -Respostas do preço do frango no atacado a um choque de um desviopadrão no preço do frango no varejo - modelo VAR estruturado com correção de erro. 


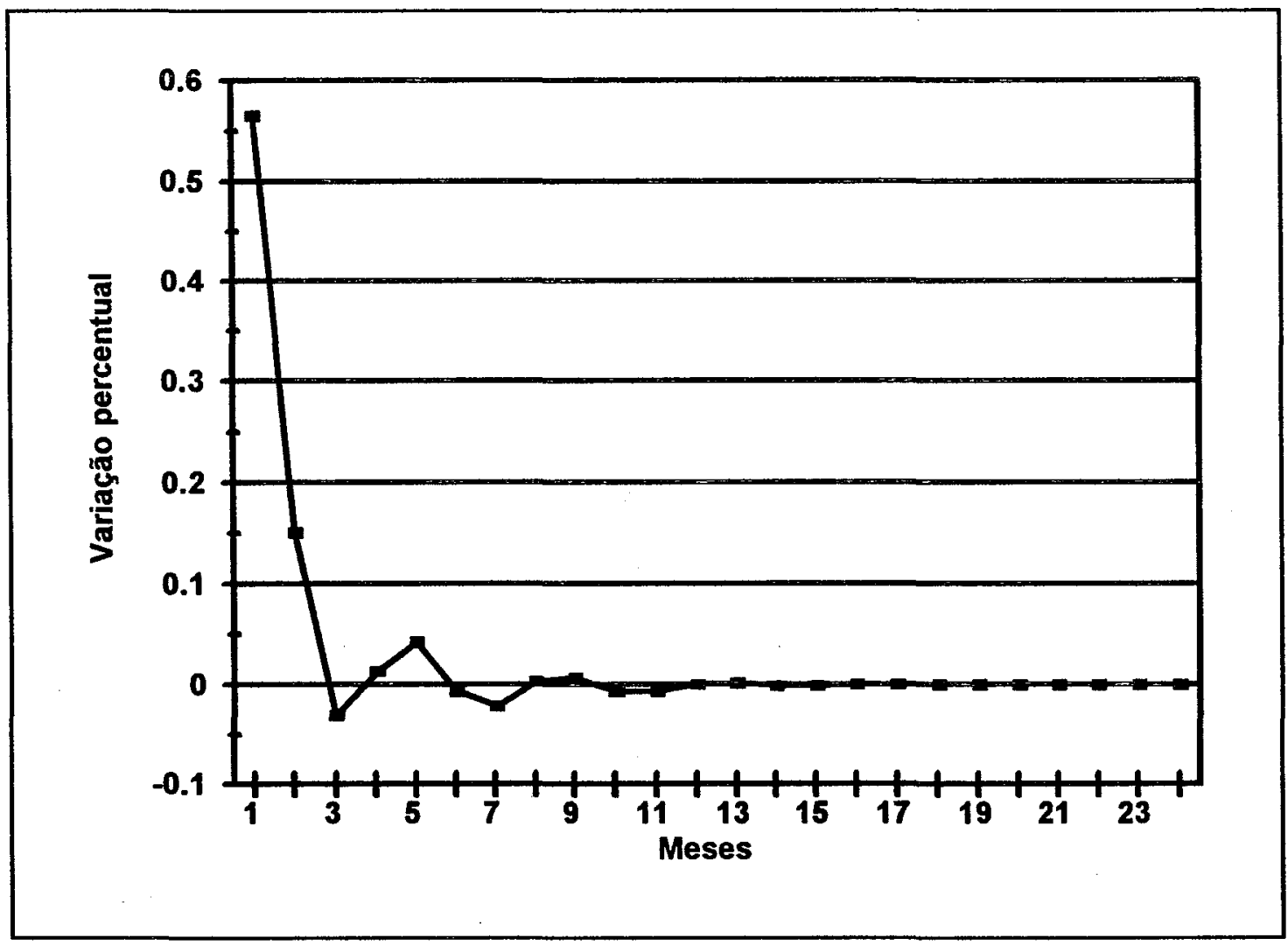

Figura 3.5 -Respostas do preço do frango no varejo a um choque de um desviopadrão no preço da carne bovina - modelo VAR estruturado com correção de erro. 
160.

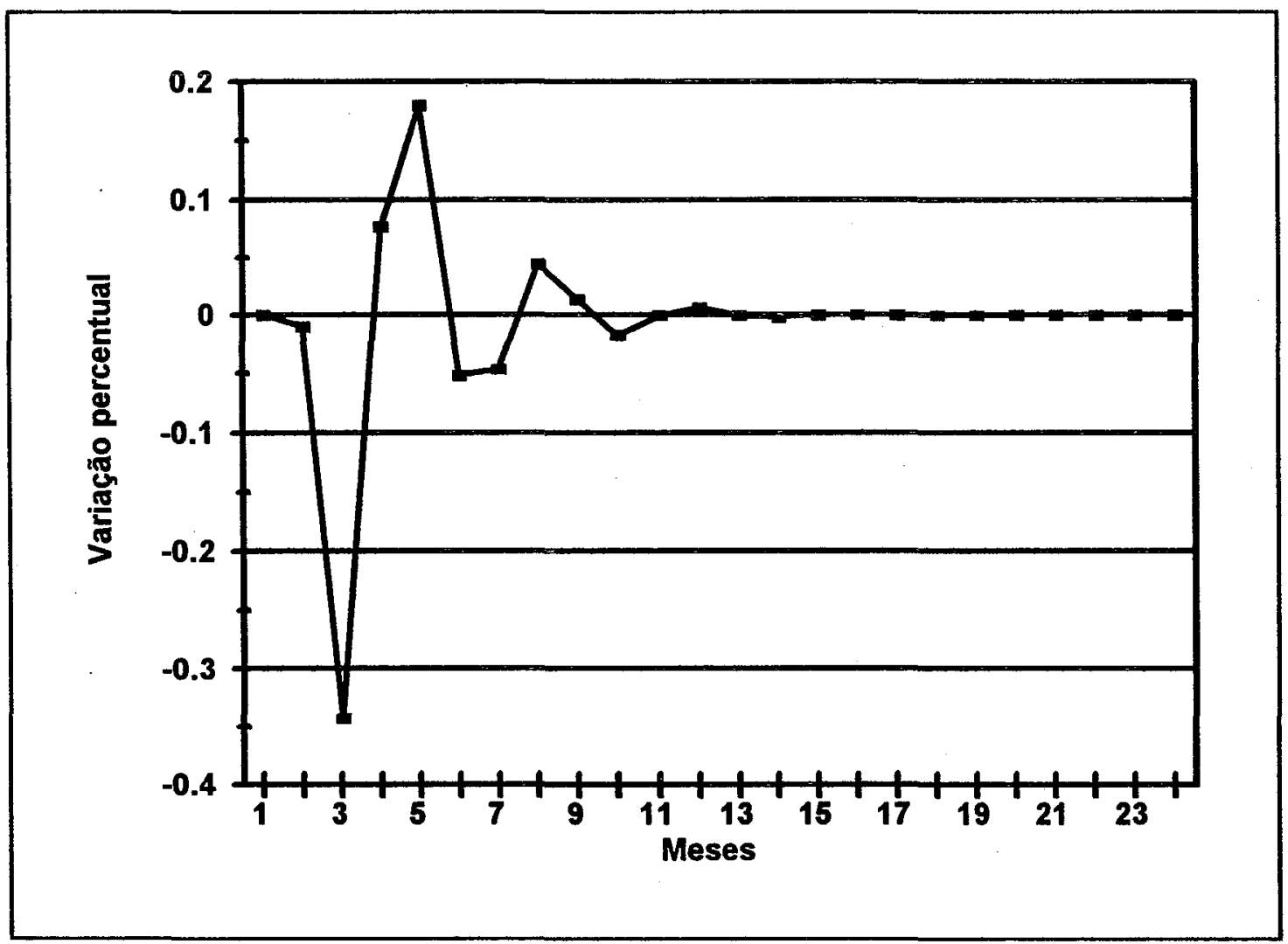

Figura 3.6 -Respostas do preço do frango no varejo a um choque de um desviopadrão no preço do frango ao produtor - modelo VAR estruturado com correção de erro 


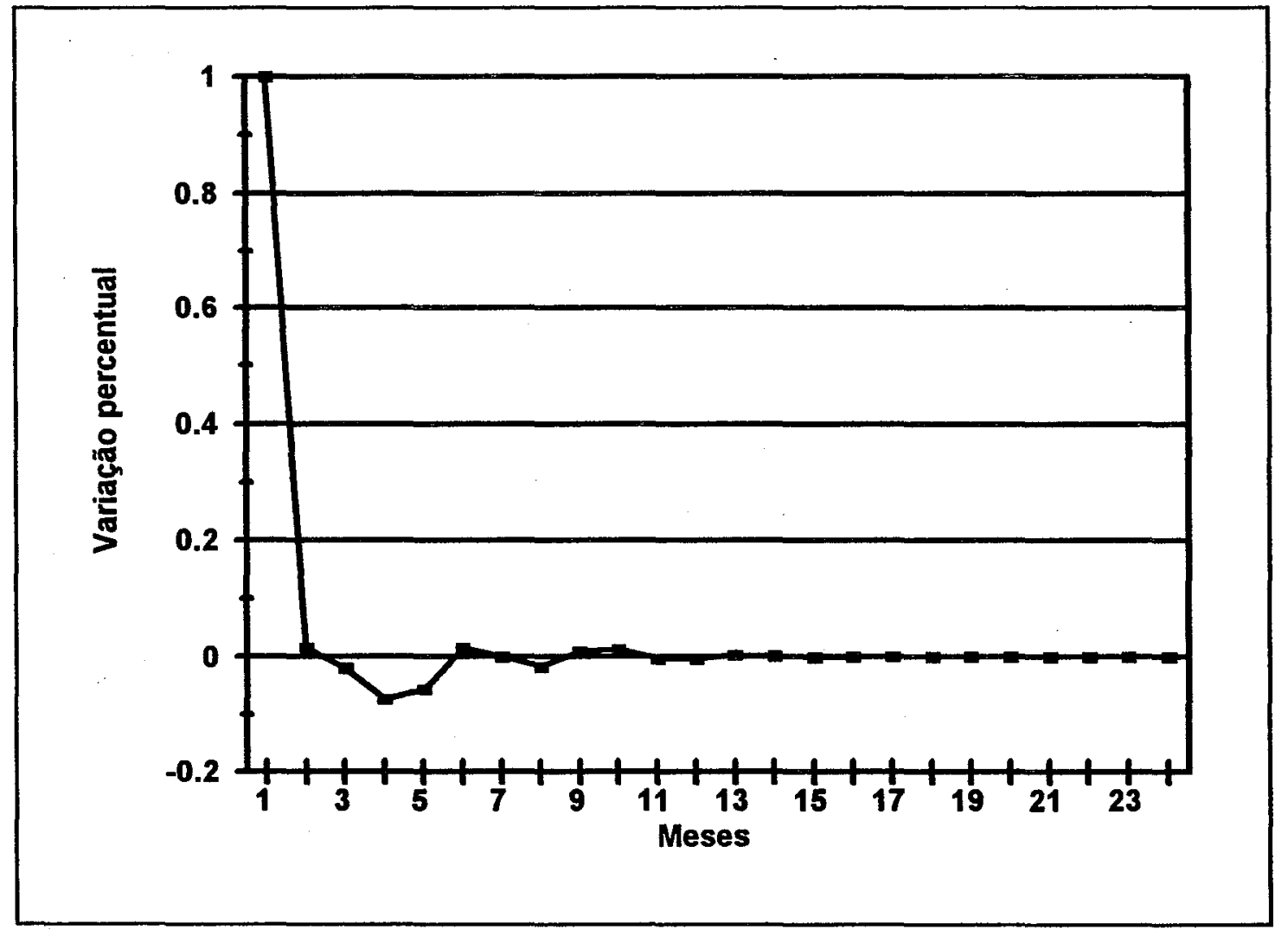

Figura 3.7 - Respostas do preço do frango no varejo a um choque de um desviopadrão no próprio preço - modelo VAR estruturado com correção de erro. 